\title{
15th International Congress on Early Onset Scoliosis and the Growing Spine
}

November 10-12, 2021

(C) Scoliosis Research Society 2021

\section{Paper 1}

Does transitioning to a brace improve HRQoL after casting for early onset scoliosis?

Jeffrey Henstenburg, Peter Sturm, Laurel Blakemore, Ying Li, Stephanie Ihnow, Suken Shah

Abstract: Introduction: Serial casting is favored for initial treatmen of early onset scoliosis (EOS), but there is concern about significant morbidity, caregiver burden and healthcare resource utilization with casting for EOS. Several studies have examined the utility of bracing as an alternative to casting in EOS with promising results. Little is known about the effects of casting or bracing regarding health-related quality of life (HRQoL) in EOS patients. We hypothesized that patients with a diagnosis of idiopathic early onset scoliosis (IEOS) experience an improvement in HRQoL when transitioning from serial casting to bracing as measured by the 24-Item Early Onset Scoliosis Questionnaire (EOSQ). Methods: Subjects with EOS were retrospectively identified from a multicenter, prospectively collected database enrolled 2012-2021. Subjects were included only if they underwent casting followed by bracing with at least one available EOSQ score completed during each treatment. Subjects with diagnoses other than idiopathic EOS were excluded. EOSQ scores were compared prior to treatment, after index casting, after transition out of cast to brace, and at final follow up. If multiple scores were reported during a treatment period, the average was used for comparison. EOSQ scores were compared using repeated measures ANOVA with post hoc tests using Bonferroni correction. Results: Sixty-six subjects met inclusion criteria and $37(56 \%)$ subjects were male. The average age at the time of index treatment was $1.93(0.37-6.42)$ years. The average follow-up based on reported EOSQ scores was $3.21(0.90$ 6.78) years. $61 / 66$ patients were still being treated with brace at final follow up, 3 were being treated with casting and 2 had growing rods placed. The HRQoL subdomain was 84.9 (CI 81.4-88.5) pre-index treatment, 75.7 (CI 72.9-78.5) during casting treatment, 84.8 (CI 81.8-88.0) during brace treatment and 87.0 (CI 83.6-90.3) at final follow up. There were no differences between baseline EOSQ scores and bracing $(\mathrm{P}=1.00)$ or final follow-up $(\mathrm{P}=0.171)$. However, casting showed a significant decrease in HRQoL from all other time points $(\mathrm{P}<0.001)$. The parental impact subdomain improved from beginning to end of treatment $(77.7-87.7, P=0.001)(n=64)$. Satisfaction significantly improved from casting to bracing (73.4-86.7, $\mathrm{p}<0.001)(\mathrm{n}=63)$ and from casting to final follow up $(73.4-87.9$, $\mathrm{p}<0.001)$ but otherwise did not show any changes. Pulmonary function and financial impact did not substantially change throughout the course of treatment. Conclusion: Patients treated with serial casting for EOS experience significant, but reversible declines in HRQoL, as measured by the EOSQ. After patients are transitioned from casting to bracing, a significant improvement in HRQoL was seen, similar to pretreatment scores and EOSQ scores at final follow up. These findings can be used to counsel families and provide anticipatory guidance for the EOS treatment plan. This information must be balanced with effectiveness of treatment for EOS with either method and customized for each patient. Level of Evidence: III.

Disclosures: P. Sturm, Depuy Synthes Spine (Consulting Fees (e.g., advisory boards)) Nuvasive (Consulting Fees (e.g., advisory boards)); S. Shah, DePuy Synthes Spine (Consulting Fees (e.g., advisory boards), Royalties).

\section{Paper 2}

\section{Can traction films predict cast correction?}

Michael Glotzbecker, Jerry Du, Anne Dumaine, Derek Kelly, Peter Sturm, Brandon Ramo, Pediatric Spine Study Group

Abstract: Background: In a recent retrospective study, in cast correction of the major curve correlated with final curve size in patients with Early Onset Scoliosis (EOS) treated with casting. There was significant variability in how the casts were applied and how the radiographs were taken. We therefore sought to perform a prospective study with controlled methodology with regard to technique and timing of radiographs to determine if there are parameters associated with reduction of coronal deformity. Methods: A prospective, observational study was conducted between 2014 and 2019 at selected sites that had a EOS casting program and were willing to comply with the radiographic and follow up protocol. Radiographic data collected included major Cobb angle and RVAD at time points of pre-cast, in traction (before first cast applied in operating room), initial in-cast (supine out of traction), and at minimum one year follow up out of cast. Multivariate linear regression models were utilized to control for potential confounders using a stepwise procedure. 29 patients met inclusion criteria. Results: On multivariate analysis, traction major curve (beta: 1.200, 95\% confidence interval [CI]: 0.043-2.357, $\mathrm{p}=0.043$ ) and initial in cast (beta: $1.302,95 \%$ CI: $0.342-2.261$, 
$\mathrm{p}=0.011)$ major curve Cobb angles were independently associated with final out of cast major curve Cobb angle. The only factor that was independently associated with failure to cure $\left(<15^{\circ}\right.$ major curve $)$ was traction major curve Cobb angle (adjusted odds ratio: 1.392 per additional degree, 95\% CI $0.520-0.993, \mathrm{p}=0.046$ ). A threshold traction major curve Cobb angle of $20^{\circ}$ was found to have $82 \%$ sensitivity and $75 \%$ specificity. A traction major curve Cobb angle over $20^{\circ}$ would accurately predict failure of casting treatment to cure scoliosis in $79 \%$ of cases. Conclusions: Radiographic measurements in traction and initially in the cast are predictive of curve size at follow up for children with EOS treated with casting. Understanding factors that may predict treatment success prior to initiation of treatment would be helpful in decision making and patient counseling. Disclosures: D. Kelly, Elsevier Publishing (Royalties); P. Sturm, Depuy Synthes Spine (Consulting Fees (e.g., advisory boards)) Nuvasive (Consulting Fees (e.g., advisory boards)); P. Study Group, DePuy Synthes Spine (Grant/Research Support) Globus Medical, Inc. (Grant/Research Support) Medtronic (Grant/Research Support) NuVasive (Grant/Research Support) OrthoPediatrics (Grant/Research Support) Pediatric Spine Foundation (Grant/Research Support) Stryker (Grant/Research Support) Zimmer Biomet (Grant/ Research Support).

\section{Paper 3}

Safety and efficacy of waterproof Mehta casting for early onset scoliosis

\section{Lorena Floccari, Keegan Conry, Melanie Morscher, Todd Ritzman}

Abstract: Introduction: Mehta casts for treating early onset scoliosis (EOS) traditionally utilize cotton padding. Inherent advantages of waterproof casting include clearance for bathing/swimming, avoiding cast holidays, and improved family satisfaction. Aims/Objectives: This is the first series describing the efficacy and safety of waterproof Mehta casts for EOS. Methods: A consecutive series of EOS patients underwent serial $75 \%$ body weight traction-elongation-flexion Mehta cast protocol with waterproof lining. The addition of 3-point apical translation with stockinettes were utilized during casting. Patients were cleared for bathing and swimming in clean, chlorinated water following waterproof casting. Bracing was initiated after correction to $<15^{\circ}$ or 1 year of serial casting. Results: 17 patients at mean age 22 months, with pre-cast Cobb angle $52.4^{\circ}$ (R: $35^{\circ}-75^{\circ}$ ), underwent 10.6 months of casting with 5.7 casts. In-cast correction index was $66 \%$, for post-cast Cobb $18.1^{\circ}$. At mean 5.1 yrs (R: 2.1-9.4 yrs), 14/ $17(82 \%)$ successfully avoided surgical intervention, and 9/17 (53\%) maintained correction $<25^{\circ} .3 / 17(18 \%)$ required a 2 nd round of casting; one underwent surgical conversion at $5.3 \mathrm{yrs}$, and two had curve control at $30^{\circ}$ and $54^{\circ}$ at 4.2 and 5.1 yrs post-casting. A total of $3 / 17(18 \%)$ ultimately required surgery with halo-gravity traction followed by magnetic growing rod therapy at 6.2 yrs post-casting; $2 / 3$ had significant noncompliance with loss to follow-up of $\geq 3$ yrs prior to surgery. No major cast related complications, decubiti, or cast holidays were encountered. One patient incurred a superficial $2 \mathrm{~cm}$ cast saw burn during creation of abdominal window, and one required early final cast removal due to parental perception of discomfort. Final in-cast correction ratio $(\mathrm{p}=0.006)$ and post-cast Cobb angle $(\mathrm{p}=0.003)$ were the only variables predictive of ultimate need for surgical conversion. Conclusion: Waterproof Mehta casting is safe and efficacious in early onset scoliosis. Of 17 patients with pre-cast Cobb $52.4^{\circ}, 82 \%$ successfully avoided surgery and $53 \%$ maintained mild curves $<25^{\circ}$ magnitude at 5.1 years follow-up. No major complications or skin decubiti occurred, and advantages include clearance for bathing/swimming and avoidance of need for cast holidays during treatment. Significance Serial waterproof Mehta casting is safe and efficacious when compared to published literature of traditional Mehta casting, with the advantages of clearance for bathing and avoidance of cast holidays.

Disclosures: T. Ritzman, Apto Orthopedics (Ownership Interest) Medtronic Spine (Grant/Research Support, Consulting Fees (e.g., advisory boards)) Stryker Spine (Speaker's Bureau).

\section{Paper 4}

\section{Bracing for infantile scoliosis: 2-year outcome data}

Stephanie Wong, Daniel Hedequist, Lawrence Karlin, Danielle Cook, M. Timothy Hresko

Abstract: Background: In patients with infantile idiopathic scoliosis, the gold standard treatment is serial Mehta casting, a procedure that requires patients to undergo repeated rounds of general anesthesia during the first few years of life. A 2016 FDA safety communication states that exposure to anesthesia in children under three years of age may affect the development of children's brains. An alternative to casting is custom bracing, which uses a customized removable brace that is adjusted or replaced periodically as the child grows. Placement of a custom brace does not require the use of anesthesia, though its removable nature may raise concerns about lack of adherence to the treatment hours prescribed by the patient's physician. Objective: This descriptive study aims to expand our understanding of the efficacy of customized bracing as an alternative form of treatment for infantile scoliosis. Methods: A retrospective case series of infantile idiopathic scoliosis patients who have undergone at least two years of custom brace treatment was reviewed. Radiographs were taken out of the brace, with the exception of the in-brace first visit X-ray. Brace wear compliance to the prescription of $18-23 \mathrm{~h}$ per day minimum was assessed based on periodic readings taken from the iButton thermal sensor within the brace, and compliance was defined as adherence to at least $80 \%$ of the in-brace hours prescribed. The change in curve magnitude from pretreatment to 2-year follow-up was calculated, along with compliance at each follow-up visit, for each patient. A Wilcoxon signed rank sum test was utilized to determine if there was a significant difference between the pretreatment curve magnitude and the 2-year follow-up curve magnitude. Linear regression analysis was used to determine if there were any associations between complication type and number of braces with compliance. Results: This cohort was comprised of 12 patients (average age 1.9 years, $50 \%$ female). The median treatment time was 38 months (range 24.0 52.0 months). The median pretreatment curve magnitude was $34.5^{\circ}$ (range $30.0^{\circ}-67.0^{\circ}$ ), and the median 2-year follow-up curve magnitude was $14.5^{\circ}$ (range $2.0^{\circ}-35.0^{\circ}$ ). There was a significant difference in the 2-year follow-up curve magnitude compared to the pretreatment curve magnitude $(\mathrm{p}=0.001)$, and the resulting median change in curve magnitude was a decrease of $23.5^{\circ}$. Ten of the 12 patients had a 2-year follow-up curve of less than $20^{\circ}$. The median compliance of the cohort stayed above $80 \%$ for all four follow-up appointments, although not everyone met the $80 \%$ compliance mark. At the 6-month follow-up, the median brace wear time was $20.5 \mathrm{~h}$ per day, and at 1 year it was $18.8 \mathrm{~h}$. The median dropped to $17.7 \mathrm{~h}$ at the 18 -month follow-up, before rising again to $20.0 \mathrm{~h}$ at the 2-year follow-up visit. Eleven of the 12 patients experienced at least one complication while wearing their custom brace. Skin breakdown and feeding difficulties were the leading complications, each experienced by seven patients (58\%), followed by rib constriction or pulmonary issues $(6 / 12 ; 50 \%)$ and other complications $(6 / 12 ; 50 \%)$. There were no significant associations between type of complication or number of braces constructed over the 2-year treatment period and brace compliance $(p>0.05)$. Conclusion: These preliminary results, which show successful reduction in curve magnitude following a 2-year period of 
compliant brace wear, were similar to results of Mehta casting and may support the use of customized braces as a safe and effective alternative to serial casting for infantile scoliosis provided the physician works with the patient's caregivers to ensure a high rate of compliance. Though complications were noted, they did not affect patients' ability to adhere to the prescribed number of hours. This study can aid in informing caregivers of treatment outcomes from bracing and the importance of brace wear compliance.

Disclosures: P. Newton: DePuy Synthes Spine (Grant/Research Support, Royalties); Globus (Consulting Fees (e.g., advisory boards)); Medronic (Consulting Fees (e.g., advisory boards)); Pacira (Consulting Fees (e.g., advisory boards)); Stryker K2M Spine (Grant/Research Support, Consulting Fees (e.g., advisory boards), Royalties); Zimmer Biomet (Grant/Research Support); B. Lonner DePuy Synthes Spine (Grant/Research Support, Consulting Fees (e.g., advisory boards), Speaker's Bureau, Royalties); OrthoPediatrics (EquityConsulting Fees (e.g., advisory boards)); Spine Search (Stock/Stock optionsOwnership Interest); Zimmer Biomet (Consulting Fees (e.g., advisory boards), Royalties); F. Miyanji Depuy Synthes Spine (Consulting Fees (e.g., advisory boards)); Stryker Spine (Consulting Fees (e.g., advisory boards)); Zimmer Biomet (Consulting Fees (e.g., advisory boards), Royalties); Harms NonFusion Study Group, DePuy Synthes Spine (Grant/Research Support); EOS imaging (Grant/Research Support); Food and Drug Administration. (Grant/Research Support); Medtronic (Grant/Research Support); NuVasive (Grant/Research Support); Stryker (Grant/ Research Support); Zimmer Biomet (Grant/Research Support).

\begin{tabular}{lrl}
\hline \multicolumn{3}{c}{ Table 1. Summary of patient radiographic measures and iButton data (N=12). } \\
\hline \multicolumn{1}{c}{ Median } & (Range) \\
\hline Curve magnitude difference (degrees) & -23.5 & $(-41.0-5.0)$ \\
Percent change curve magnitude & $-61.9 \%$ & $(-93.5-16.7 \%)$ \\
Rib-vertebral angle difference (degrees) & -17 & $(-32.0--4.0)$ \\
Percent change in rib-vertebral angle & $-68.8 \%$ & $(-84.2 \%--9.3 \%)$ \\
6-month brace wear time (hours) & 20.5 & $(14.7-23.2)$ \\
1-year brace wear time (hours) & 18.8 & $(12.9-21.8)$ \\
18-months brace wear time (hours) & 17.7 & $(14.6-21.8)$ \\
2-year brace wear time (hours) & 20 & $(12.5-21.8)$ \\
6-month compliance & $90.4 \%$ & $(63.9 \%-113.5 \%)$ \\
1-year compliance & $93.2 \%$ & $(56.1 \%-99.1 \%)$ \\
18-month compliance & $96.6 \%$ & $(63.5 \%-108.9 \%)$ \\
2-year compliance & $90.9 \%$ & $(72.2 \%-113.9 \%)$ \\
\hline
\end{tabular}

Summary of patient radiographic measures and iButton data

\section{Paper 5}

Treating early onset scoliosis with the spring distraction system: are there differences in efficacy between etiological groups?

Isabelle Blaauw, Justin Lemans, Casper Tabeling, Moyo Kruyt, René Castelein

Abstract: Introduction: Early onset scoliosis (EOS) is a challenging condition in growing children with still suboptimal surgical solutions. The treatment goal of EOS is controlling the 3D deformity while maximizing thoracic height to optimize pulmonary volume and function. Current 'growth-friendly' implants, like the Traditional Growing Rod (TGR) and Magnetically Controlled Growing Rod (MCGR), have many limitations such as the need for repeated lengthenings, the occurrence of the "law of diminishing returns", stiffening of the spine and high complication- and failure rates. We designed the Spring Distraction System (SDS) designed to circumvent these limitations. The SDS is an experimental implant with a helical coil spring placed either uni- or bilaterally. The spring provides a continuous correcting and growth-stimulating force. Previous studies have shown SDS' efficacy in a heterogenous patient population. However, its performance across different etiological groups is still unknown. Aims: To compare clinical and radiological SDS outcomes in different etiological categories, i.e., congenital, neuromuscular, idiopathic and syndromic patients, to get a better understanding of which patients implanted with SDS perform well, and to be able to provide more tailored patient counseling and improve expectation management. Methods: In this single-center, retrospective analysis, all consecutive EOS patients who received the SDS with at least 2year follow-up were evaluated. All patients were skeletally immature and had a progressive primary curve of at least $40^{\circ}$. Demographic-, surgical- and complication-related data as well as number of unplanned returns to the operating room (UPRORs) were extracted from the electronic patient record. Radiographic measurements included coronal Cobb angles, T5-T12 kyphosis, L1-S1 lordosis, sagittal vertical axis and freehand length growth of the T1-T12, T1-S1 and the instrumented segment, measured with Surgimap v.2.3.1.1 (Nemaris Inc, New York, NY, USA). These measurements were performed pre-operatively, post-operatively at first erect radiograph and at latest follow-up (with the SDS implanted, i.e., before final fusion). Patient- and curve characteristics were compared at baseline with independent t-tests (continuous data) or Fisher's exact test (categorical data). Outcomes were compared across groups with twoway repeated-measurement ANOVA. Results: Forty-one patients were included, 7 idiopathic, 14 congenital, 17 neuromuscular and 3 syndromic patients (Table 1). Mean age was $8.6 \pm 2.2$, mean followup was $2.9 \pm 0.9$ years. The mean primary curve was corrected from $66.3^{\circ} \pm 20.6^{\circ}$ to $38.5^{\circ} \pm 15.6^{\circ}(42 \%)$ postoperatively and was $46.1^{\circ} \pm 17.8^{\circ}$ at latest follow-up across all patients. Between the idiopathic, congenital and neuromuscular groups (syndromic group disregarded due to low sample size), there were significant baseline differences in age $(p=0.005)$, proportion of primary implantations $(p=0.013)$, and main coronal curve $(p=0.012)$. No significant differences were observed regarding preoperative T5-T12 kyphosis, L1S1 lordosis, skin to skin surgery time, estimated blood loss, time to discharge and follow-up length. For coronal curve correction, there was a highly significant $(\mathrm{p}=0.011)$ interaction between etiology and follow-up length (i.e., coronal curve correction over time was significantly different between groups). Neuromuscular patients had the highest curve correction $\left(70.6^{\circ}-35.0^{\circ}\right)$, which was maintained at latest follow-up $\left(39.9^{\circ}\right)$ (Table $2 /$ Fig. 1 ). The congenital patients' primary curves decreased from $66.4^{\circ}$ to $44.2^{\circ}$, which was maintained as well at latest follow-up. $\left(49.6^{\circ}\right)$. Correction of idiopathic curves $\left(50.2^{\circ}\right.$ $29.5^{\circ}$ ) was not maintained at latest follow-up $\left(50.7^{\circ}\right)$. Mean kyphosis decreased from $29.5^{\circ}$ to $22.3^{\circ}$ postoperatively and increased to $31.6^{\circ}$ at latest follow-up, with no notable differences between groups. Mean lordosis was $52.2^{\circ}$ preoperatively, $45.2^{\circ}$ postoperatively and $50.9^{\circ}$ at latest follow-up. All T1-S1 length gains were similar with a mean growth of $11.8 \pm 5.4 \mathrm{~mm} /$ year (Table 3 ). Mean instrumented segment growth was $0.6 \mathrm{~mm} /$ level/year, which was highly similar to the growth values for the T1-T12 (0.6) and T1-S1 (0.7) segments. There were 44 complications in 27 out of 41 patients $(66 \%)$ after a median follow-up time of 0.9 (IQR: 0.3-1.9) years, most frequently rod fractures $(\mathrm{N}=9)$ and implant prominence $(\mathrm{N}=9)$ (Table 4). The congenital and neuromuscular patients suffered the most complications (congenital: 19 in 14 patients; neuromuscular: 18 in 17 patients). Other complications included connector fracture $(\mathrm{N}=2)$, proximal junctional kyphosis $(\mathrm{PJK})(\mathrm{N}=2)$ and deep surgical site infections $(\mathrm{N}=3)$. There were 26 UPRORs, most $(\mathrm{N}=14 / 26)$ occurred in the neuromuscular patients. Nine patients underwent retensioning of the spring in a small reoperation, among which two patients required a retensioning twice. Conclusions: SDS treatment provides adequate initial 3D curve correction, which is maintained in all etiologies, except the idiopathic group. With respect to growth maintenance, the SDS appears to be equally beneficial in all EOS etiologies. As with other "growth-friendly" systems, complication rate is high and 
definitive surgery is still needed. The complication- and UPROR rates were high but the technique of dynamic growth-guidance with SDS offers many opportunities for further improvement.

Disclosures: J. Lemans, Stryker Spine (Grant/Research Support); C. Tabeling, Stryker Spine (Grant/Research Support); M. Kruyt, Stryker Spine (Grant/Research Support); R. Castelein, Stryker Spine (Grant/Research Support).

Figure and tables.

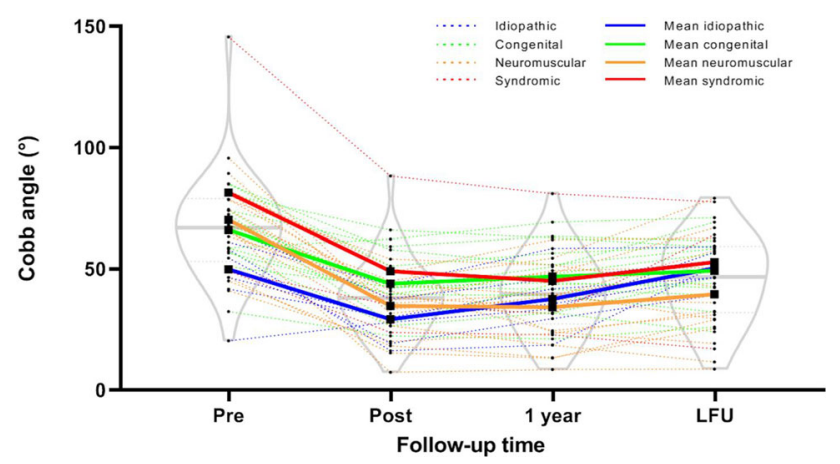

Table 1: Patient demographics

\begin{tabular}{|c|c|c|c|c|c|c|c|c|c|c|c|}
\hline & \multicolumn{2}{|c|}{$\begin{array}{c}\text { All } \\
(\mathrm{N}=41)\end{array}$} & \multicolumn{2}{|c|}{$\begin{array}{l}\text { Idiopathic } \\
(\mathrm{N}=7)\end{array}$} & \multicolumn{2}{|c|}{$\begin{array}{c}\text { Congenital } \\
(\mathrm{N}=14)\end{array}$} & \multicolumn{2}{|c|}{$\begin{array}{c}\text { Neuromuscular } \\
(N=17)\end{array}$} & \multicolumn{2}{|c|}{$\begin{array}{c}\text { Syndromic } \\
(\mathrm{N}=3)\end{array}$} & \multirow[t]{2}{*}{ p-value } \\
\hline & Mean & SD & Mean & SD & Mean & SD & Mean & SD & Mean & SD & \\
\hline Age at surgery (years) & 8,6 & 2,2 & 10,5 & 0,8 & $7,7^{1}$ & 2,5 & $8,4^{\prime}$ & 1,3 & 10,4 & 3,2 & 0,005 \\
\hline Female sex (\%) & $\begin{array}{c}19 \\
46,3 \%\end{array}$ & & $\begin{array}{c}6 \\
85,7 \%\end{array}$ & & $\begin{array}{c}5 \\
35,7 \%\end{array}$ & & $\begin{array}{c}6 \\
35,3 \%\end{array}$ & & $\begin{array}{c}2 \\
66,7 \%\end{array}$ & & 0,054 \\
\hline Primary implantations(\%)* & $\begin{array}{c}33 \\
80,5 \% \\
\end{array}$ & & $\begin{array}{c}5 / 7^{\mathrm{N}} \\
71,4 \% \\
\end{array}$ & & $\begin{array}{c}9 / 14 \\
64,3 \% \\
\end{array}$ & & $\begin{array}{c}17 / 17 \\
100,0 \% \\
\end{array}$ & & $\begin{array}{c}1 / 3 \\
33,3 \% \\
\end{array}$ & & 0,013 \\
\hline Preoperative primary curve $\left({ }^{\circ}\right)$ & 66,3 & 20,6 & $50,2^{N}$ & 14,4 & 66,4 & 14,1 & 70,6 & 14,8 & 81,8 & 45,5 & 0,012 \\
\hline Preoperative T5-T12 kyphosis ( $\left.{ }^{\circ}\right)$ & 29,5 & 29,8 & 23,6 & 11,0 & 25,3 & 25,9 & 27,3 & 28,7 & 70,7 & 44,5 & 0,943 \\
\hline Preoperative L1-S1 lordosis ( ${ }^{\circ}$ ) & 52,2 & 17,8 & 57,3 & 10,2 & 49,8 & 15,0 & 52,1 & 17,2 & 53,3 & 34,1 & 0,573 \\
\hline Surgery skin to skin time $(\mathrm{min})$ & 192,7 & 52,1 & 170,7 & 42,5 & 187,4 & 63,2 & 215,0 & 41,6 & 183,3 & 18,9 & 0,116 \\
\hline Estimated blood loss (mL) & 362,8 & 167,0 & 270,0 & 124,9 & 371,9 & 186,8 & 390,0 & 162,5 & 345,0 & 0,0 & 0,277 \\
\hline Instrumented levels & 13,9 & 3,4 & $11,3^{N}$ & 1,0 & $12,3^{N}$ & 4,0 & 16,5 & 1,2 & 12,7 & 1,2 & $<0,0001$ \\
\hline Free vertebrae & 9,1 & 3,6 & $6,4^{\mathrm{N}}$ & 1,0 & $6,6^{\mathrm{N}}$ & 3,0 & 12,5 & 1,5 & 7,3 & 0,9 & $<0,0001$ \\
\hline Time to discharge (days) & 7,2 & 7,1 & 4,1 & 1,4 & 6,6 & 3,5 & 9,2 & 10,1 & 6,3 & 2,1 & 0,283 \\
\hline Follow-up length (years) & 2,9 & 0,8 & 2,3 & 1,3 & 3,1 & 0,9 & 2,7 & 0,9 & 2,6 & 0,6 & 0,261 \\
\hline
\end{tabular}

*SDS was the first implant the patient received, conversion patients had previously received TGR or MCGR.

Superscript letter denotes a statistically significant lower value compared to the superscript group; I: idiopathic; C: congenital; N; neuromuscular 
Table 2: Curve correction and sagittal profile

\begin{tabular}{|c|c|c|c|c|c|c|c|c|c|c|c|c|}
\hline & \multicolumn{2}{|c|}{ Preoperative } & \multicolumn{3}{|c|}{ Postoperative } & \multicolumn{2}{|c|}{1 year follow-up } & \multicolumn{2}{|c|}{2 year follow-up } & \multicolumn{3}{|c|}{ Latest follow-up } \\
\hline & Mean & SD & Mean & SD & Change & Mean & SD & Mean & SD & Mean & SD & Change \\
\hline Primary curve $\left({ }^{\circ}\right)$ & 66,3 & 20,6 & 38,5 & 15,6 & $-42 \%$ & 40,1 & 16,4 & 43,0 & 16,7 & 46,1 & 17,8 & $-31 \%$ \\
\hline -Idiopathic & 50,2 & 14,4 & 29,5 & 8,8 & $-41 \%$ & 37,9 & 11,8 & 43,9 & 9,5 & 50,7 & 6,4 & $1 \%$ \\
\hline -Congenital & 66,4 & 14,1 & 44,2 & 13,3 & $-33 \%$ & 47,2 & 13,1 & 47,4 & 15,5 & 49,6 & 14,7 & $-25 \%$ \\
\hline -Neuromuscular & 70,6 & 14,8 & 35,0 & 13,0 & $-50 \%$ & 34,5 & 15,6 & 38,1 & 16,8 & 39,9 & 19,0 & $-44 \%$ \\
\hline -Syndromic & 81,8 & 45,5 & 49,4 & 28,2 & $-40 \%$ & 45,4 & 25,7 & 48,0 & 23,2 & 53,2 & 26,0 & $-35 \%$ \\
\hline Secundary curve $\left({ }^{\circ}\right)$ & 35,2 & 15,4 & 23,5 & 12,5 & $-33 \%$ & 24,8 & 13,9 & 25,5 & 13,3 & 28,6 & 15,5 & $-19 \%$ \\
\hline -Idiopathic & 35,2 & 11,9 & 24,8 & 9,8 & $-30 \%$ & 26,9 & 10,8 & 27,8 & 9,8 & 33,9 & 10,3 & $-4 \%$ \\
\hline -Congenital & 40,7 & 13,8 & 28,7 & 11,7 & $-29 \%$ & 27,0 & 12,1 & 27,9 & 11,4 & 33,8 & 13,5 & $-17 \%$ \\
\hline -Neuromuscular & 30,2 & 16,4 & 18,7 & 10,5 & $-38 \%$ & 21,3 & 14,6 & 22,4 & 12,3 & 21,5 & 15,2 & $-29 \%$ \\
\hline -Syndromic & 46,2 & 11,1 & 25,7 & 18,5 & $-44 \%$ & 33,1 & 15,6 & 36,5 & 17,7 & 35,2 & 18,4 & $-24 \%$ \\
\hline T5-T12 Kyphosis ( $\left(^{\circ}\right)$ & 29,5 & 29,8 & 22,3 & 19,5 & $-24 \%$ & 27,4 & 19,8 & 29,2 & 23,2 & 31,6 & 25,1 & $7 \%$ \\
\hline -Idiopathic & 23,6 & 11,0 & 19,3 & 10,9 & $-18 \%$ & 29,1 & 8,6 & 32,0 & 11,6 & 30,0 & 8,0 & $27 \%$ \\
\hline -Congenital & 25,3 & 25,9 & 27,1 & 18,8 & $7 \%$ & 33,8 & 16,6 & 36,8 & 22,4 & 41,2 & 27,6 & $63 \%$ \\
\hline -Neuromuscular & 27,3 & 28,7 & 15,1 & 14,6 & $-45 \%$ & 16,7 & 17,2 & 16,8 & 17,5 & 19,6 & 16,1 & $-28 \%$ \\
\hline -Syndromic & 70,7 & 44,5 & 50,4 & 26,8 & $-29 \%$ & 53,5 & 24,2 & 60,5 & 26,2 & 60,3 & 34,3 & $-15 \%$ \\
\hline L1-S1 Lordosis $\left({ }^{\circ}\right)$ & 52,2 & 17,8 & 45,2 & 13,7 & $-13 \%$ & 46,9 & 20,3 & 46,3 & 18,9 & 50,9 & 18,8 & $-2 \%$ \\
\hline -Idiopathic & 57,3 & 10,2 & 51,6 & 9,1 & $-10 \%$ & 64,2 & 11,1 & 64,4 & 10,9 & 61,2 & 10,4 & $7 \%$ \\
\hline -Congenital & 49,8 & 15,0 & 47,7 & 12,5 & $-4 \%$ & 54,5 & 15,1 & 52,6 & 15,5 & 58,2 & 16,7 & $17 \%$ \\
\hline -Neuromuscular & 52,1 & 17,2 & 39,2 & 12,4 & $-25 \%$ & 33,0 & 18,8 & 35,4 & 14,2 & 39,7 & 18,2 & $-24 \%$ \\
\hline -Syndromic & 53,3 & 34,1 & 54,2 & 16,9 & $2 \%$ & 56,5 & 12,3 & 43,0 & 26,4 & 61,3 & 6,3 & $15 \%$ \\
\hline SVA (mm)* & 15,9 & 32,6 & 15,1 & 37,6 & $-5 \%$ & 13,8 & 45,6 & 14,3 & 42,4 & 7,2 & 42,8 & $-55 \%$ \\
\hline -Idiopathic & $-6,7$ & 22,9 & $-10,0$ & 31,7 & $49 \%$ & $-16,5$ & 28,8 & $-14,6$ & 28,2 & $-11,3$ & 42,0 & $69 \%$ \\
\hline -Congenital & 14,9 & 26,6 & 9,2 & 39,0 & $-38 \%$ & $-6,8$ & 36,4 & $-6,2$ & 43,9 & $-7,4$ & 38,1 & $-150 \%$ \\
\hline - Neuromuscular & 18,0 & 30,3 & 33,3 & 29,6 & $85 \%$ & 41,1 & 45,3 & 34,1 & 31,6 & 26,9 & 0,0 & $49 \%$ \\
\hline -Syndromic & 60,4 & 31,3 & $-7,4$ & 22,1 & $-112 \%$ & 9,4 & 22,3 & 49,7 & 27,9 & $-6,0$ & 24,0 & $-110 \%$ \\
\hline $\begin{array}{l}\text { Preoperative radiograph b } \\
\text { Postoperative radiograph } \\
\text { *Sagittal Vertical Axis (SVA }\end{array}$ & $\begin{array}{l}\text { efore SDS } \\
\text { before dis }\end{array}$ & implanta & ation surg & gery & & & & & & & & \\
\hline
\end{tabular}


Table 3: Height and length measurements and growth rates

\begin{tabular}{|c|c|c|c|c|c|c|c|c|c|c|c|c|c|}
\hline & \multicolumn{2}{|c|}{ Preoperative } & \multicolumn{2}{|c|}{ Postoperative } & \multicolumn{2}{|c|}{$\begin{array}{c}1 \text { year } \\
\text { Follow-up }\end{array}$} & \multicolumn{2}{|c|}{$\begin{array}{c}2 \text { year } \\
\text { Follow-up }\end{array}$} & \multicolumn{2}{|c|}{$\begin{array}{l}\text { Latest } \\
\text { Follow-up }\end{array}$} & \multicolumn{2}{|c|}{$\begin{array}{c}\text { Growth/ } \\
\text { year }(\mathbf{m m})^{*}\end{array}$} & \multirow{2}{*}{$\begin{array}{c}\begin{array}{c}\text { Growth/ } \\
\text { level/year }\end{array} \\
\text { Mean }\end{array}$} \\
\hline & Mean & SD & Mean & SD & Mean & SD & Mean & SD & Mean & SD & Mean & SD & \\
\hline T1-T12 height (mm) & 165,3 & 38,2 & 183,2 & 35,1 & 186,7 & 35,3 & 191,9 & 35,4 & 198,9 & 35,4 & 5,3 & 3,4 & 0,4 \\
\hline -Idiopathic & 207,9 & 14,3 & 223,8 & 10,4 & 225,4 & 14,9 & 233,3 & 13,2 & 236,2 & 13,0 & 3,9 & 3,5 & 0,3 \\
\hline -Congenital & 142,7 & 33,9 & 151,8 & 29,2 & 156,1 & 31,1 & 161,5 & 30,8 & 167,9 & 29,2 & 4,8 & 3,3 & 0,4 \\
\hline -Neuromuscular & 168,1 & 25,4 & 191,0 & 19,8 & 195,0 & 21,7 & 200,7 & 21,2 & 208,7 & 23,6 & 5,1 & 3,4 & 0,4 \\
\hline -Syndromic & 158,6 & 57,2 & 194,0 & 33,1 & 195,8 & 25,9 & 191,1 & 24,9 & 202,3 & 30,4 & 3,5 & 2,0 & 0,3 \\
\hline T1-T12 length (mm) & 184,5 & 33,9 & 192,8 & 34,5 & 199,0 & 35,5 & 204,5 & 36,0 & 213,4 & 36,2 & 7,1 & 2,9 & 0,6 \\
\hline -Idiopathic & 220,5 & 13,2 & 231,4 & 10,9 & 236,1 & 15,5 & 244,0 & 12,7 & 251,2 & 12,4 & 6,4 & 3,2 & 0,5 \\
\hline -Congenital & 158,3 & 33,9 & 162,9 & 33,6 & 168,4 & 35,0 & 175,4 & 36,3 & 183,0 & 34,2 & 6,1 & 3,8 & 0,5 \\
\hline -Neuromuscular & 188,4 & 20,8 & 198,4 & 18,5 & 205,7 & 19,7 & 210,3 & 21,1 & 220,7 & 23,6 & 7,4 & 3,4 & 0,6 \\
\hline -Syndromic & 202,2 & 21,6 & 212,7 & 14,1 & 218,8 & 12,5 & 218,7 & 15,6 & 225,8 & 21,1 & 4,9 & 2,8 & 0,4 \\
\hline T1-S1 height (mm) & 285,7 & 52,7 & 316,5 & 47,1 & 320,4 & 49,8 & 330,9 & 49,7 & 340,5 & 48,4 & 8,2 & 6,2 & 0,5 \\
\hline -Idiopathic & 345,0 & 19,7 & 369,6 & 19,7 & 369,3 & 30,2 & 380,9 & 30,5 & 386,0 & 27,4 & 5,1 & 5,4 & 0,3 \\
\hline -Congenital & 267,3 & 48,6 & 282,2 & 43,5 & 284,1 & 44,0 & 295,7 & 43,8 & 305,2 & 39,3 & 6,3 & 6,1 & 0,4 \\
\hline -Neuromuscular & 278,5 & 37,1 & 320,7 & 32,7 & 330,4 & 39,2 & 340,3 & 39,1 & 352,8 & 41,0 & 9,7 & 4,3 & 0,5 \\
\hline -Syndromic & 280,1 & 85,5 & 331,2 & 38,3 & 326,0 & 32,8 & 333,0 & 34,8 & 333,4 & 35,7 & 0,8 & 3,2 & 0,0 \\
\hline T1-S1 length (mm) & 315,7 & 47,5 & 332,2 & 48,0 & 340,5 & 48,0 & 351,2 & 51,6 & 366,1 & 51,9 & 11,8 & 5,4 & 0,7 \\
\hline -Idiopathic & 365,3 & 20,2 & 382,9 & 19,7 & 389,4 & 19,7 & 402,1 & 25,7 & 414,7 & 27,5 & 10,1 & 5,0 & 0,6 \\
\hline -Congenital & 291,4 & 51,2 & 299,8 & 51,3 & 305,3 & 51,3 & 318,4 & 53,3 & 333,1 & 51,6 & 10,0 & 6,9 & 0,6 \\
\hline -Neuromuscular & 311,9 & 33,0 & 332,7 & 30,7 & 346,2 & 30,7 & 354,4 & 37,9 & 371,1 & 41,1 & 12,6 & 5,5 & 0,7 \\
\hline -Syndromic & 338,6 & 40,7 & 361,8 & 22,3 & 363,4 & 22,3 & 373,9 & 31,1 & 379,3 & 34,9 & 6,7 & 5,1 & 0,4 \\
\hline Instrumented height (mm) & 208,0 & 62,4 & 235,5 & 72,0 & 241,0 & 76,8 & 247,7 & 77,6 & 254,7 & 80,9 & 6,4 & 5,3 & 0,4 \\
\hline -Idiopathic & 200,9 & 23,5 & 218,1 & 20,6 & 220,4 & 21,3 & 225,1 & 22,0 & 227,6 & 18,7 & 3,0 & 1,8 & 0,4 \\
\hline -Congenital & 155,1 & 52,5 & 167,4 & 56,7 & 169,6 & 59,1 & 176,2 & 59,7 & 179,9 & 60,1 & 4,0 & 6,2 & 0,6 \\
\hline -Neuromuscular & 257,7 & 39,9 & 298,5 & 38,0 & 309,0 & 42,3 & 317,0 & 42,2 & 328,7 & 43,3 & 9,6 & 2,5 & 0,3 \\
\hline -Syndromic & 186,3 & 33,0 & 230,3 & 15,6 & 231,4 & 13,6 & 234,8 & 16,7 & 238,3 & 15,2 & 3,1 & 0,2 & 0,2 \\
\hline Instrumented length (mm) & 233,0 & 66,6 & 247,2 & 72,2 & 255,7 & 77,1 & 262,4 & 77,2 & 272,3 & 80,5 & 8,5 & 5,2 & 0,6 \\
\hline -Idiopathic & 218,4 & 21,3 & 229,2 & 19,9 & 237,1 & 18,6 & 242,9 & 17,0 & 248,3 & 18,0 & 6,0 & 3,1 & 0,5 \\
\hline -Congenital & 173,3 & 58,9 & 178,3 & 59,5 & 181,7 & 61,2 & 189,3 & 62,2 & 196,3 & 64,2 & 5,8 & 6,3 & 0,5 \\
\hline -Neuromuscular & 286,4 & 38,5 & 307,9 & 35,8 & 321,8 & 39,4 & 328,8 & 40,4 & 342,9 & 41,2 & 11,7 & 3,5 & 0,7 \\
\hline -Syndromic & 238,1 & 17,1 & 258,1 & 33,2 & 262,1 & 34,0 & 265,2 & 29,4 & 271,4 & 24,4 & 5,0 & 3,9 & 0,4 \\
\hline th per year post-op to last fo & ip & & & & & & & & & & & & \\
\hline
\end{tabular}


Table 4: Complications and UPRORs

\begin{tabular}{|c|l|l|l|l|l|l|}
\hline & Complications & $\begin{array}{c}\text { Complications } \\
\text { /patient }\end{array}$ & $\begin{array}{c}\text { Complications } \\
\text { /patient/year }\end{array}$ & UPROR & $\begin{array}{l}\text { UPROR } \\
\text { /patient }\end{array}$ & $\begin{array}{c}\text { UPROR } \\
\text { /patient/year }\end{array}$ \\
\hline All & 44 & 1,1 & 0,4 & 26 & 0,6 & 0,2 \\
\hline Idiopathic & 6 & 0,9 & 0,4 & 3 & 0,4 & 0,2 \\
\hline Congenital & 18 & 1,3 & 0,4 & 8 & 0,6 & 0,2 \\
\hline $\begin{array}{c}\text { Neuromuscu } \\
\text { lar }\end{array}$ & 18 & 1,1 & 0,4 & 14 & 0,8 & 0,3 \\
\hline Syndromic & 2 & 0,7 & 0,3 & 1 & 0,3 & 0,1 \\
\hline
\end{tabular}

\section{Paper 6}

Finite element comparison of the spring distraction system and the traditional growing rod for the treatment of early onset scoliosis

Justin Lemans, Manoj Kodigudla, Amey Kelkar, Daksh Jayaswal, René Castelein, Moyo Kruyt, Vijay Goel, Aakash Agarwal

Abstract: Introduction: In the surgical treatment of Early Onset Scoliosis, distraction-based implants such as the Traditional Growing Rod (TGR) aim to control the scoliotic curve, whilst facilitating growth of the spine and thorax through periodic implant lengthenings. While the TGR is effective at controlling the deformity, it has several disadvantages. First, frequent re-operations are required, causing increased anesthetic and surgical stress, and increasing the risk of wound complications. Second, TGR distraction efficacy decreases over time, a phenomenon known as the "law of diminishing returns". Third, implant complications such as screw pull-out and rod fractures are frequently observed. Previous studies have implicated spinal stiffening and autofusion, which necessitate higher periodic distraction forces, as potential causes for the "law of diminishing returns" and the high rates of implant complications. We developed the Spring Distraction System (SDS), a growth-friendly implant that employs continuous, dynamic spring forces to correct the spine. Theoretically, SDS treatment should result in lower implant stresses, and reduced stress-shielding of the spine and intervertebral disc (IVD), which may prevent IVD height loss. While investigating such potential biomechanical advantages in-vivo is difficult, finite element (FE) comparisons between implants that use continuous distractive forces (SDS) and those that use intermittent forces (TGR) present a second- 
best alternative. Aims/Objectives: To identify biomechanical differences between SDS and TGR treatment of EOS in a representative FE analysis that simulates implantation surgery and 18 months of followup with epiphyseal growth. Methods: A previously validated, ligamentous, scoliotic FE-model was used in this study. The model was created to match the spinal morphology of a 9 year-old female EOS patient (C-EOS I2N). Two versions of the same model were created; one that mimicked TGR (side-to-side connector fixed to both rods after each distraction, bi-annual distraction) and one that mimicked SDS (free sliding side-to-side connector and bilateral $75 \mathrm{~N}$ spring distraction). Except for the unlocked, sliding connector and the addition of the SDS spring, both models were identical with respect to pre-operative curve morphology and intra-operative implant position. Both models simulated implantation surgery, post-operative ambulation (including follower load), and spinal growth (by modeling the Hueter-Volkmann law) until 18-month follow-up, just before (not including) the 18-month TGR distraction. The SDS continually distracts during this follow-up, where spring forces linearly decrease as they increase in length ( $75 \mathrm{~N}$ at $38 \mathrm{~mm} ; 0 \mathrm{~N}$ at $72 \mathrm{~mm}$ ). For the TGR model, two distractions after the index surgery (6- and 12-month distraction) were modeled according to current standard of care. The primary outcome was von Mises stress magnitude in the rods. For the TGR model, rod stresses before and after each distraction were calculated. The size and location of maximum stress in each of the four rods ( 2 proximal, 2 distal) was evaluated and compared between both implants. A secondary outcome was loading/stress-shielding of the IVD, which was measured for each IVD within the distraction construct by measuring compressive/tensile loads normal to the superior and inferior IVD surface using free-body diagrams. All outcomes were measured and compared at different timepoints: immediately post-operatively, and at 6-, 12- and 18 month follow-up. Results: The instrumented FE models are shown in Fig. 1. Maximum Von Mises stress post-operatively (after follower load introduction) was
$249 \mathrm{MPa}$ for SDS (Fig. 2) and $205 \mathrm{MPa}$ for TGR (Fig. 3). However, during the first TGR distraction at 6 months, maximum von Mises stresses in the TGR rods increased twofold to a maximum of $417 \mathrm{MPa}, 59 \%$ higher than the maximum SDS rod stress (262 MPa). TGR rod stresses decreased somewhat as follower load was applied, decreased further during spinal growth but increased again during the next distraction. Overall, TGR von Mises stresses remained consistently higher than those in the SDS model, where a maximum of $296 \mathrm{MPa}$ was seen at the end of 18-month follow-up. There were characteristic differences in stress location between models that were already present after the initial surgery. For the TGR model (Fig. 4), stress maxima were consistently present in the mid-construct section of the long rods, while in the SDS model (Fig. 5), stresses were distributed near the rod-screw interface. Overall, the TGR model had larger regions of increased stress compared to the SDS model. While the SDS model initially showed lower relative compressive forces across the superior and inferior IVD surface compared to the TGR model, this reversed following the TGR distraction at 6 months (Fig. 6). At 18-month follow-up, the upper IVD surfaces in the SDS model were all under higher compressive loads (mean difference: $+112 \pm 19 \mathrm{~N}$ ) than their TGR counterparts. For the lower IVD surfaces, the same pattern was seen with higher compressive loads in the SDS model (mean difference: $+100 \pm 17 \mathrm{~N}$ ). Conclusions: During FE simulation of the first 18 months of typical SDS and TGR treatment, the bi-annual TGR distractions resulted in a higher propensity for rod fractures and increased stress-shielding of the IVD compared to SDS treatment.

Disclosures: J. Lemans, Stryker Spine (Grant/Research Support); R. Castelein, Stryker Spine (Grant/Research Support); M. Kruyt, Stryker Spine (Grant/Research Support); V. Goel, Stryker Spine (Grant/Research Support); A. Agarwal, Spinal Balance (Ownership Interest).

Abstract figures 
Fig 1: Instrumented FE model
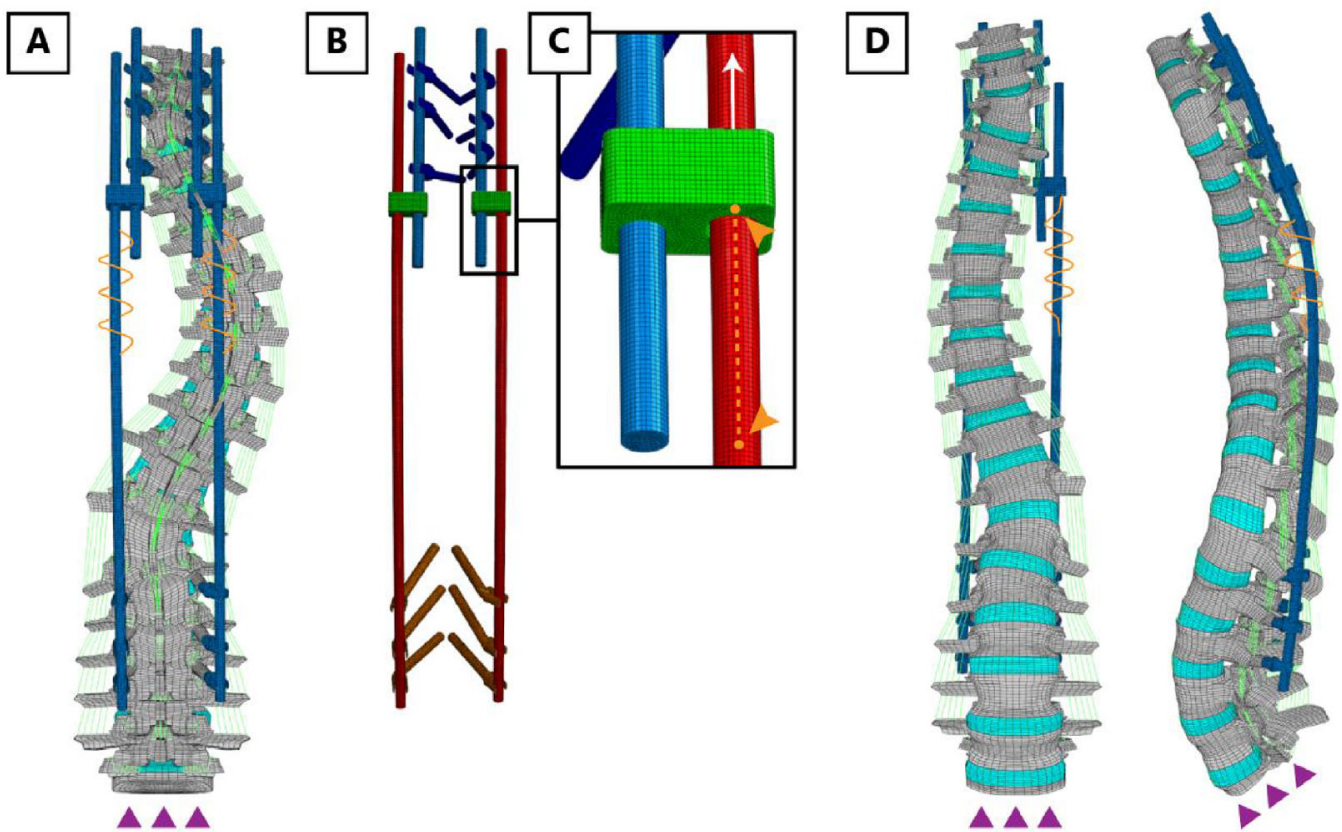

A. Posterior view of the model with implants (blue) and the SDS springs (orange). During simulation, the inferior side of S1 is fixed in all degrees of freedom (purple triangles). B. Implant configuration. The proximal rods (blue) are tied to the proximal pedicle screws and to the side-to-side connector (green). The distal rods (red) are mounted on the distal pedicle screws and are either tied to the side-to-side connector (TGR) or are able to slide through it (SDS). C. The expanded view shows the sliding direction of the connector over the rod during growth (white arrow). The SDS spring is fixated on one side onto the inferior face of the side-to-side connector and on the other side onto the sliding rod after being compressed (orange arrows). D. Anterior and sagittal view of the instrumented spine.

Fig 2: Spring Distraction System rod stress (MPa)

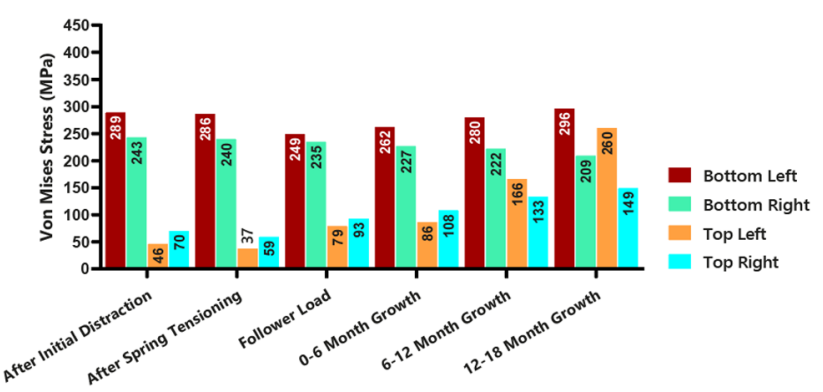


Fig 3: Traditional Growing Rod rod stress (MPa)

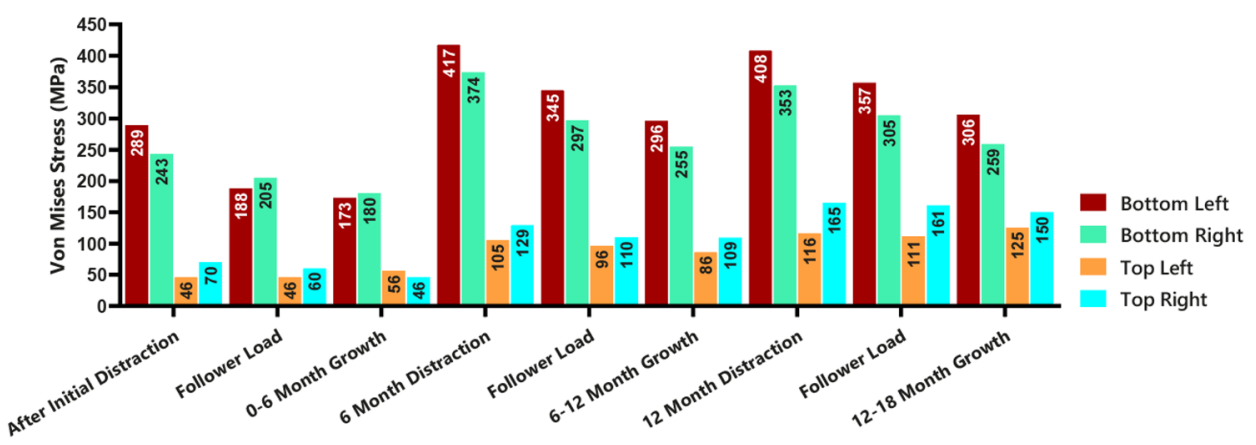

Fig 4: Spring Distraction System stress distribution

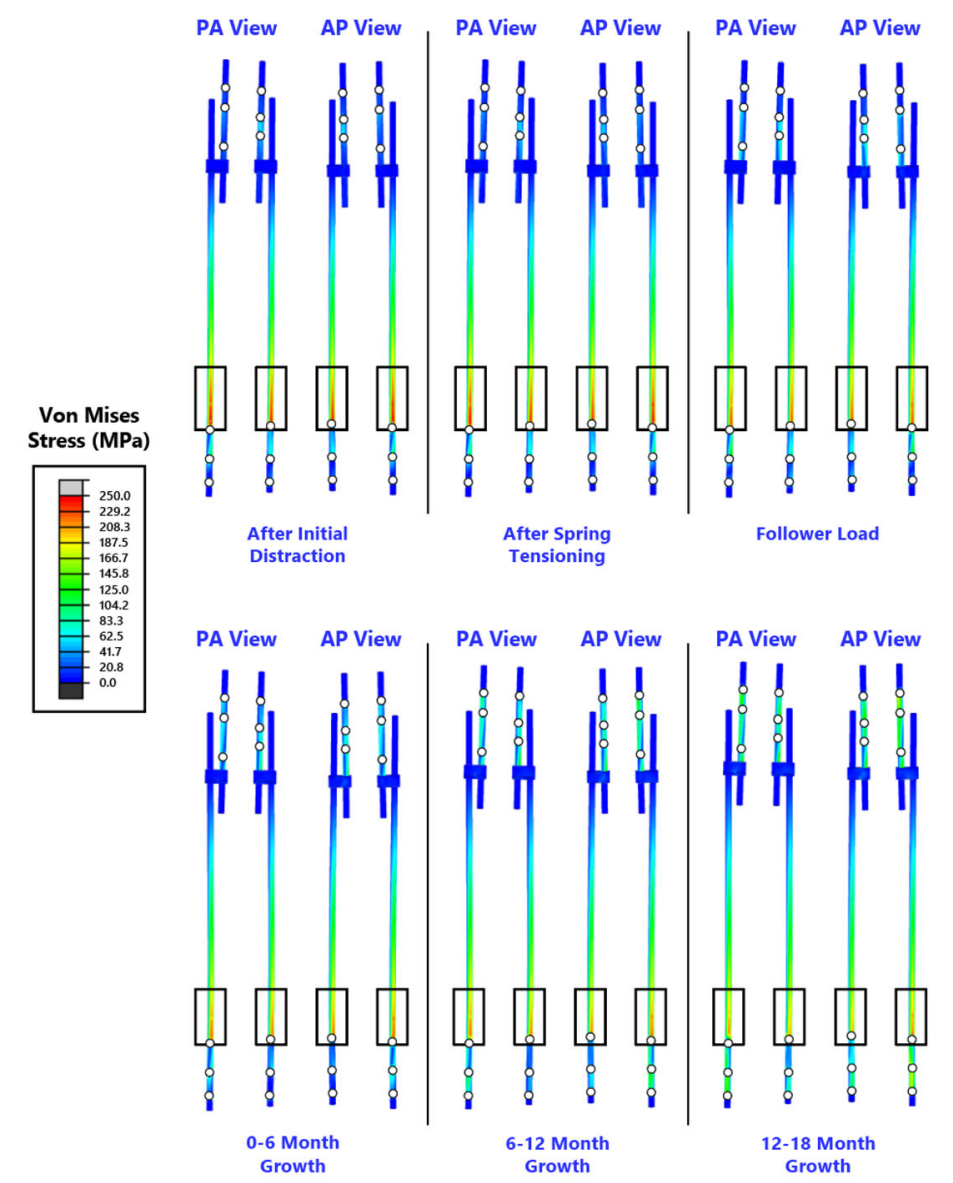

Stress magnitude and locations in each rod are shown in the PA and AP positions. Changes over time are shown from top left to bottom right. The regions of high stress are outlined in black. 
Fig 5: Traditional Growing Rod stress distribution
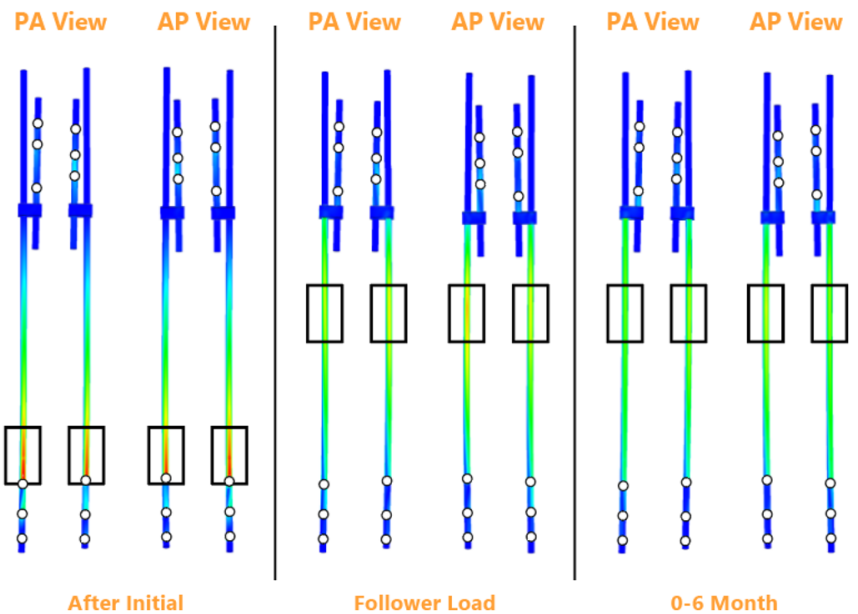

Distraction

Follower Load

0-6 Month

Growth

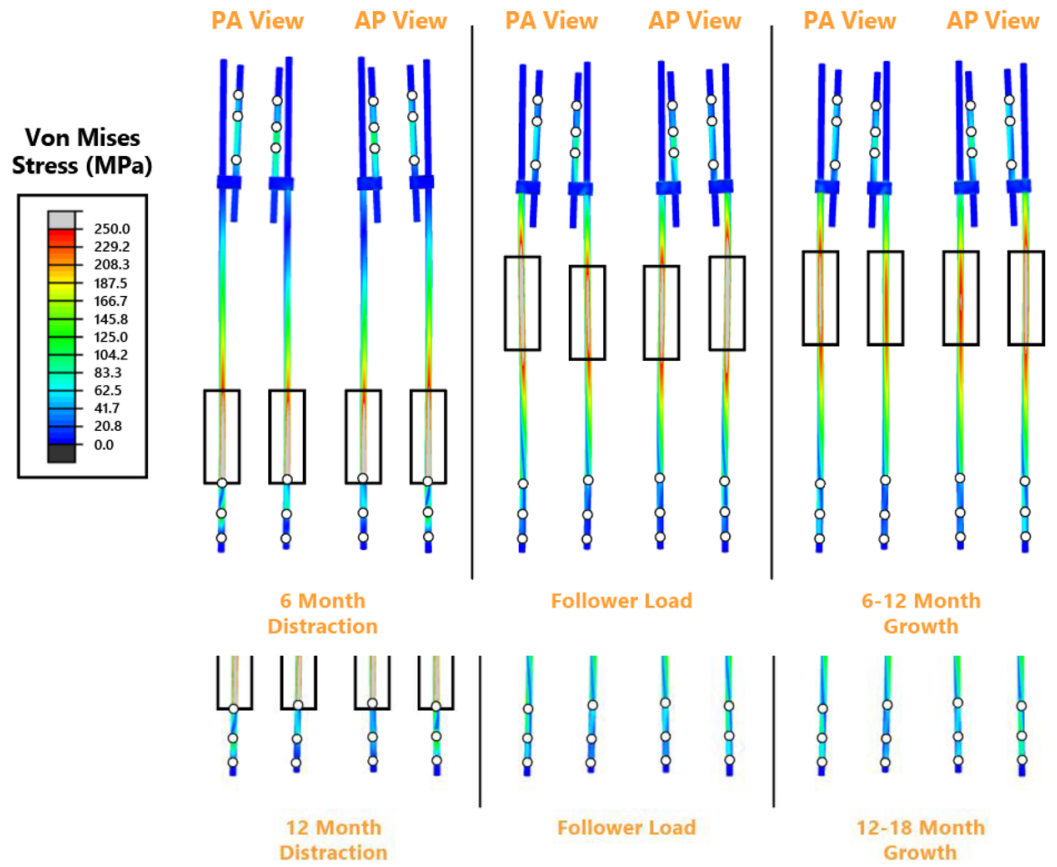

Stress magnitude and locations in each rod are shown in the PA and AP positions. Changes over time are shown from top left to bottom right.

The regions of high stress are outlined in black. 


\section{Fig 6: Forces on the intervertebral discs spanned by the construct}
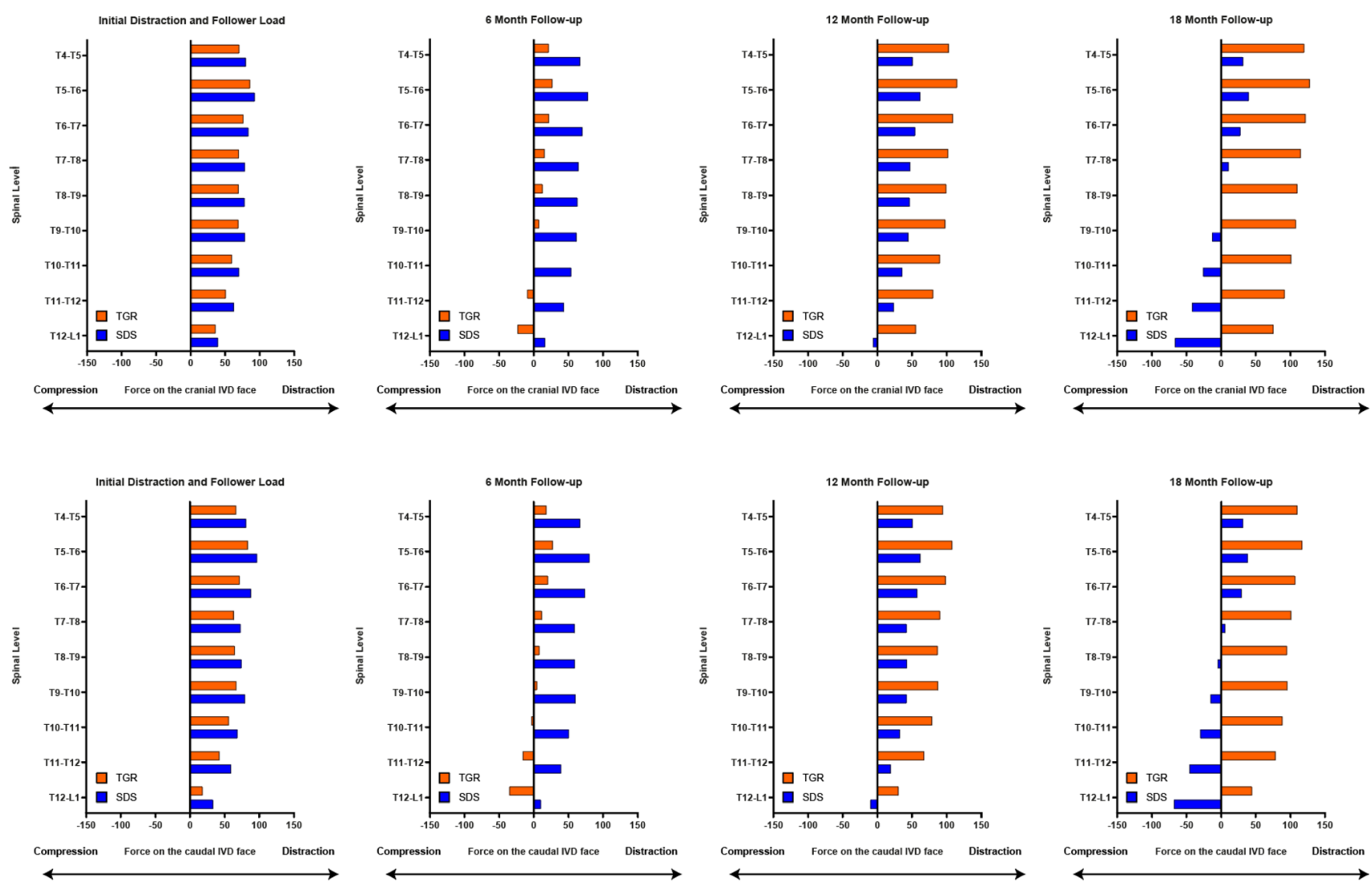

Normal forces on the upper IVD faces (top) and the lower IVD faces (bottom) extracted from the free-body diagrams. The evaluated IVDs were the ones spanned by the growing construct. Changes over time are shown from left to right. Positive forces denote distraction, negative forces denote compression.

\section{Paper 7}

The basic science supporting usage of the rib construct Richard Gross, Mohammed Alshareef, Daniel Bonthius, Hai Yao

Abstract: Introduction: Rib fixation. (RF), primarily with the VEPTR, has not been effective in improving pulmonary function, and has been ineffective for management of hyperkyphosis. We present an in vitro comparison study of RF with pedicle screws (PS) quantitating resistance to kyphotic pullout forces, and a subsequent in vivo study of the ability of RF to induce remodeling of the hyperkyphotic juvenile spine. For this study, RF denotes a "claw" configuration of 2 superior downgoing hooks and 2 inferior upgoing hooks placed on the proximal ribs adjacent to the costovertebral joints. Aim: Present basic science evidence supporting usage of RF. Objectives: (1) describe RF resistance to kyphotic pullout forces compared with PS. (2) Describe creation of a kyphotic animal model (3) describe the gross and cellular response of the immature kyphotic porcine spine to corrective instrumentation (4) discuss the effect of biomechanical forces resulting from position of the body segment(s) superior to the instrumentation on junctional failure. Methods: In vitro study of porcine spines from $20 \mathrm{~kg}$ pigs, comparable in size to a 7 year old human. The pig has 15 ribs. Pedicle screws inserted at T3 and T4, comparable to superior construct for growing rods; RF consisted of downgoing laminar hooks on T3-4, upgoing on T5-6. Rods placed, potted proximally and distally, bending forces applied with 858 Bionix II. A Kyphotic animal model was created in $10 \mathrm{~kg}$ pigs via thoracotomy, partial vertebrectomy of T10, screws placed T9 and T11, compressed with wire loop, and release of posterior ligaments T9-11. Initial attempts to assess response of immature kyphotic spine to corrective instrumentation consisted of RF proximally and lumbar pedicle screws distally, all failed secondary to distal junctional failure. An extraspinal all rib construct was successful. 8 weeks after placement of instrumentation, necropsy was performed, with CT scan, 
slab section gross and histologic study. Results: In the in vitro study, the pedicle screw group withstood $64.6^{\circ} \pm 7.3^{\circ}$ of bending and $118.6 \pm 25.7 \mathrm{~N}$ of maximal force, at which point all proximal fixations failed. The rib construct group withstood $97.9^{\circ} \pm 10.0^{\circ}$ of bending $(\mathrm{p}<0.001)$ and $119.7 \pm 13.9 \mathrm{~N}$ of maximal force with no proximal fixation failure. The in vivo study substantiated the ability of the instrumented spine to remodel sufficiently to completely compensate for the fixed kyphotic deformity, resulting in less compression on the spinal cord. Histologically, the posterior node of Ranvier was disorganized resulting in a thin, concave bone bark. The anterior node was robust, with a normal bone bark, and the nucleus pulposis was displaced anteriorly. This remodeling capability was confirmed clinically in a child with congenital dislocation of the spine. That case also illustrates the biomechanical effect of anterior displacement of the thorax on producing junctional failure, and the positive effect of correcting that anterior displacement of the thorax on promoting beneficial remodeling. Conclusions: RF provides more secure proximal fixation for kyphotic deformity than spinal fixation, and induces favorable remodeling of pediatric kyphotic deformity. Biomechanical analysis of deforming forces is helpful for selection of the best surgical construct.

Disclosures: J. Pahys: DePuy Synthes (Consulting Fees (e.g., advisory boards)); NuVasive (Consulting Fees (e.g., advisory boards)); Zimmer Biomet (Consulting Fees (e.g., advisory boards)); S. Hwang: Zimmer Biomet (Speaker's Bureau); A. Samdani: DePuy Synthes Spine (Consulting Fees (e.g., advisory boards)); Ethicon (Consulting Fees (e.g., advisory boards)); Globus Medical (Consulting Fees (e.g., advisory boards)); Medical Device Business Services (Consulting Fees (e.g., advisory boards)); Mirus (Consulting Fees (e.g., advisory boards)); NuVasive (Consulting Fees (e.g., advisory boards), Royalties); Orthofix (Consulting Fees (e.g., advisory boards)); Stryker (Consulting Fees (e.g., advisory boards)); Zimmer Biomet (Consulting Fees (e.g., advisory boards), Royalties): L. Andras: Eli Lilly (Ownership Interest); NuVasive (Consulting Fees (e.g., advisory boards), Speaker's Bureau); Orthobullets (Royalties); Zimmer Biomet (Consulting Fees (e.g., advisory boards), Speaker's Bureau); P. Newton: DePuy Synthes Spine (Grant/Research Support, Royalties); Globus (Consulting Fees (e.g., advisory boards)); Medronic (Consulting Fees (e.g., advisory boards)); Pacira (Consulting Fees (e.g., advisory boards)); Stryker K2M Spine (Grant/Research Support, Consulting Fees (e.g., advisory boards), Royalties); Zimmer Biomet (Grant/Research Support); B. Yaszay: Biogen (Consulting Fees (e.g., advisory boards)); Depuy Synthes Spine (Grant/Research Support, Consulting Fees (e.g., advisory boards)); Globus (Consulting Fees (e.g., advisory boards)); Harms Study Group/Depuy Johnson and Johnson (Grant/Research Support); K2M/Stryker (Grant/Research Support, Consulting Fees (e.g., advisory boards), Royalties); Medtronic (Consulting Fees (e.g., advisory boards)); Nuvasive (Grant/Research Support, Consulting Fees (e.g., advisory boards)); Orthopediatrics (Grant/Research Support, Consulting Fees (e.g., advisory boards)): B. Akbarnia: DePuy Spine (Royalties); NociMed (Stock/Stock OptionsOwnership Interest); NuVasive (Royalties); Stryker Spine (Royalties).
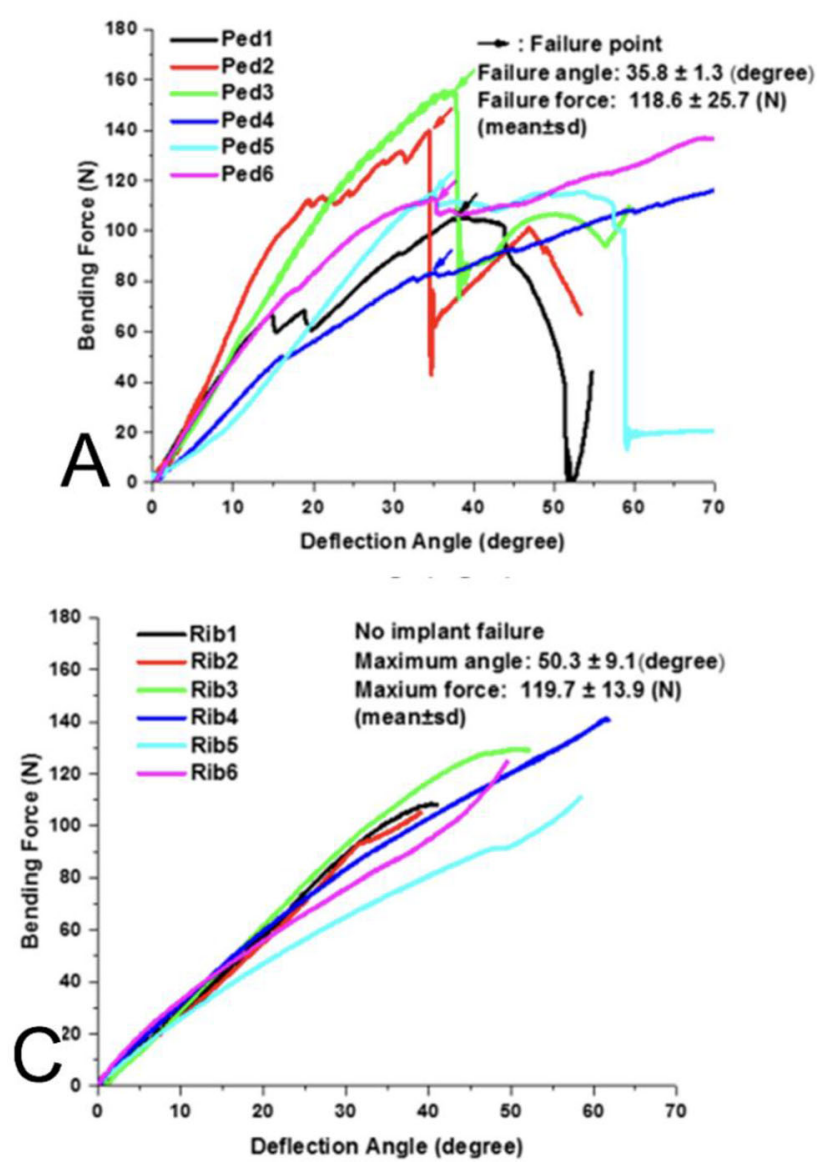

Paper 8

Spinal height for growth guidance treatment in early-onset idiopathic scoliosis: analysis through final surgical treatment

Meg Cornaghie, David Bumpass, Lauren Roeder, Richard McCarthy

Abstract: Introduction: GG uses the inherent growth potential of the spine to achieve elongation along guiding rods while fusing the deformity apex. Debate continues as to whether GG achieves sufficient thoracic and spinal height that is similar to outcomes with distraction-based constructs. Aims/Objective: Provide evidence that in I-EOS patients, GG achieves thoracic and spinal height comparable to distraction-based treatment at time of definitive final surgery. Methods: All I-EOS patients who underwent GG were reviewed. T1L1 and T1-S1 heights were measured using the traditional coronal method as well as the Halifax sagittal spinal length (SSL) technique. The SSL technique has been previously shown to more accurately measure true spinal height. Results: Of 37 I-EOS patients who underwent GG 2004-2019, 30 had returned for 2-yrs f/u (mean 7.0 yrs, range 2.4-15.4 yrs). Mean age at GG implantation was $7.5 \mathrm{yrs}$ (range 2.0-11.7 yrs); 13 were male and 17 female. 15 pts have undergone final fusion after GG completion, with a mean $5.5 \mathrm{yrs}$ of GG treatment prior to fusion (range 2.0-11.4 yrs). Mean increase in SSL thoracic height at the end of GG treatment was $1.2 \mathrm{~cm}$ when compared to the immediate post-GG implantation measurement; this increased to $5.2 \mathrm{~cm}$ after fusion. Mean increase in SSL spinal height at end of GG treatment was $3.1 \mathrm{~cm}$ relative to immediate post-GG implantation, increasing to $9.7 \mathrm{~cm}$ after final fusion. Only 2 pts $(5 \%)$ have not yet reached a minimum thoracic height of $18 \mathrm{~cm}$; both are still undergoing GG treatment, having had their implants placed at ages 2.7 and 3.7 yrs respectively. Conclusion: GG achieves 
notable and sufficient ultimate thoracic and spinal height. Recently published SSL values for distraction-based treatment of I-EOS report thoracic height increase of $3.5-5.5 \mathrm{~cm}$ during treatment; our results demonstrate comparability (mean $5.2 \mathrm{~cm}$ ). GG achieved slightly less elongation at end of guidance but the remaining flexibility of the spine allowed for substantially more lengthening with final fusion surgery. Disclosures: D. Bumpass, Medtronic (Grant/Research Support, Consulting Fees (e.g., advisory boards)) NuShores LLC (Ownership Interest); R. McCarthy, Medtronic (Speaker's Bureau) Orthopediatrics (Consulting Fees (e.g., advisory boards), Speaker's Bureau).

Thoracic height with guided growth data table

\begin{tabular}{|c|c|c|c|c|c|c|c|c|}
\hline & $\begin{array}{l}\text { T1-T12 } \\
\text { Coronal } \\
(\mathrm{cm})\end{array}$ & $\begin{array}{c}\text { Change } \\
\text { from } \\
\text { Immediate } \\
\text { Post-GG } \\
\text { (cm) }\end{array}$ & $\begin{array}{c}\text { T1-S1 } \\
\text { Coronal } \\
(\mathrm{cm})\end{array}$ & 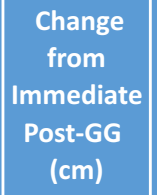 & $\begin{array}{l}\mathrm{T} 1-\mathrm{T} 12 \\
\mathrm{SSL} \\
(\mathrm{cm})\end{array}$ & \begin{tabular}{|c|}
$\begin{array}{c}\text { Change } \\
\text { from }\end{array}$ \\
Immediate \\
Post-GG \\
(cm)
\end{tabular} & $\begin{array}{l}\text { T1-S1 } \\
\text { SSL } \\
(\mathrm{cm})\end{array}$ & $\begin{array}{l}\text { Change } \\
\text { from } \\
\text { Immediate } \\
\text { Post-GG } \\
\text { (cm) }\end{array}$ \\
\hline Pre-GG & 17.2 & & 29.1 & & 18.4 & & 30.8 & \\
\hline Immediately Post-GG & 20.1 & & 33.1 & & 21.3 & & 35.1 & \\
\hline 2 yrs Post-GG & 20.8 & 0.7 & 33.9 & 0.8 & 21.8 & 0.5 & 36.4 & 1.3 \\
\hline Final GG (Pre-Fusion) & 21.6 & $1.5^{*}$ & 35.5 & $2.5^{*}$ & 22.6 & 1.2 & 38.2 & $3.1^{*}$ \\
\hline Final Post-Fusion & 25.2 & $5.1^{*}$ & 41.3 & $8.2^{*}$ & 26.5 & $5.2^{*}$ & 44.8 & $9.7^{*}$ \\
\hline${ }^{*} \mathrm{p}<0.05$ usi & t-test & & & & & & & \\
\hline
\end{tabular}




\section{Paper 9}

The Harms Study Group retrospective comparison study on anterior vertebral body tethering versus posterior spinal fusion for primary thoracic curves

Peter Newton, Stefan Parent, Firoz Miyanji, Ahmet Alanay, Baron Lonner, Kevin Neal, Daniel Hoernschemeyer, Burt Yaszay, Laurel Blakemore, Suken Shah, Harms Study Group

Abstract: Introduction: A large, multi-center comparison of the outcomes of AVBT to PSF for thoracic idiopathic scoliosis (IS) is necessary to inform clinicians and patients about treatment decisions. Objective: To compare outcomes of Anterior Vertebral Body Tethering (AVBT) to Posterior Spinal Fusion (PSF) at a minimum of 2 years postoperatively. Methods: Retrospective cases of thoracic idiopathic scoliosis patients who underwent AVBT with a minimum follow-up of 2 years underwent propensity guided matching to PSF patients from a prospective IS database registry. Radiographic, clinical and SRS-22 data were compared preoperatively and at $\geq 2$ year follow-up. Results: A total of 241 patients $(12.1 \pm 1.6 \mathrm{yrs}, 84 \% \mathrm{~F}$, $80 \%$ Risser $0-1$ ) in the AVBT group from 16 surgeons were compared to 241 patients $(13.4 \pm 1.4 \mathrm{yrs}, 83 \% \mathrm{~F}, 43 \%$ Risser $0-1)$ in the PSF group from 25 surgeons. The mean follow-up was similar: $2.2 \pm 0.5$ yrs for AVBT vs $2.3 \pm 0.5$ yrs for PSF. Preoperatively, main thoracic curves of $48^{\circ} \pm 9^{\circ}$ (range $30-74^{\circ}$ ) for AVBT were on average lower than $53^{\circ} \pm 8^{\circ}$ (range $40^{\circ}-78^{\circ}$ ) for PSF, $\mathrm{p}<0.001$. Initial \% correction was $41 \pm 16 \%$ vs $70 \pm 11 \%$ for AVBT and PSF respectively, $\mathrm{p}<0.001$. At the time of latest follow-up the residual thoracic deformity was $27^{\circ} \pm 12^{\circ}$ in the AVBT group compared with $20^{\circ} \pm 7^{\circ}$ for the PSF group ( $\left.\mathrm{p}<0.001\right) .76 \%$ of AVBT patients had a thoracic curve $<35^{\circ}$ at latest follow-up compared to $97.5 \%$ of PSF patients, $\mathrm{p}<0.001$. No PSF case had a residual curve at latest followup $>50^{\circ}$ while $7(3 \%)$ had such after AVBT. Forty-six $(19.1 \%)$ revision procedures (17 conversion to PSF) were performed on 38 (16\%) AVBT patients vs $3(1.2 \%)$ for PSF patients, $\mathrm{p}<0.01$. AVBT patients had lower median preoperative SRS-22 mental health scores compared to PSF patients $(\mathrm{p}<0.05)$ and had less improvement in pain, self-image, and total scores between preoperative and $\geq 2$ year follow-up ( $p<0.05$ ). Conclusion: At a mean follow-up of 2.3 years, AVBT for thoracic idiopathic scoliosis in 241 patients resulted in correction to $<35^{\circ}$ in $76 \%$ of cases with a $19.1 \%$ revision rate and an additional $3 \%$ with curves $>50^{\circ}$ that may require revision/PSF. This compares to $97.5 \%$ with a residual curve $<35^{\circ}$ and a $1.7 \%$ revision rate for the PSF cohort. This may help inform the decision facing patients and families considering these two options.

Disclosures: P. Newton, DePuy Synthes Spine (Grant/Research Support, Royalties) Globus (Consulting Fees (e.g., advisory boards)) Medronic (Consulting Fees (e.g., advisory boards)) Pacira (Consulting Fees (e.g., advisory boards)) Stryker K2M Spine (Grant/ Research Support, Consulting Fees (e.g., advisory boards), Royalties) Zimmer Biomet (Grant/Research Support); S. Parent, DePuy Synthes Spine (Grant/Research Support, Consulting Fees (e.g., advisory boards)) EOS imaging (Consulting Fees (e.g., advisory boards)) K2M (Consulting Fees (e.g., advisory boards)) Orthopaediatrics (Speaker's Bureau) Spinologics Inc. (Ownership Interest); F. Miyanji, Depuy Synthes Spine (Consulting Fees (e.g., advisory boards)) Stryker Spine (Consulting Fees (e.g., advisory boards)) Zimmer Biomet (Consulting Fees (e.g., advisory boards), Royalties); A. Alanay, Depuy Synthes (Grant/Research Support) Globus Medical (Consulting Fees (e.g., advisory boards)) Medtronic (Grant/ Research Support) Zimmer Biomet (Consulting Fees (e.g., advisory boards), Royalties); B. Lonner, DePuy Synthes Spine (Grant/Research Support, Consulting Fees (e.g., advisory boards), Speaker's Bureau, Royalties) OrthoPediatrics (Consulting Fees (e.g., advisory boards), Equity) Spine Search (Ownership Interest, Stock/Stock options) Zimmer Biomet (Consulting Fees (e.g., advisory boards), Royalties); B. Yaszay, Biogen (Consulting Fees (e.g., advisory boards)) Depuy Synthes Spine (Grant/Research Support, Consulting Fees (e.g., advisory boards)) Globus (Consulting Fees (e.g., advisory boards)) Harms Study Group/Depuy Johnson and Johnson (Grant/ Research Support) K2M/Stryker (Grant/Research Support, Consulting Fees (e.g., advisory boards), Royalties) Medtronic (Consulting Fees (e.g., advisory boards)) Nuvasive (Grant/Research Support, Consulting Fees (e.g., advisory boards)) Orthopediatrics (Grant/ Research Support, Consulting Fees (e.g., advisory boards)); S. Shah, DePuy Synthes Spine (Consulting Fees (e.g., advisory boards), Royalties); H. Study Group, DePuy Synthes Spine (Grant/Research Support) EOS imaging (Grant/Research Support) Food and Drug Administration. (Grant/Research Support) Medtronic (Grant/Research Support) NuVasive (Grant/Research Support) Stryker (Grant/ Research Support) Zimmer Biomet (Grant/Research Support).

\section{Paper 10}

Results of vertebral body tethering (VBT) for non-idiopathic patients: a multicenter study

Natalie Pulido, Michael Vitale, Stefan Parent, Todd Milbrandt, Firoz Miyanji, Ron El Hawary, A. Noelle Larson, Pediatric Spine Study Group

Abstract: Study design: Retrospective review. Introduction: VBT is growing in popularity for patients with idiopathic scoliosis. Results of the technique in patients with syndromic, congenital, and neuromuscular scoliosis have not been reported. Methods: An international multicenter registry of pediatric spine patients was retrospectively queried for non-idiopathic scoliosis patients who underwent VBT with minimum 2-year follow-up. Radiographs and clinical course were evaluated. Success at 2 years was defined as Cobb angle $<35^{\circ}$ and no fusion surgery. Results: Of the 251 patients treated with VBT, 20 had non-idiopathic scoliosis and minimum 2-year follow-up. Mean age at surgery was 12.4 years (range 10-17 years). Mean Cobb angle at enrollment was $56^{\circ}$, with 2 lumbar curves treated. Mean BMI 18.8 (range 15-29). Mean number of levels instrumented levels was 8 (range 6-11). Mean EBL was 281 (range 25-1200). Mean operative time was $267 \mathrm{~min}$ (range 128-486). Of the 20 patients, 9 met criteria for success $(45 \%)$. Success was more common in patients with a smaller preoperative Cobb angle $\left(50^{\circ}\right.$ vs. $\left.62^{\circ}, \mathrm{p}=0.01\right)$ and those with smaller Cobb angle on 1 st erect imaging $\left(28^{\circ}\right.$ vs. $46^{\circ}$, $\mathrm{p}=0.0007$ ). All patients with Cobb angle $<35^{\circ}$ on 1 st erect imaging had a successful result, with the exception of one patient who overcorrected and required fusion. Syndromic patients had a higher likelihood of success (5 of 7, 71\%) compared to neuromuscular patients ( 2 of $10,20 \%, \mathrm{p}=0.03$ ). Two congenital patients were successful. The other had adding on after correction of the instrumented thoracic curve, resulting in lumbar curve progression. Of the 12 unsuccessful results, 9 outcomes were considered poor (4 fusions and 5 had a curve $>50^{\circ}$ ) and were associated with larger preoperative major Cobb angle $\left(63^{\circ}\right.$ vs. $\left.52^{\circ}, \mathrm{p}=0.01\right) .9$ of the 16 females had a successful result ( 2 congenital, 2 neuromuscular/ CP, 5 syndromic). None of the 4 males had a successful result $(p=0.03)$. Conclusion: Selected non-idiopathic scoliosis can be successfully treated with VBT, but failure rates are high and were associated with large curves with inadequate intraoperative correction and also with neuromuscular diagnosis. Achieving a Cobb angle less than 35 on 1st standing radiograph was associated with a successful outcome and found in $45 \%$ of patients.

Disclosures: M. Vitale, Stryker (Consulting Fees (e.g., advisory boards)) Zimmer biomet (Consulting Fees (e.g., advisory boards), Royalties); S. Parent, DePuy Synthes Spine (Grant/Research 
Support, Consulting Fees (e.g., advisory boards)) EOS imaging (Consulting Fees (e.g., advisory boards)) K2M (Consulting Fees (e.g., advisory boards)) Orthopaediatrics (Speaker's Bureau) Spinologics Inc. (Ownership Interest); T. Milbrandt, medtronic (Consulting Fees (e.g., advisory boards)) orthopediatrics (Consulting Fees (e.g., advisory boards)) zimmer (Consulting Fees (e.g., advisory boards)); F. Miyanji, Depuy Synthes Spine (Consulting Fees (e.g., advisory boards)) Stryker Spine (Consulting Fees (e.g., advisory boards)) Zimmer Biomet (Consulting Fees (e.g., advisory boards), Royalties); R. El Hawary, Depuy Synthes (Grant/Research Support, Consulting Fees (e.g., advisory boards)) Medtronic (Grant/Research Support, Consulting Fees (e.g., advisory boards)) Orthopediatrics (Grant/ Research Support, Consulting Fees (e.g., advisory boards), Stocks); A. Larson, Globus, Medtronic, Stryker, Depuy, Orthopediatrics (Consulting Fees (e.g., advisory boards), All proceeds to Mayo Clinic research); P. Study Group, DePuy Synthes Spine (Grant/Research Support) Globus Medical, Inc. (Grant/Research Support) Medtronic (Grant/Research Support) NuVasive (Grant/Research Support) OrthoPediatrics (Grant/Research Support) Pediatric Spine Foundation (Grant/Research Support) Stryker (Grant/Research Support) Zimmer Biomet (Grant/Research Support).

Table 1 Cobb angles and success rates of vertebral body tethering in non-idiopathic pediatric populations. Success is defined as major Cobb angle $<35^{\circ}$

\begin{tabular}{|c|c|c|c|c|}
\hline & $\begin{array}{l}\text { Preop } \\
\text { major } \\
\text { Cobb angle } \\
(\text { mean, in } \\
\left.{ }^{\circ}\right)\end{array}$ & $\begin{array}{l}\text { Postop } \\
\text { major Cobb } \\
\text { angle } \\
\left(\text { mean, in }{ }^{\circ}\right)\end{array}$ & $\begin{array}{l}2 \text { year follow- } \\
\text { up major Cobb } \\
\text { angle (mean, } \\
\text { in }^{\circ} \text { ) }\end{array}$ & $\begin{array}{l}\text { Success } \\
\text { rate }\end{array}$ \\
\hline $\begin{array}{l}\text { Congenital } \\
\quad(\mathrm{n}=3)\end{array}$ & $55(49-59)$ & $42(31-50)$ & $44(32-51)$ & $2(66 \%)$ \\
\hline $\begin{array}{l}\text { Neuromuscular } \\
\quad(\mathrm{n}=10)\end{array}$ & $59(40-68)$ & $43(21-64)$ & $43(16-62)$ & $2(20 \%)$ \\
\hline $\begin{array}{l}\text { Syndromic } \\
(\mathrm{n}=7)\end{array}$ & $55(39-74)$ & $33(29-49)$ & $35(15-56)$ & $5(71 \%)$ \\
\hline
\end{tabular}

following vertebral body tethering in non-idiopathic patients. Unsuccessful outcomes $(n=11)$ defined as Cobb angle $>35^{\circ}$ or required reoperation. Successful outcomes $(n=9)$ defined as Cobb angle $<35^{\circ}$

\section{Paper 11}

Intervertebral disc health following vertebral body tethering for adolescent idiopathic scoliosis

Taylor Jackson, Todd Milbrandt, Smitha Mathew, Jeremiah Heilman, A. Noelle Larson

Abstract: Introduction: Interest in vertebral body tethering (VBT) as an alternative to posterior spinal fusion for adolescent idiopathic scoliosis (AIS) continues to grow. Preservation of motion is thought to be protective against accelerated disc degeneration and adjacent segment disease. However, compression of the intervertebral discs from the tensioned tether may theoretically increase strain on the discs and accelerate degenerative changes. Objective: Data on VBT effect on the human intervertebral disc are limited. The purpose of this study was to prospectively assess intervertebral disc health on MRI at 1 year following VBT in AIS patients. Methods: Prospective FDA Investigational Device Exemption (IDE) Study. AIS patients were prospectively enrolled in a surgeon-sponsored IDE study and underwent MRI at 1-year following VBT as part of a research protocol. Intervertebral discs were rated according to the Pfirrmann grading criteria. Curves were analyzed separately in patients with both a tethered thoracic and a lumbar curve. All discs spanned by the tether were graded. In addition, the untethered discs immediately adjacent to the upper (UIV) and lower (LIV) instrumented levels were also evaluated. The apical disc as well as the periapical discs (immediately above and below the apical disc) were also compared. Associations between patient factors and pre-operative and post-operative disc health and patient reported outcomes were evaluated. Results: Twenty-two patients were enrolled with a post-operative MRI (25 curves, 188 discs), and 7 patients ( 7 curves) had both preoperative and postoperative MRIs (67 discs). Mean age was 12.7 years. Most were Risser $0(65 \%)$ and either Sanders Skeletal Maturity Score $3(35 \%)$ or $4(53 \%)$. Average pre- and post-operative major Cobb angles were 510 and 310 , respectively. In the 7 patients

\section{Major Cobb Angle over Time following Vertebral Body Tethering in Non-Idiopathic Patients}

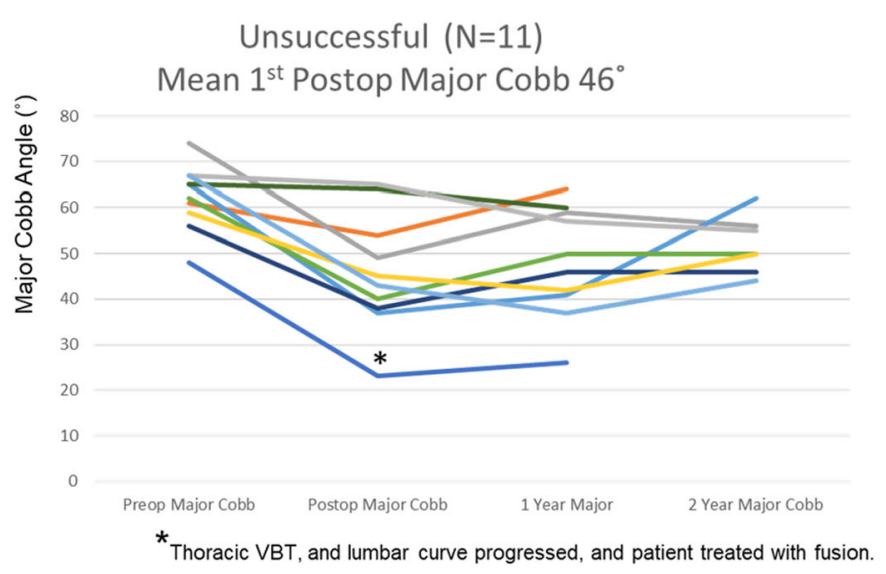

Fig. 1 Major Cobb angle over time (Preop, Postop, 1-, and 2-year)

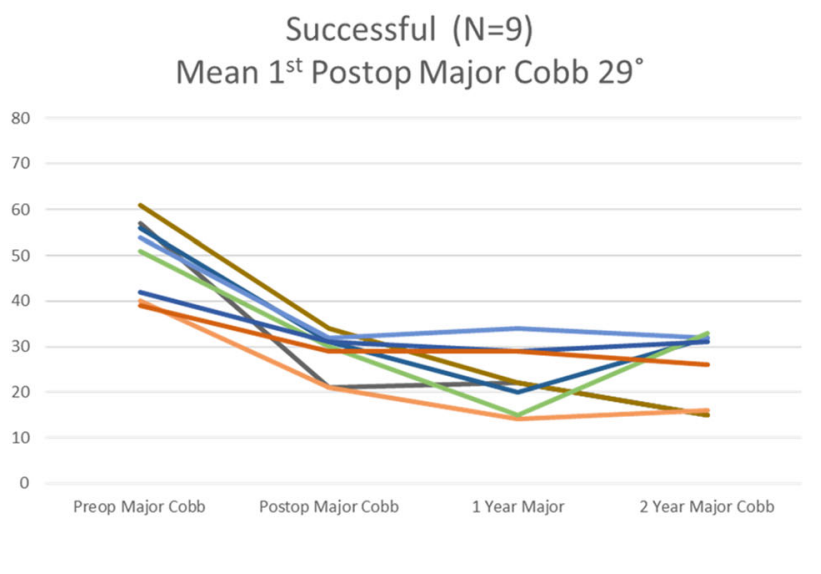


with pre-operative and post-operative MRI, the mean Pfirrmann grade of the discs spanned by the tether were 1.88 pre-operatively and 2.31 post-operatively $(\mathrm{p}=0.0075)$. No statistically significant differences in pre-operative versus post-operative Pfirrmann grade were identified in the discs adjacent to the upper (1.42 vs $1.57, \mathrm{p}=0.6036)$ or lower ( 2.14 vs $2.14, p=1.000)$ instrumented vertebrae (Fig. 1). No association was found between patient reported outcomes (SRS scores) and Pfirrmann grade. Conclusion: At 1 year postoperatively, there was no evidence of adjacent segment disc disease. However, progressive degeneration in discs spanned by the tether was identifiable on MRI. These changes were not associated with patient reported outcomes. While VBT may accelerate degenerative disc changes, the clinical significance of these disc changes is unclear, and the longterm disc health following VBT warrants further study. Level of Evidence: Level II.

Disclosures: T. Milbrandt, medtronic (Consulting Fees (e.g., advisory boards)) orthopediatrics (Consulting Fees (e.g., advisory boards)) zimmer (Consulting Fees (e.g., advisory boards)); A. Larson, Globus, Medtronic, Stryker, Depuy, Orthopediatrics (Consulting Fees (e.g., advisory boards), All proceeds to Mayo Clinic research). induced by a thoracic anterior spinal growth tether (ASGT) will be dependent on skeletal maturity at time of surgery. Methods: This was a retrospective multicenter study that included thoracic idiopathic scoliosis patients with minimum 2 years follow-up after AVBT who had measurements of coronal screw angulation for each level from T5-6 to T11-12 measured at the first erect postoperative visit and every 6 months up to 24 months. The rate of change ( $/$ month) between each time point was calculated in addition to the cumulative correction (deg) per level over the 24-month duration. Patients were grouped using preoperative Sanders maturity score $(2,3,4,5+6)$. Data for levels with a broken tether or screw plow were excluded. Results: 157 patients age $12.6 \pm 1.6(9-16)$ years with main thoracic curve magnitude of $50^{\circ} \pm 10^{\circ}$ (range $30^{\circ}-74^{\circ}$ ), initial correction of $44 \pm 20 \%$ and Sanders scores of 2-6 had an overall segmental angular rate of coronal correction that was different based on preoperative Sanders score $(\mathrm{p}<0.001)$. The distribution of preoperative Sanders scores was: S2:15\%, S3:58\%, S4:14\%, S5:6\%, S6:7\% (S5 and S6 combined for analysis). The average rates of correction for each postoperative time period based on the preoperative Sanders score were fastest for S2, slowest for S4 and S5-6. The duration of growth modulation (postoperative periods with rates significantly greater than zero) was 24, 18 and $<12$ months for S2, S3 and S4-6,
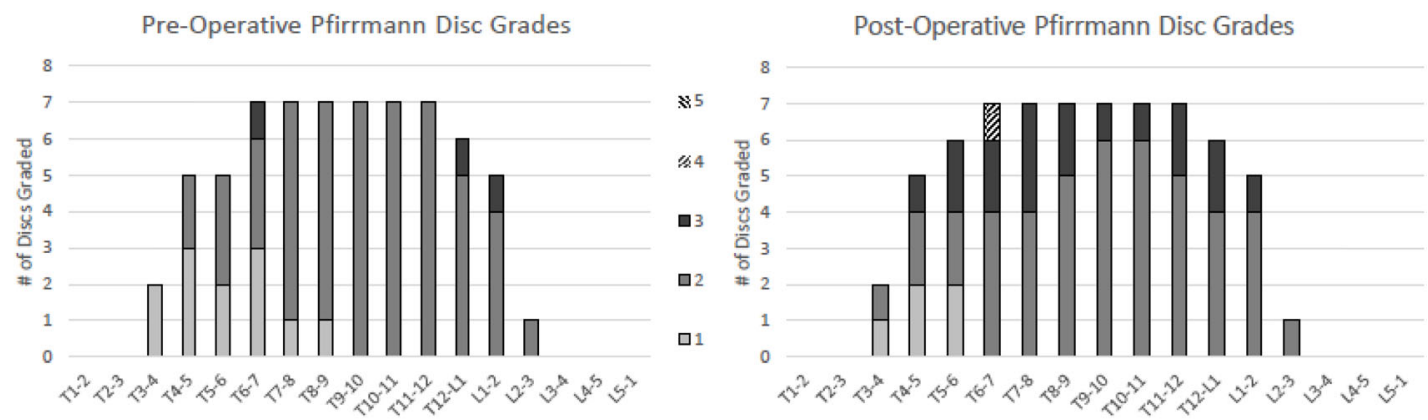

\begin{tabular}{|l|l|l|l|}
\hline \multicolumn{3}{|c|}{ Matched Comparison of Pre-Operative and Post-Operative Intervertebral Discs } \\
\hline & Pre-Operative & Post-Operative & p-value \\
\hline UIV Adjacent Disc, mean (SD) & $1.42(0.79)$ & $1.57(0.79)$ & 0.6036 \\
\hline IV Adjacent Disc, mean (SD) & $2.14(0.38)$ & $2.14(0.38)$ & 1.0000 \\
\hline Spanned Disc, mean (SD) & $1.88(0.12)$ & $2.31(0.30)$ & 0.0075 \\
\hline Apical Disc, mean (SD) & $2($ NA) & $2.43(0.79)$ & 0.1996 \\
\hline Periapical Disc, mean (SD) & $1.86(0.38)$ & $2.33(0.51)$ & 0.1291 \\
\hline
\end{tabular}

Comparison of Pfirmann disc grades from pre- and post-operative MRIs of AVBT patients showed greater degenerative changes postoperatively at the levels spanned by the cord.

\section{Paper 12}

Sanders 2 skeletal maturity patients have the greatest rate and duration of post anterior tether scoliosis correction

Peter Newton, Baron Lonner, Kevin Neal, Daniel Hoernschemeyer, Firoz Miyanji, Tracey Bastrom, Harms Non-Fusion Study Group

Abstract: Introduction: Harnessing spinal growth with a vertebral body tether is proposed as a means of progressively correcting scoliosis. Research is needed to better understand the relationship between remaining growth and potential curve correction. Objective: To test the hypothesis that the rate of subsequent scoliosis correction respectively $(\mathrm{p}<0.01)$. No group had a significant correction rate after 24 months. Initial correction to $<30^{\circ}$ did not affect correction rates $(p=0.7)$. The average cumulative 24 -month postoperative correction, following the first erect X-ray was $4.9^{\circ} \pm 2.1^{\circ}$ for S2, $1.7^{\circ} \pm 1.7^{\circ}$ for $\mathrm{S} 3,1.0^{\circ} \pm 2.0^{\circ}$ for $\mathrm{S} 4$ and $0.9^{\circ} \pm 0.9^{\circ}$ for $\mathrm{S} 5-6$, per tethered level based on Sanders score at the time of surgery $(\mathrm{p}<0.001)$. Conclusion: There was considerable variation in the progressive post-implantation thoracic curve correction following ASGT based on initial skeletal maturity. The cumulative effect based on preoperative Sanders score may help guide surgical timing and set initial correction goals. 
Disclosures: P. Newton, DePuy Synthes Spine (Grant/Research Support, Royalties) Globus (Consulting Fees (e.g., advisory boards)) Medronic (Consulting Fees (e.g., advisory boards)) Pacira (Consulting Fees (e.g., advisory boards)) Stryker K2M Spine (Grant/ Research Support, Consulting Fees (e.g., advisory boards), Royalties) Zimmer Biomet (Grant/Research Support); B. Lonner, DePuy Synthes Spine (Grant/Research Support, Consulting Fees (e.g., advisory boards), Speaker's Bureau, Royalties) OrthoPediatrics (Consulting Fees (e.g., advisory boards), Equity) Spine Search (Ownership Interest, Stock/Stock options) Zimmer Biomet (Consulting Fees (e.g., advisory boards), Royalties); F. Miyanji, Depuy Synthes Spine (Consulting Fees (e.g., advisory boards)) Stryker Spine (Consulting Fees (e.g., advisory boards)) Zimmer Biomet (Consulting Fees (e.g., advisory boards), Royalties); H. Study Group, DePuy Synthes Spine (Grant/Research Support) EOS imaging (Grant/Research Support) Food and Drug Administration. (Grant/Research Support) Medtronic (Grant/Research Support) NuVasive (Grant/Research Support) Stryker (Grant/Research Support) Zimmer Biomet (Grant/Research Support).

\section{Paper 13}

Systematic analysis of corrosion, wear debris, compositional changes, and physical properties of explanted magnetically controlled growing rods (MCGR)

Basel Khader, Karl Jepsen, Brandon Ramo, Anna McClung, David Thornberg, Ying $\mathrm{Li}$

Abstract: Introduction: Magnetically controlled growing rods (MCGR) have become widely used to treat early onset scoliosis (EOS). MCGRs are made from a titanium (Ti) alloy (Ti6Al4V) and have been associated with significant metallosis. Wear debris has been reported to be a source of this metallosis but it remains unclear whether other types of debris are generated inside MCGRs. Corrosion unused control rod were systematically analyzed. Microscopy was used to evaluate the external surface for wear-damage and presence of debris. Nano-computed tomography (nano-CT) was used to evaluate for damage to internal structural components and presence of internal debris. After opening the rods, the internal components, debris, and corrosion types found in different areas of the MCGR surface morphology were evaluated using scanning electron microscopy (SEM). Energy dispersive X-ray (EDX) was used to identify elemental composition of MCGR parts, wear, and corrosive debris. Results: All of the MCGR explants showed signs of corrosion regardless of the implantation time and curve magnitude. Microscopy showed different types of corrosion formation on the rods, such as crevice, pitting, fretting corrosion, and possible galvanic chemical reaction due to our findings of dis-similar materials inside the devices (copper, stainless steel, and neodymium). Nano-CT showed degeneration of the internal components and presence of debris inside the actuators (Figure). Upon opening the actuator, most of the devices showed evidence of corrosion and wear debris on and around the extending rod and metal to metal friction signs, as well as fractured actuator pins in some of the devices. Damage to the O-ring and base of the O-ring were also evident. SEM showed the presence of wear debris, chemical reactions on the internal surfaces, and that the development of corrosive metal led to corroded surfaces and friction between the internal parts and surfaces. EDX showed that new elements $(\mathrm{F}, \mathrm{Cl}, \mathrm{P}, \mathrm{Mg}, \mathrm{Ca}$ ) were introduced to the Ti alloy composition and/or surface of the explanted rods, and these elements led to oxide deposition by forming oxide layers in the Ti alloy composition and/or surface. This was not found in the unused control rod. EDX also showed copper, stainless steel, and neodymium elements in all of the rods, including the control rod. The chemical reactions and oxide layer formation facilitated different types of wet corrosion changes to the rod surface morphology and had a significant impact on the material and mechanical properties of the MCGRs. Conclusion: This is the first study to demonstrate corrosion of the internal components of explanted MCGRs and accumulation of corrosive metal debris, suggesting the metallosis seen in the periimplant tissues may not be limited to wear debris. Further study of the composition of the metallosis in the peri-implant tissues of children

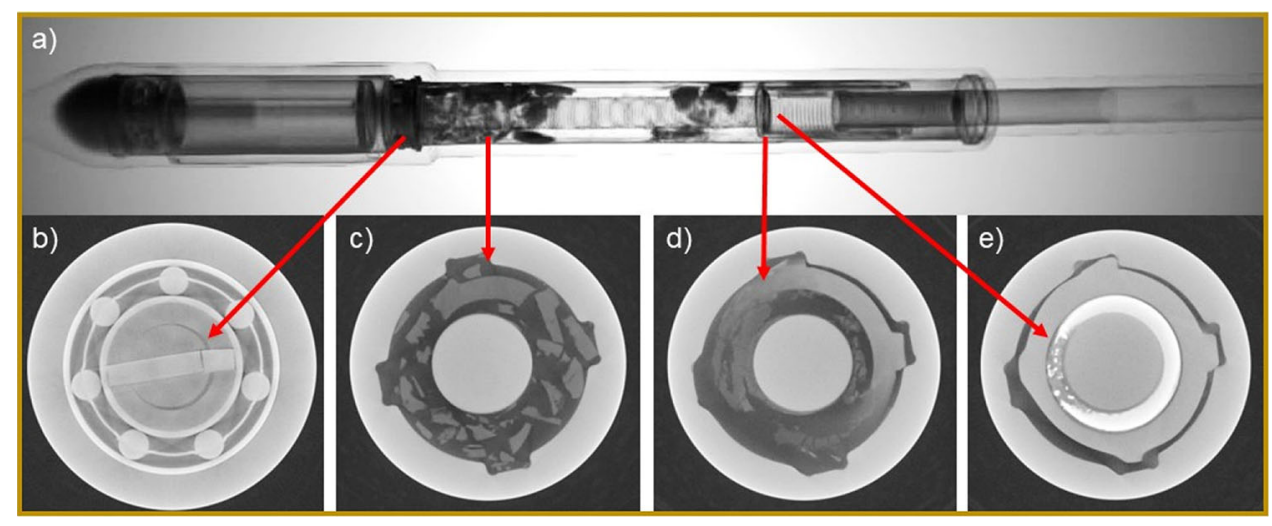

resistance is an important factor when assessing the biocompatibility of metal implants. Corrosion processes may lead to the release of allergenic, toxic/cytotoxic, or carcinogenic species into the body. We are unaware of any studies that have evaluated the corrosion performance of MCGRs. Aims/Objectives: The purpose of this study was to assess MCGR explants for non-wear sources of debris and different failure areas. We hypothesized that corrosion is an additional source of debris. Methods: 26 MCGR explants from two institutions and one with EOS treated with MCGR is critical.

(a) Nano-CT image showing the internal parts of the MCGR and debris prior to opening; (b) Fractured actuator pin; (c) Accumulation of wear/corrosive debris surrounding the actuator screw; (d) The internal corrosion found at the end of the extending rod; (e) Corrosion of the manipulated copper area. 


\section{Paper 14}

Does growing rod salvaging lead to increased recurrent infection rates?

Krishna Vangipuram Suresh, Majd Marrache, Paul Sponseller, Pediatric Spine Study Group

Abstract: Introduction: Deep surgical site infections (SSI) in patients with magnetically controlled growing rods (MCGR) represent a serious financial and medical burden for patients and families. As a result, surgeons may consider more conservative management with incision and drainage compared to rod removal and exchange. We hypothesize that retaining rods following deep wound infection is not associated with greater rates of recurrent wound infection compared to rod removal or exchange. Aims: To determine incidence of deep wound infection across various etiologies of early onset scoliosis (EOS) To compare rates of recurrent deep wound infection in patients who underwent implant removal and exchange following index deep wound infection versus those who retained implants Methods: Using a multicenter registry, we identified patients with EOS who underwent surgical correction with MCGR. We defined deep SSI as any infection that required subsequent $I \& D$ and antibiotic therapy. Recurrent infection was defined as any additional deep SSI following treatment of index deep infection. We considered MCGR to be salvaged if implant exchange or removal was not performed for at least 1 year following date of infection. Bivariate statistical analyses were performed to identify differences in rates of recurrent infection as well patient characteristics between those who underwent rod removal/ exchange and those who had implants salvaged. Results" 992 EOS patients were identified, of whom 33 (3.3\%) developed deep SSI. The mean time between initial surgery and first deep SSI was 13.1 months (Interquartile range [IQR]: 1-25 months. Infection rates by EOS diagnosis were as follows: $13 / 354$ patients $(3.6 \%)$ had neuromuscular scoliosis (NMS), 9/225 (4.0\%) syndromic, 6/248 (2.4\%) idiopathic, 3/ 135 congenital $(2.2 \%)$, and $2 / 30(6.6 \%)$ unknown etiology. MCGR was salvaged in $69 \%$ of NMS patients, $77 \%$ of syndromic patients, $100 \%$ of congenital patients, and $83 \%$ of idiopathic patients $(83 \%)$. There were only four recurrent infections (2/13 NMS, 2/9 syndromic) and no differences in rates of recurrent infection between salvaged or replaced/exchanged MCGR. $(\mathrm{p}=0.97)$ Conclusion: Deep wound infection occurred in $3 \%$ of MCGR patients at a mean of 13.1 months. There were no significant differences in rates of recurrent infection between salvaged implants and those removed or exchanged. Surgeons may consider more conservative interventions, such as I\&D or revision, prior to considering total implant removal/ exchange.

Disclosures: P. Sponseller, DePuy Synthes Spine (Grant/Research Support, Consulting Fees (e.g., advisory boards), Royalties) Globus (Royalties) Orthopediatrics (Consulting Fees (e.g., advisory boards)); P. Study Group, DePuy Synthes Spine (Grant/Research Support) Globus Medical, Inc. (Grant/Research Support) Medtronic (Grant/Research Support) NuVasive (Grant/Research Support) OrthoPediatrics (Grant/Research Support) Pediatric Spine Foundation (Grant/Research Support) Stryker (Grant/Research Support) Zimmer Biomet (Grant/Research Support).

\section{Paper 15}

Proximal level selection in magnetically controlled growing rods: T2 or T3 may be protective against implant related complications and UPROR

Robert Ames, William Kerr, Bahar Shahidi, Bailee Monjazeb, William Kerr, Pooria Hosseini, Joshua Pahys, Steven Hwang, Amer Samdani,
Matthew Oetgen, Lindsay Andras, Peter Newton, Burt Yaszay, Bahar Shahidi, Behrooz Akbarnia

Abstract: Introduction: In comparison to traditional growing rods (TGRs), magnetically controlled growing rods (MCGRs) intend to reduce planned surgeries for lengthenings in the early onset scoliosis (EOS) population. Despite this, implant related complications and unplanned return to OR (UPROR) remains high. Clinical equipoise still exists surrounding the selection of upper instrumented vertebra (UIV) and its impact on UPROR. Aims/Objectives: The purpose of our study was to determine what impact the proximal UIV has on implant related complications (IRC) leading to UPROR. Methods: This was a retrospective cohort study. Patients were identified from an international multicenter EOS database. Inclusion criteria were patients with a diagnosis of EOS treated with dual MCGR, age 9 years and younger, availability of complete radiographs, and minimum of two year follow up. 506 patients were initially identified. Immediate postop and final follow-up X-rays were individually analyzed by two senior EOS specialists and two orthopaedic spine fellows. A digital spine template was created to document the UIV, number, type and exact anatomic location of proximal and distal anchors, rod orientation and implant configuration. To date, 185 patients have been reviewed. Results: 48/185 (26.1\%) patients experienced implant related complications. 32/185 (17.4\%) patients experienced implant related UPROR; the most common complications leading to UPROR were implant migration (7.6\%), anchor prominence $(2.2 \%)$, implant breakage $(1.6 \%)$, absolute failure of the implant to lengthen $(1.6 \%)$ and actuator malfunction $(0.5 \%)$. There was a larger proportion of males with UPROR compared to females (35.4 vs $19.4 \%, \mathrm{p}=0.015)$. No statistically significant differences were noted with respect to etiology of the scoliosis. A smaller change in spine height on initial postoperative imaging was associated with an increased risk for UPROR $(\mathrm{p}=0.049)$. A larger postoperative immediate curve $\left(41.2^{\circ}\right.$ vs. $\left.36.2^{\circ}\right)$ was also associated with IRC, although not with UPROR. There were no statistical differences noted with respect to the proximal attachment site (rib only, spine only, vs hybrid, $p=0.497$ ), or orientation of the rod (standard vs offset, $\mathrm{p}=0.742)$. With respect to the UIV, there were $164(88.6 \%)$ patients with a UIV of T2 or T3, and $21(11.4 \%)$ patients with other levels selected for the UIV. Patients with a T2 or T3 had a significantly lower UPROR rate of $23.8 \%$ compared to $47.6 \%$ for other levels $(p=0.02)$. Logistic regression analysis revealed patients with a UIV level of $\mathrm{T} 2$ or $\mathrm{T} 3$ are $66 \%$ less likely to return to OR compared to other levels $(p=0.024)$. Conclusions: Proximal UIV of T2 or T3 is protective against implant related UPROR in EOS patients treated with dual MCGR. A larger postoperative coronal curve angle and a smaller change in spine height postoperatively were associated with IRC, and implant related UPROR respectively. There were no statistically significant differences noted with respect to rod orientation, or when comparing rib-based vs. spine-based constructs.

Disclosures: J. Pahys, DePuy Synthes (Consulting Fees (e.g., advisory boards)) NuVasive (Consulting Fees (e.g., advisory boards)) Zimmer Biomet (Consulting Fees (e.g., advisory boards)); S. Hwang, Zimmer Biomet (Speaker's Bureau); A. Samdani, DePuy Synthes Spine (Consulting Fees (e.g., advisory boards)) Ethicon (Consulting Fees (e.g., advisory boards)) Globus Medical (Consulting Fees (e.g., advisory boards)) Medical Device Business Services (Consulting Fees (e.g., advisory boards)) Mirus (Consulting Fees (e.g., advisory boards)) NuVasive (Consulting Fees (e.g., advisory boards), Royalties) Orthofix (Consulting Fees (e.g., advisory boards)) Stryker (Consulting Fees (e.g., advisory boards)) Zimmer Biomet (Consulting Fees (e.g., advisory boards), Royalties); L. Andras, Eli Lilly (Ownership Interest) NuVasive (Consulting Fees (e.g., advisory boards), Speaker's Bureau) Orthobullets (Royalties) Zimmer Biomet (Consulting Fees (e.g., advisory boards), Speaker's Bureau); P. Newton, DePuy Synthes Spine (Grant/Research Support, Royalties) 
Globus (Consulting Fees (e.g., advisory boards)) Medronic (Consulting Fees (e.g., advisory boards)) Pacira (Consulting Fees (e.g., advisory boards)) Stryker K2M Spine (Grant/Research Support, Consulting Fees (e.g., advisory boards), Royalties) Zimmer Biomet (Grant/Research Support); B. Yaszay, Biogen (Consulting Fees (e.g., advisory boards)) Depuy Synthes Spine (Grant/Research Support, Consulting Fees (e.g., advisory boards)) Globus (Consulting Fees (e.g., advisory boards)) Harms Study Group/Depuy Johnson and Johnson (Grant/Research Support) K2M/Stryker (Grant/Research Support, Consulting Fees (e.g., advisory boards), Royalties) Medtronic (Consulting Fees (e.g., advisory boards)) Nuvasive (Grant/ Research Support, Consulting Fees (e.g., advisory boards)) Orthopediatrics (Grant/Research Support, Consulting Fees (e.g., advisory boards)); B. Akbarnia, DePuy Spine (Royalties) NociMed (Ownership Interest, Stock/Stock Options) NuVasive (Royalties) Stryker Spine (Royalties).

\section{Paper 16}

Do clinic performed MCGR lengthenings happen as frequently as intended? A site-specific analysis of magnetically controlled growing rod treatment intervals

Matthew LaBarge, Ishaan Swarup, Matthew Oetgen, Paul Sponseller, John Smith, Tenner Guillaume, Craig Louer, Pediatric Spine Study Group

Abstract: Background: Magnetically controlled growing rods (MCGR) have been implemented as a growth-friendly treatment for EOS in an effort to reduce anesthetic and operative risks associated with traditional growing rods. MCGR treatment relies on subsequent lengthening to increase spine length over time. There is currently no broadly accepted standard timing for MCGR follow-up. There is a concern that a lack of consistent follow-up and long durations with failure to follow-up (FFU) among patients with MCGR may be underappreciated. Purpose: The purpose of this study was to assess followup intervals for MCGR lengthenings as well as rates of "failure to follow-up" (FFU; defined as an interval > 180 days) across multiple sites. We hypothesize that there will be variability amongst the sites for both follow-up intervals as well as FFU rates. Methods: A retrospective review of a multi-center EOS registry was conducted on patients treated with MCGR from 1997 to 2021. Patients of all ages and etiologies of EOS who were implanted with MCGR and had a minimum of 2-year follow-up were included in the study. Registrywide and center-specific MCGR treatment data was analyzed for median time to initial lengthening, median time between lengthenings, spread of lengthening intervals (measured by inter-quartile range; IQR), and FFU events. The site-specific FFU rate and lengthening interval spread was plotted for all centers with more than 20 patients. Outliers were defined by being more than $1 \times \mathrm{IQR}$ from the 25th and 75th quartiles. Lengthening intervals from 02/01/2019$02 / 01 / 2020$ to $02 / 02 / 2020-02 / 01 / 2021$ were compared to assess the impact of COVID-19 on patient follow-up. Normality testing was performed using a Shapiro-Wilk tests. Median values and ranges were determined for each variable. Continuous variables were analyzed using Mann-Whitney $U$ tests for non-parametric data and unpaired t-tests for parametric data. $\mathrm{p}$ values $<0.05$ were considered significant. All statistical analysis was performed using Prism Graphpad (version 9.1.2). Results: 1198 patients from 52 sites were included in the study. Shapiro-Wilk testing determined non-normal distribution for time to initial lengthening $(\mathrm{p}<0.0001)$ and subsequent MCGR lengthening intervals $(\mathrm{p}<0.0001)$, but normal distribution for percent FFU ( $p=0.2557)$. The median time to the initial MCGR lengthening for all sites was 114.30 days with a range of 47.01-459.5 days. The median interval for all subsequent MCGR lengthenings for all sites was 118.90 days with a range of 58.64296.50 days. Forty-one percent of patients across all sites experienced at least one FFU, with site-specific frequency ranging from $0-80 \%$. For FFU rate in large centers, two centers were considered low and high outliers, with FFU rates of 6.5 and $76.7 \%$, respectively. For lengthening interval spread, one high outlier was identified with an IQR of 90 days. A comparison of follow-up intervals immediately preceding and following start of COVID epidemic was not significantly different $(p=0.133)$. Discussion: There is significant variability in timing of MCGR lengthening intervals and patient follow-up rates across sites included in the study. Over $40 \%$ of patients experience an unintended "failure to follow-up" event during their MCGR treatment. It was thought that the COVID-19 pandemic would influence patient follow-up rates, but statistical analysis of intervals from 2019 to 2021 do not show a significant difference. The site-to-site inconsistency implicates site-specific factors that influence follow-up intervals, but further study is needed.

Disclosures: P. Sponseller, DePuy Synthes Spine (Grant/Research Support, Consulting Fees (e.g., advisory boards), Royalties) Globus (Royalties) Orthopediatrics (Consulting Fees (e.g., advisory boards)); J. Smith, Globus (Royalties) GS Medical (Royalties, Product Development); T. Guillaume, Nuvasive (Consulting Fees (e.g., advisory boards)) Zimmer Biomet (Consulting Fees (e.g., advisory boards)); P. Study Group, DePuy Synthes Spine (Grant/Research Support) Globus Medical, Inc. (Grant/Research Support) Medtronic (Grant/Research Support) NuVasive (Grant/Research Support) OrthoPediatrics (Grant/Research Support) Pediatric Spine Foundation (Grant/Research Support) Stryker (Grant/Research Support) Zimmer Biomet (Grant/Research Support).

Figure 1: Site-specific median MCGR lengthening intervals in days (left axis) and percent of patients with at least one failure to follow-up event (right axis). Data points are indicative of relative contribution to overall patient population. 
Figure 1: Site-specific median MCGR lengthening intervals in days (left axis) and percent of patients with at least one failure to follow-up event (right axis). Data points are indicative of relative contribution to overall patient population.

Site-specific median MCGR lengthening intervals and failure to follow-up rates

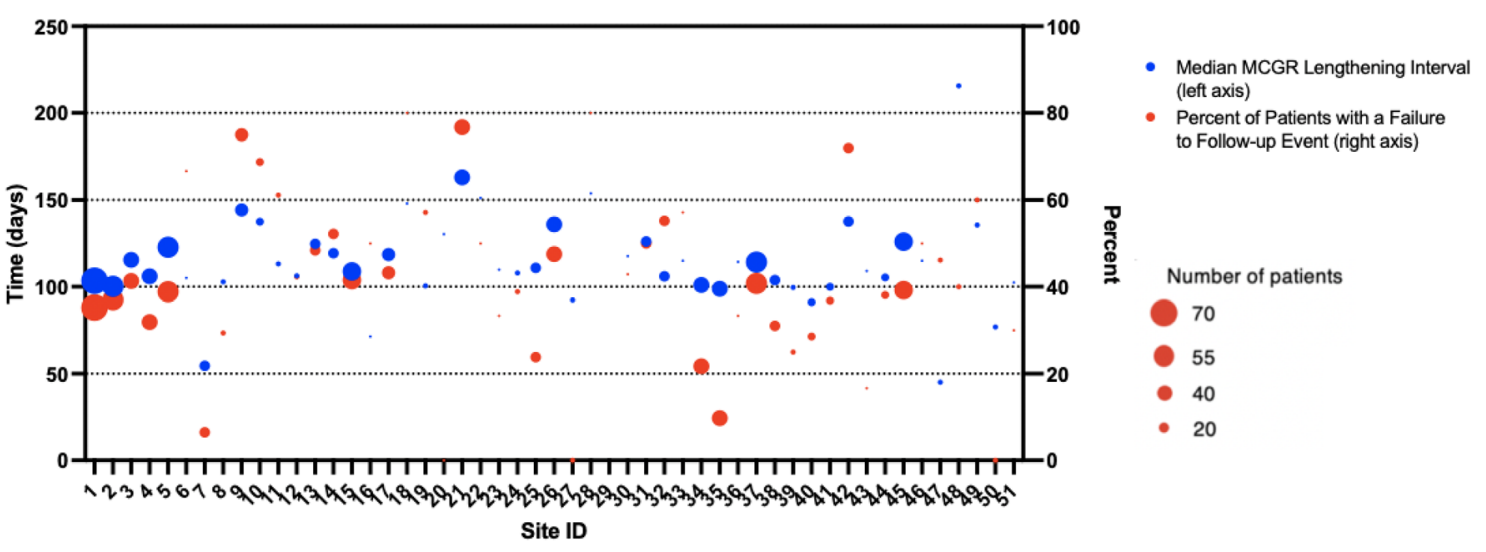

\section{Paper 17}

Lung parenchymal characterization in early onset scoliosis using dynamic magnetic resonance imaging: a parenchymal aeration phantom study

Yubing Tong, Jayaram Udupa, Joseph McDonough, Caiyun Wu, Carina Lott, Calvin Chan, Robert Carson, Jason Anari, Drew

Torigian, Patrick Cahill

Abstract: Introduction: Quantitative thoracic dynamic MRI (dMRI) has been utilized to depict volume dynamics of free breathing. This includes the lung, hemi-diaphragm, and chest wall, both left and right components separately. However, changes in lung tissue characteristics have not been studied in the past due to the lack of simple and readily available non-invasive techniques. Such studies would provide an understanding of lung physiology during normal growth and in early onset scoliosis (EOS) patients both pre- and post-treatment. Aims/Objectives: No practical technique exists for measuring lung parenchymal aeration in pediatric patients with EOS. We present a new technique using a dynamic magnetic resonance imaging (dMRI) protocol to study lung dynamics of patients with EOS. Methods: We built a parenchymal aeration phantom using sponge material. It consisted of 7 plastic film-sealed sponge blocks coated with a liquid vinyl sealant, which dried to form a moisture proof barrier. Each block has different air occupancy that simulates tissue aeration, described by a ratio of the volume of air to the volume of the block. We arranged 7 blocks in the order of air occupancy increasing from low to high (in the range $0.50-0.80$, with $5 \%$ difference between blocks) and scanned the phantom using dMRI with sagittal slice acquisitions. We investigated the association between intensity and air occupancy to study the sensitivity of MR imaging to detect a change in tissue aeration. Results: Mean image intensity within blocks was highly negatively correlated with known air occupancy with a Pearson correlation coefficient of $-0.96(p=0.0002)$. The intensities within blocks were observed visually to become darker with increasing air content. The smallest difference in air occupancy between blocks in our phantom was $5 \%$ which was detected via intensity difference $(\mathrm{p}<0.0001)$. Conclusion: This basic science study illustrates feasibility of using dMRI as a surrogate marker of lung aeration in EOS, including the natural history of the disease and intervention on pulmonary outcomes. We found that the dMRI can detect a difference in lung parenchymal aeration to within $5 \%$.

Disclosures: D. Torigian, Quantitative Radiology Solutions LLC (Grant/Research Support, Ownership Interest, co-founder). 


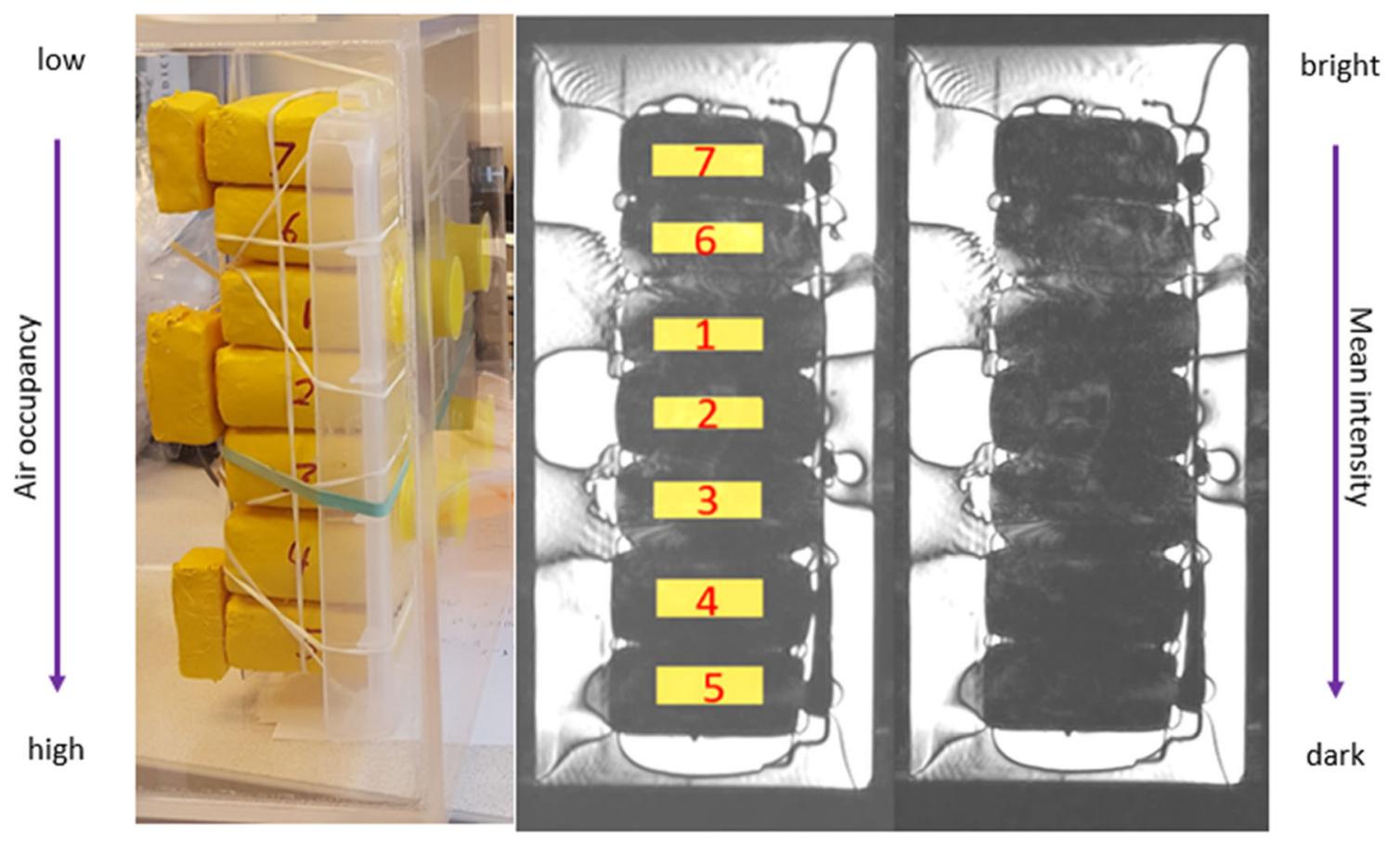

p values from pairwise T-Tests between mean intensities of phantom blocks. Air occupancy of each block as the ratio of air volume within the block to the volume of phantom block is depicted in the 1st row.

\begin{tabular}{|c|c|c|c|c|c|c|c|}
\hline $\begin{array}{l}\text { Air } \\
\text { occupancy }\end{array}$ & block7 & block6 & block1 & block2 & block3 & block4 & block5 \\
\hline block7 & $\mathrm{n} / \mathrm{a}$ & $<.00001$ & $<.00001$ & $<.00001$ & $<.00001$ & $<.00001$ & $<.00001$ \\
\hline block6 & & $\mathrm{n} / \mathrm{a}$ & $<.00001$ & $<.00001$ & $<.00001$ & $<.00001$ & $<.00001$ \\
\hline block1 & & & $\mathrm{n} / \mathrm{a}$ & $<.00001$ & $<.00001$ & $<.00001$ & $<.00001$ \\
\hline block2 & & & & $\mathrm{n} / \mathrm{a}$ & $<.00001$ & $<.00001$ & $<.00001$ \\
\hline block3 & & & & & $\mathrm{n} / \mathrm{a}$ & $<.00001$ & $<.00001$ \\
\hline block4 & & & & & & $\mathrm{n} / \mathrm{a}$ & $<.00001$ \\
\hline block5 & & & & & & & $\mathrm{n} / \mathrm{a}$ \\
\hline
\end{tabular}

\section{Paper 18}

The impact of vertebral body tethering on pulmonary function

Steven Hwang, Joshua Pahys, Brandon Toll, Alejandro Quinonez, Harsh Grewal, Amer Samdani

Abstract: Background: Anterior approaches for spinal fusion in deformity surgery have been associated with a decline in pulmonary function; however, the impact of vertebral body tethering (VBT) on pulmonary status remains unclear. Objective: We sought to examine pulmonary function testing (PFT) in patients having undergone VBT and revision VBT (rVBT). Methods: A retrospective single center experience of non-consecutive patients was reviewed for all patients having pre-op and post-op PFTs studies having undergone a VBT procedure or a revision VBT. Outcomes were compared using $\%$ predicted values as continuous and categorical variables (using $10 \%$ change as significant) as well as divided into categorical values based on ATS standards (FEV1\%: 99-70\% mild, 60-60\% moderate,50$59 \%$ moderate-severe, $35-49 \%$ severe, $<35 \%$ very severe). Results: 58 AIS patients were included with a mean age of $12.5 \pm 1.4$ years and follow-up of $4.2 \pm 1.1$ years. The mean thoracic curve was $47^{\circ} \pm 9^{\circ}$ with improvement to $21^{\circ} \pm 12^{\circ}$. At baseline, the mean FEV1\% was $79 \%$ and $\mathrm{FVC} \%$ was $82 \%$. 4 patients had normal FEV1\% ( $\geq 100 \%)$, and $67 \%$ had mild restrictive disease $(70-99 \%)$ with the rest having worse FEV1\%. Mean FEV1 improved from 2.2 to $>2.6 \mathrm{~L}(\mathrm{p}<0.05)$ and FVC improved from 2.5 to $>3.0 \mathrm{~L}$ $(\mathrm{p}<0.05)$; however, $\%$ predicted values remained unchanged (FEV1\% 79- > 80\%; FVC\% 82- > 80\%, p >0.05) with mean postop PFTs at $37 \pm 12$ months post-op. Using the ATS classification, 6 patients worsened 1 category whereas 8 patients improved $1-4$ categories. 11 patients worsened $>10 \%$ predicted FEV1 and 7 improved $>10 \%$. Use of mini-open thoracotomy was not associated 
with worsening PFTs, but extension of LIV below T12 correlated with decreasing FEV1\% in bivariate analysis $(\mathrm{p}<0.05)$. Double VBT was not independently associated with worsening PFTs but was limited to only 6 patients in this series. Patients with worse pre-op FVC $\%(80 \pm 13 \%$ vs. $90 \pm 11 \%, \mathrm{p}=0.03)$ and FEV1\% $(77 \pm 17 \%$ vs. $87 \pm 12 \%, \mathrm{p}=0.06)$ also had a greater likelihood of declining post-op FEV1\%. 16 (28\%) patients had a revision surgery (rVBT). 6 patients had post rVBT PFTs a mean $21 \pm 8$ months after surgery. FEV1 improved from pre-op to post revision (1.8 $\pm 0.2-$ $>2.7 \pm 0.7 \mathrm{~L}, \mathrm{p}=0.03)$ as did FVC $(2.0 \pm 0.18->2.9 \pm 0.8 \mathrm{~L}$, $\mathrm{p}=0.04)$, whereas \% FEV1 and \%FVC predicted remained unchanged $(84 \pm 14->81 \pm 12, p=0.68 ; 83 \pm 12->77 \pm 9$, $\mathrm{p}=0.37$ ). Two of these patients did not have pre-op rVBT PFTs but demonstrated stable PFTs after the revision compared to prior to the primary surgery. One patient had worsening of FEV1\% after their initial surgery and one worsened after the rVBT. Overall 5 of the 6 patients remained stable after their rVBT. Reasons for revision included 4 releases for overcorrection and 2 revision and extension for adding-on. When comparing post-op PFTs of rVBT to primary VBT patients, there were no significant differences (FEV1:2.7 \pm 0.7 vs $2.6 \pm 0.5 \mathrm{~L}, \mathrm{p}=0.87$; \% FEV1: $81 \pm 12$ vs $80 \pm 13$, p = 0.84; FVC: $2.9 \pm 0.8$ vs $3.0 \pm 0.6, p=0.79 ; \%$ FVC: $77 \pm 9$ vs $80 \pm 12$, $\mathrm{p}=0.48$ ) Conclusion: The pulmonary function in the majority of patients undergoing VBT remain stable $(76 \%)$ or may improve $(14 \%)$; however, a subset may worsen (10\%). Further studies are needed to identify risk factors for this group, but worse pre-op PFTs and extension below T12 may be risk factors for worsening pulmonary function. Although only a small number of patients, revision VBT does not appear to adversely impact pulmonary function, and patients' PFTs are comparable to post primary VBT surgery.

Disclosures: S. Hwang, Zimmer Biomet (Speaker's Bureau); J. Pahys, DePuy Synthes (Consulting Fees (e.g., advisory boards)) NuVasive (Consulting Fees (e.g., advisory boards)) Zimmer Biomet (Consulting Fees (e.g., advisory boards)); H.Grewal, Auctus Surgical (Ownership Interest) Zimmer Biomet (Consulting Fees (e.g., advisory boards)); A. Samdani, DePuy Synthes Spine (Consulting Fees (e.g., advisory boards)) Ethicon (Consulting Fees (e.g., advisory boards)) Globus Medical (Consulting Fees (e.g., advisory boards)) Medical Device Business Services (Consulting Fees (e.g., advisory boards)) Mirus (Consulting Fees (e.g., advisory boards)) NuVasive (Consulting Fees (e.g., advisory boards), Royalties) Orthofix (Consulting Fees (e.g., advisory boards)) Stryker (Consulting Fees (e.g., advisory boards)) Zimmer Biomet (Consulting Fees (e.g., advisory boards), Royalties).

Radiographic and PFT values after VBT

\section{Paper 19}

Risk of ventricular peritoneal shunt malfunction in early onset scoliosis

Mitchell Johnson, Carina Lott, Benjamin Kennedy, Gregory Heuer, Patrick Cahill, Jason Anari

Abstract: Introduction: Ventricular peritoneal (VP) shunt placement is a common neurosurgical procedure performed in scoliosis patients. These shunts allow diversion of fluid from the ventricles of the brain to the peritoneum for reabsorption. Several case reports and small retrospective reviews have pointed towards the possibility of VP shunt fracture or malfunction following operative correction of scoliosis. However, no information is available for patients treated with growth friendly strategies of scoliosis correction. Aims/Objectives: We aim to determine complication rates with VP shunts around spine lengthening operations in early onset scoliosis (EOS) patients. Methods: Retrospective chart review of all EOS patients with VP shunts who underwent growing instrumentation at a single institution over a 13-year time frame was performed. A minimum of 2 year follow up was required for inclusion. Demographic and clinical data collection was performed with operative shunt complications recorded. Results: 19 patients with a VP shunt underwent implantation of rib-based construct for treatment of scoliosis (Fig. 1). The mean age at shunt placement and spine instrumentation surgery was 13.7 months ( 1 day to 13 years old) and 6.1 years $(0.5-15.1)$ respectively. The diagnoses leading to shunt implantation were: 12 spina bifida, 3 structural defects or obstructions, 2 intraventricular hemorrhage, 1 cerebral palsy, and 1 campomelic dwarfism. During the first two years following rib-based insertion, there was a mean of 2.5 expansion/revision procedures $(0-5)$ with no shunt related complications. The mean length of follow up in this series was 7.0 years (2.6-13.2). A total of $3(15.8 \%)$ patients underwent shunt revision following their rib-based insertion, 2 patients with proximal malfunctions and one with a mid-catheter breakage, at 2.4, 2.6, and 5.6 years postoperatively (Fig. 2). Each of these shunt revisions occurred more than 50 days following a rib-based expansion procedure $(1.9,2.9$, and 5.7 months). Conclusion: Growing instrumentation procedures in EOS are associated with low risk for post-operative shunt complications in patients with ventricular peritoneal shunts. There were no shunt revision procedures performed in the first two years following rib-based insertion. $16 \%$ of all patients went on to need a shunt revision at some point during their follow up, which is comparable to the baseline rate of shunt revision as seen in the literature $(27 \%)$.

\begin{tabular}{|l|l|l|l|l|l|l|l|l|}
\hline & $\begin{array}{c}\text { Thoracic } \\
\text { curve } \\
\left({ }^{\circ}\right)\end{array}$ & $\begin{array}{c}\text { Lumbar } \\
\text { Curve } \\
\left({ }^{\circ}\right)\end{array}$ & $\begin{array}{c}\text { Thoracic } \\
\text { kyphosis }\left({ }^{\circ}\right)\end{array}$ & $\begin{array}{l}\text { Lumbar } \\
\text { lordosis }\left({ }^{\circ}\right)\end{array}$ & $\begin{array}{l}\text { FEV1 } \\
(\mathrm{L})\end{array}$ & $\begin{array}{l}\text { FVC } \\
(\mathrm{L})\end{array}$ & $\begin{array}{l}\text { FEV1 \% } \\
\text { predicted }\end{array}$ & $\begin{array}{c}\text { FVC \% } \\
\text { predicted }\end{array}$ \\
\hline $\begin{array}{l}\text { Pre- } \\
\text { op }\end{array}$ & $47 \pm 9$ & $30 \pm 10$ & $21 \pm 11$ & $49 \pm 14$ & $\begin{array}{l}2.2 \pm \\
0.4\end{array}$ & $\begin{array}{l}2.5 \pm \\
0.5\end{array}$ & $79 \pm 16$ & $82 \pm 13$ \\
\hline $\begin{array}{l}\text { Post- } \\
\text { op }\end{array}$ & $21 \pm 12$ & $18 \pm 11$ & $23 \pm 13$ & $47 \pm 15$ & $\begin{array}{l}2.6 \pm \\
0.5\end{array}$ & $\begin{array}{l}3.0 \pm \\
0.6\end{array}$ & $80 \pm 13$ & $80 \pm 12$ \\
\hline P-value & $<0.05$ & $<0.05$ & 0.28 & 0.78 & $<0.05$ & $<0.05$ & 0.70 & 0.33 \\
\hline
\end{tabular}



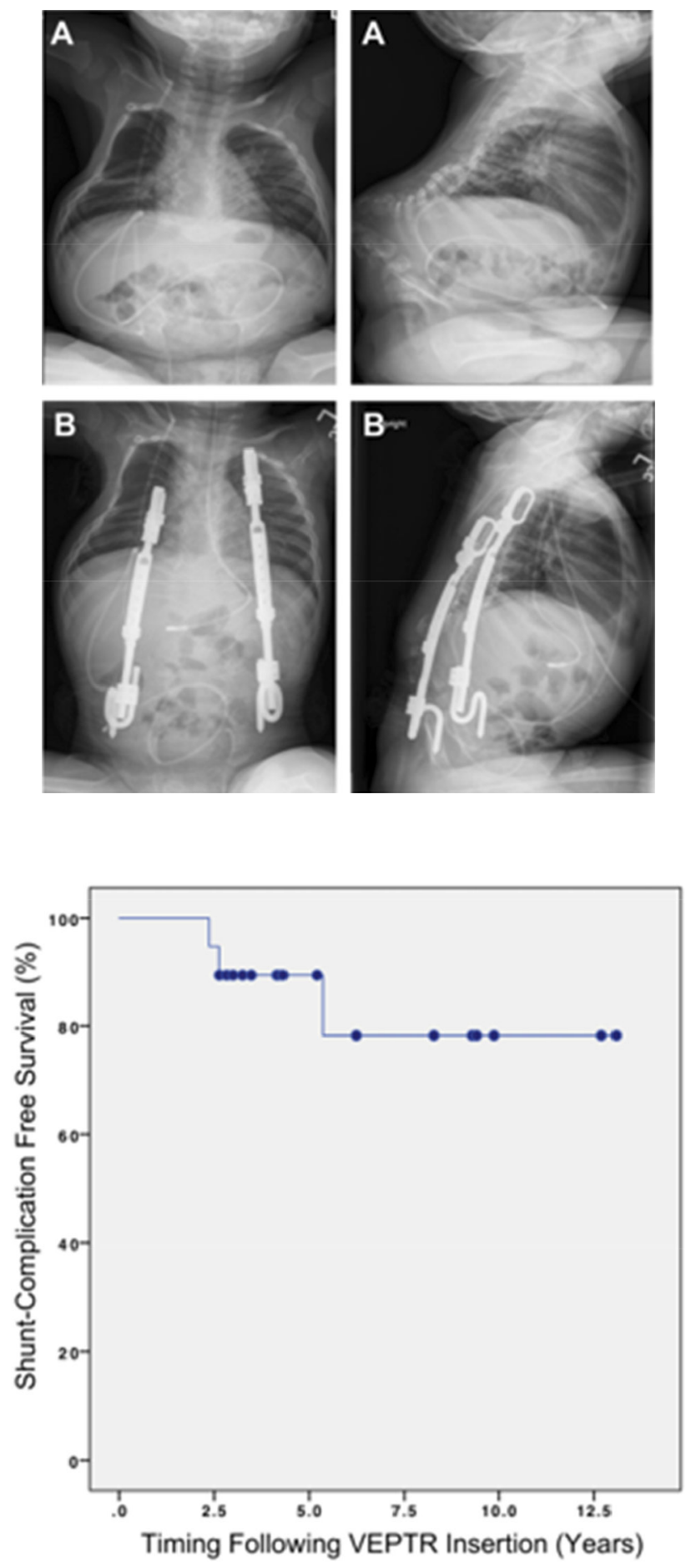

\section{Paper 20}

Baclofen pump use: complications after growth-friendly instrumentation for early-onset scoliosis

Amy Xu, Majd Marrache, Christina Hardesty, Mari Groves, Mark Erickson, Robert Murphy, George Thompson, Paul Sponseller, Pediatric Spine Study Group

Abstract: Introduction: Patients with early-onset scoliosis (EOS) and spasticity may receive treatment with an intrathecal baclofen pump.
Aims/Objectives: (1) To assess how baclofen pumps are associated with the odds of complications and secondary interventions after growth-friendly (GF) spine surgery for EOS and (2) to analyze infectious complications within the pump cohort Methods: Using a prospectively maintained, international multicenter database, we studied patients with neuromuscular EOS with baclofen pumps who underwent growth-friendly spine surgery from 2002 through 2019 $(\mathrm{n}=25)$. Baclofen pumps were implanted before GF instrumentation in 18 patients, during in 2 patients, and after in 5 patients. Patients with existing pumps at initial GF spine surgery were matched 1:3 with 54 patients (control group) without pumps according to treatment center, year of surgery, diagnosis, surgery type, and preoperative curve magnitude. Univariate analysis and multivariate logistic regression were performed to compare complications and secondary interventions between the 2 cohorts. Results: Patients with baclofen pumps had 4.8 times the odds (95\% confidence interval [CI]: $1.5-16$ ) of experiencing any complication within 1 year after initial GF spine surgery compared with controls. During mean follow-up of $6.9 \pm 4.3$ years, they had 4.7 times the odds (95\% CI $1.3-16)$ of deep surgical site infection (DSSI) and 5.6 times the odds (95\% CI 1.2-26) of spinal rod removal after any complication. Differences in rates of mechanical complication, such as rod migration and breakage, were nonsignificant between the 2 groups. For the 9 patients (50\%) with pumps who experienced infections, the most common microorganisms were Staphylococcus aureus (4 patients) and Pseudomonas aeruginosa (2). The pump/catheter was revised or removed, in addition to antibiotic therapy or surgical irrigation and debridement, in 2 patients. Conclusions: Among patients with neuromuscular EOS, those with baclofen pumps are much more likely to experience complications within 1 year after growth-friendly spine surgery. They are also more likely to have DSSIs, with S. aureus and P. aeruginosa being the most common causative organisms, and to require spinal rod removal.

Disclosures: C. Hardesty, Medtronic (Consulting Fees (e.g., advisory boards)) Orthopediatrics (Consulting Fees (e.g., advisory boards), Royalties); M. Erickson, Medtronic (Consulting Fees (e.g., advisory boards)) Nuvasive (Consulting Fees (e.g., advisory boards)); G. Thompson, Orthopediatrics (Consulting Fees (e.g., advisory boards), Ownership Interest, Royalties); P. Sponseller, DePuy Synthes Spine (Grant/Research Support, Consulting Fees (e.g., advisory boards), Royalties) Globus (Royalties) Orthopediatrics (Consulting Fees (e.g., advisory boards)).

\section{Paper 21}

Leave it alone: the natural history of growth friendly graduates without a final fusion

Christina Hardesty, Bryan Ren, Robert Murphy, Jeffrey Sawyer, Jack Flynn, John Emans, John Smith, Paul Sponseller, Norman Ramirez

Abstract: Hypothesis: Graduates of growth friendly surgery who do not undergo a final fusion procedure (observation) have an uneventful natural history following their definitive procedure. Those who have retained their implants maintain their curve magnitudes compared to those who have their implants removed. The rate of unplanned return to the operative room (UPROR) is similar in these groups. Study design: A retrospective analysis of prospectively collected data from an international database of patients with early onset scoliosis. Introduction: The natural history of growth friendly graduates treated with growing instrumentation but no final fusion is unknown. Two small reports, including 30 patients who had traditional growing rods (TGR) and 12 patients treated with vertical expandable prosthetic titanium rib (VEPTR), exist, but there is no comprehensive data set in the literature. Methods: The Pediatric Spine Study Group database 
was queried for patients treated with TGR or VEPTR who had at least two years of follow up. Patients met inclusion criteria if they had not undergone a final fusion procedure but had completed planned interventions for their early onset scoliosis. Demographic data included age, gender, race, etiology, diagnosis, comorbidities, height, weight, ambulatory status, and prior treatment. Radiographic data included major/minor cobb angles and levels, spinal height, sagittal kyphosis, and proximal junctional degree. Results: There were 1215 patients who underwent growth-friendly surgery TGR or VEPTR with no documented final fusion, and 234 of those had minimum 2 years follow up. Diagnoses were heterogeneous (99 congenital, 71 neuromuscular, 43 syndromic, 20 idiopathic, and 1 other/not-specified). Definitive treatment strategy was implant maintenance in $204(87 \%)$ and removal in $30(13 \%)$. Of those who did not keep their implants, $18 / 30(60 \%)$ had an UPROR sometime prior to implant removal and $1 / 30(3 \%)$ had an UPROR which was implant removal. Of the patients who retained their implants, the UPROR rate prior to definitive pro- after their definitive procedure. The curve magnitude has been well maintained in this cohort whether implants were removed or kept.

Disclosures: C. Hardesty, Medtronic (Consulting Fees (e.g., advisory boards)) Orthopediatrics (Consulting Fees (e.g., advisory boards), Royalties); J. Sawyer, Depuy Synthes (Grant/Research Support) Orthopaediatrcis (Consulting Fees (e.g., advisory boards)); J. Flynn, Biomet (Royalties, IP Royalties) Wolters Kluwer Health-Lippincott Williams \& Wilkins (Royalties, Publishing royalties, financial or material support); J. Emans, Synthes/Johnson\&Johnson (Royalties) Zimmer/Biomet (Consulting Fees (e.g., advisory boards)); J. Smith, Globus (Royalties) GS Medical (Royalties, Product Development); P. Sponseller, DePuy Synthes Spine (Grant/Research Support, Consulting Fees (e.g., advisory boards), Royalties) Globus (Royalties) Orthopediatrics (Consulting Fees (e.g., advisory boards)).

Figure 1. Proportion of patients successfully avoiding an UPROR after definitive procedure in those who retained versus removed implants.

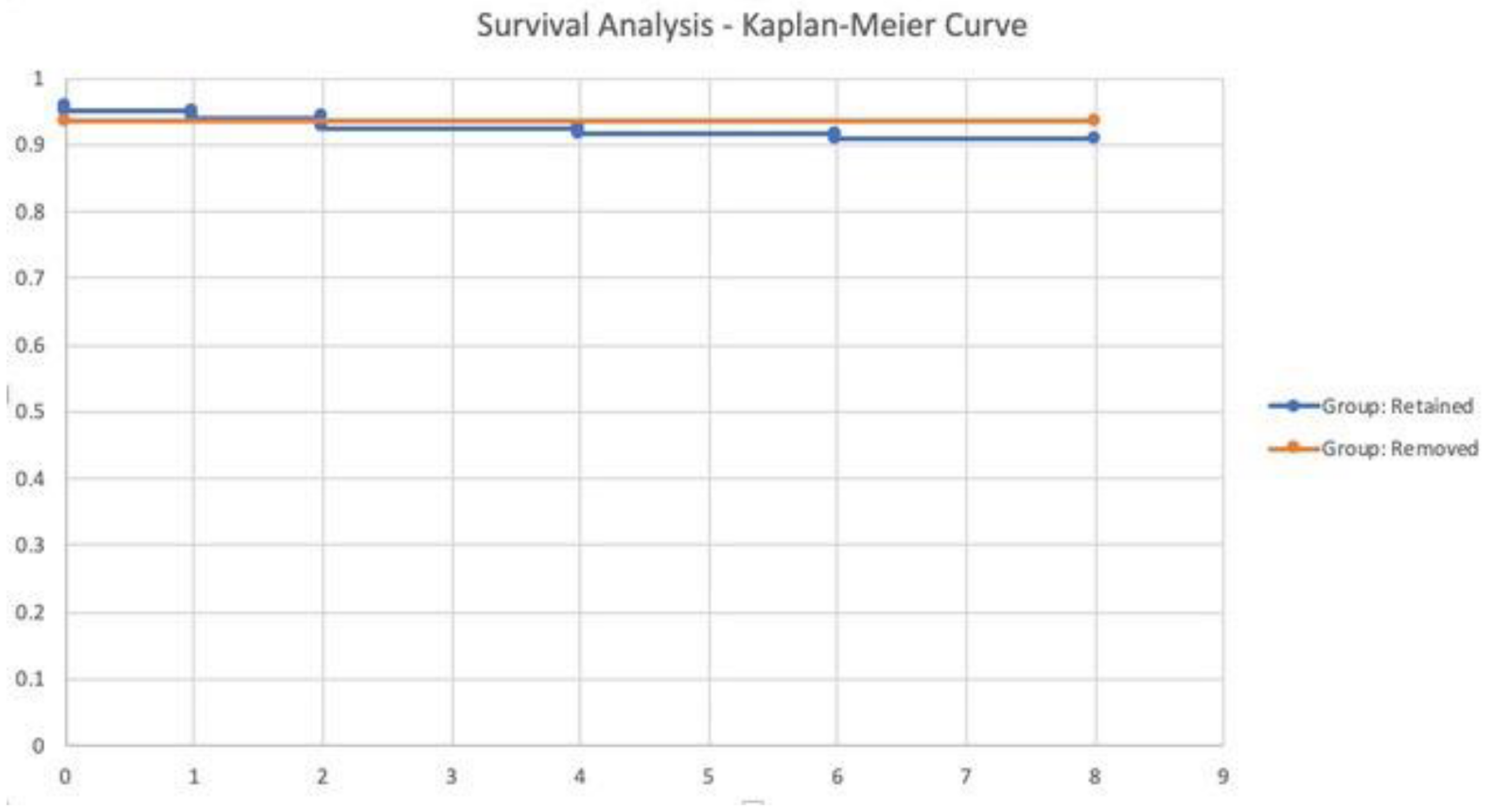

The $x$-axis represents number of years following the patient's definitive procedure. The $y$ axis represents patients who have successfully avoided an UPROR after their definitive procedure.

cedure was 30\% (62/204). In that group, 9/204 (4\%) had an UPROR following their definitive procedure. The proportion of patients who successfully avoided an UPROR after definitive procedure was similar between those who retained compared to removed implants (Fig. 1). Patients whose implants were removed lost a mean 7 degrees of curvature compared to $3^{\circ}$ in those who implants were retained. The means of all other measurements, including minor Cobb angle, spinal height, and kyphosis were similar between the two groups. Conclusions: Growth friendly graduates who are observed but do not undergo a final fusion have a high UPROR rate overall, but only $4 \%$

\section{Paper 22}

Why are graduates failing late? A detailed investigation of patients with more than 2 years follow up

Anjali Prior, Robert Murphy, John Emans, George Thompson, Paul Sponseller, John Smith, David Skaggs, Pediatric Spine Study Group

Abstract: Introduction: Following growth friendly treatment for early onset scoliosis, patients will either have their implants retained, undergo a spinal fusion, or have their implants removed. This is 
known as "graduation" from the growing spine program. Within the first two years after graduation, rates of revision surgery are as high as $20 \%$. The purpose of this study was to determine the rate of revision surgery and reasons for revision two or more years after the definitive treatment strategy. Methods: Query of a multicenter pediatric spine registry was completed for all patients who underwent growing spine surgery and had a minimum of 2 years follow up documented, either by clinical or radiographic evidence. Curve etiology, graduation strategy, and incidence and number of revision surgeries were queried. Reasons for revision were ascertained. Results: There were 933 patients with a minimum of 2 years follow up after graduation. A total of 141 underwent ANY revision surgery, and 98 of these occurred between 0 and 2 years after graduation. Further analysis revealed 43 patients ( 13 males) who underwent first revision greater than 2 years from their "definitive" procedure. There were 16 congenital, 12 neuromuscular, 9 syndromic, and 6 idiopathics. Of these patients, 41 had TGR/VEPTR as their growth friendly construct and 2 had MCGR. Thirty-six patients underwent spinal fusion as their definitive procedure, 6 had implants retained, and 1 had implants removed. Patients underwent an average of 1.2 procedures after graduation (range 1-2). The average time from graduation to revision in this cohort was 3.7 years (range 2.1-7.4). The most common reasons for revision included symptomatic pain in 14, prominent implants/hardware failure in 12 , curve progression in 8 , and infection in 5. Conclusion: The rate of revision in this cohort of $933 \mathrm{GF}$ spine graduates was $15 \%$, and the rate of late revision ( $>2$ years from graduation) was $5 \%$. The most common reason for revision was due to complaints of pain. The results of this study demonstrate the need for continued, long-term monitoring after definitive treatment, as complications may arise several years out from graduation.

Disclosures: J. Emans, Synthes/Johnson\&Johnson (Royalties) Zimmer/Biomet (Consulting Fees (e.g., advisory boards)); G. Thompson, Orthopediatrics (Consulting Fees (e.g., advisory boards), Ownership Interest, Royalties); P. Sponseller, DePuy Synthes Spine (Grant/Research Support, Consulting Fees (e.g., advisory boards), Royalties) Globus (Royalties) Orthopediatrics (Consulting Fees (e.g., advisory boards)); J. Smith, Globus (Royalties) GS Medical (Royalties, Product Development); D. Skaggs, Grand Rounds (Consulting Fees (e.g., advisory boards)) Green Sun Medical (Ownership Interest) Orthobullets (Consulting Fees (e.g., advisory boards), Ownership Interest) Wolters Kluwer Health (Royalties) ZimmerBiomet (Consulting Fees (e.g., advisory boards), Speaker's Bureau, Royalties); P. Study Group, DePuy Synthes Spine (Grant/ Research Support) Globus Medical, Inc. (Grant/Research Support) Medtronic (Grant/Research Support) NuVasive (Grant/Research Support) OrthoPediatrics (Grant/Research Support) Pediatric Spine Foundation (Grant/Research Support) Stryker (Grant/Research Support) Zimmer Biomet (Grant/Research Support).

\section{Paper 23}

Graduation protocol of traditional dual growing rods technique in the treatment of early onset scoliosis

\section{Terry Jianguo Zhang, Shengru Wang, Yang Yang}

Abstract: Introduction: Traditional dual growing rods (TDGR) were widely used in early onset scoliosis (EOS), while the graduation criteria and protocol remained controversial. Objectives: To evaluate the effect of different treatment options on clinical outcomes when patients graduated from TDGR. Methods: A total of 170 patients were treated with TDGR in our hospital from 2004 to 2020. Patients diagnosed as EOS and had more than 2 years follow-up after final fusion or last lengthening were included. Patients were further divided into Final Fusion Group (who received final fusion surgery) or
Observation Group (who had TDGR left in situ). Demographic data and radiographic measurement were compared between two groups. Results: Sixty-five patients were enrolled, and 45 patients were congenital EOS. Final Fusion Group (FFG) had 41 patients, and Observation Group (OG) had 24 patients. No patients performed growing rods removal without new instruments inserted. The mean age at index surgery ( $8.3 \mathrm{vs} 8.1 \mathrm{yrs})$ and graduation (13.4 vs $12.7 \mathrm{yrs})$ showed no difference between two groups $(\mathrm{P}>0.05)$. The length of TDGR treatment (5.0 vs $4.6 \mathrm{yrs})$ and the number of lengthenings (5.5 vs 4.8) also showed no difference $(\mathrm{P}>0.05)$. The pre-operative main curve magnitude in both groups were similar, while the correction rate in OG was significantly higher than that in FFG (55.4 vs. $44.4 \%$, $\mathrm{P}<0.05)$. The increase of T1-12 height and T1-S1 height between two groups showed no difference $(\mathrm{P}>0.05)$. Before final fusion surgery, 63 complications occurred in FFG, while 35 complications occurred in OG. And most complications were implant-related (35 vs 21). During final fusion surgery, auto-fusion of the spine were observed in all 41 patients. Osteotomy was performed in 20 patients. Ten complications occurred after final fusion surgery. Conclusions: For EOS patients around 13 years old, graduation from TDGR may be taken into consideration. Patients with better correction of main curve may avoid final fusion surgery. For patients received fusion surgery, further follow-up is still needed.

\section{Paper 24}

\section{Expect complications when managing dystrophic neurofibromatosis 1-related early onset scoliosis and a reprieve with conversion to fusion}

Steven Hwang, Paul Sponseller, Lindsay Andras, Kenneth Cheung, Jaime Gomez, Purnendu Gupta, Amer Samdani, Joshua Pahys

Abstract: Introduction: Traditionally dystrophic neurofibromatosis type 1 (NF-1) curves are more challenging and have been associated with a higher risk of complications. Hypothesis: In EOS, dystrophic type NF-1 curves treated with growing constructs will have more complications than non-dystrophic curves. Methods: A retrospective query of a multicenter growing-spine registry was performed identifying patients with NF-1 scoliosis undergoing a definitive spinal fusion (DSF) with at least 2 years of follow-up. Patients were classified by dystrophic (D) or non-dystrophic (ND) curves. Clinical, radiographic, and operative details and complications were reviewed for comparison. Student-t and Fisher exact tests were used for comparison. Results: 19 patients were identified with a mean age of $11 \pm 3$ years and mean follow-up of $3.3 \pm 1.8$ years [1.9-8.8 years]. 12 had some prior growing device implanted (6 VEPTR, 4 TGR, 1 MCGR, 1 Shilla). The mean major coronal curve prior to DSF was $58 \pm 15^{\circ}$ with kyphosis of $55^{\circ} \pm 33^{\circ}$ and T1-T12 height of $22 \pm 5 \mathrm{~cm}$. Final coronal curvature was $33^{\circ} \pm 15^{\circ}$. Overall, $79 \%$ of patients had at least 1 of 51 complications. The most common type of complication was instrumentation related (16 rod breakages, 11 anchor loss, 1 prominent instrumentation, and 1 clip break) followed by 11 wound dehiscence/infections. $100 \%$ of patients with dystrophic curves had a complication during their care as compared to $50 \%$ of ND patients $(p=0.02)$. The ND group had complications in $4 / 9$ patients during growing spine management prior to DSF and 2/9 after. The dystrophic group had complications in $7 / 10$ patients prior to DSF after $2 / 10$ after $(\mathrm{p}=0.37)$. Of the 7 patients that did not have growing instrumentation, 2 dystrophic patients had an aborted surgery due to hypotension or an intra-op CSF leak, but both had their DSF completed without other issues. Conclusion: NF1-related scoliosis is associated with a high risk of complications (79\%), particularly in dystrophic curves managed with growing constructs $(100 \%)$ prior to their final fusion. Following conversion to fusion, fewer 
complications were observed. Dystrophic NF-1 curves treated with growing constructs are associated with a high complication rate, and conversion to DSF appears to decrease this rate.

Disclosures: S. Hwang, Zimmer Biomet (Speaker's Bureau); P. Sponseller, DePuy Synthes Spine (Grant/Research Support, Consulting Fees (e.g., advisory boards), Royalties) Globus Medical (Royalties) JBJS-Am (Royalties) Orthopediatrics (Grant/Research Support, Other financial or material support); L. Andras, Eli Lilly (Ownership Interest) NuVasive (Consulting Fees (e.g., advisory boards), Speaker's Bureau) Orthobullets (Royalties) Zimmer Biomet (Consulting Fees (e.g., advisory boards), Speaker's Bureau); K. Cheung, Ellipse Technologies (Grant/Research Support, Consulting Fees (e.g., advisory boards)); J. Gomez, Biomet (Consulting Fees (e.g., advisory boards)) Stryker (Grant/Research Support, Speaker's Bureau); P. Gupta, DePuy Synthes Spine (Consulting Fees (e.g., advisory boards)); A. Samdani, DePuy Synthes Spine (Consulting Fees (e.g., advisory boards)) Ethicon (Consulting Fees (e.g., advisory boards)) Globus Medical (Consulting Fees (e.g., advisory boards)) Medical Device Business Services (Consulting Fees (e.g., advisory boards)) Mirus (Consulting Fees (e.g., advisory boards)) NuVasive (Consulting Fees (e.g., advisory boards), Royalties) Orthofix (Consulting Fees (e.g., advisory boards)) Stryker (Consulting Fees (e.g., advisory boards)) Zimmer Biomet (Consulting Fees (e.g., advisory boards), Royalties); J. Pahys, DePuy Synthes (Consulting Fees (e.g., advisory boards)) NuVasive (Consulting Fees (e.g., advisory boards)) Zimmer Biomet (Consulting Fees (e.g., advisory boards)).
Abstract: Introduction: Surgeon experience may play a role in minimizing complications associated with the treatment of EOS. Several studies have assessed the role of surgeon experience in outcomes of both AIS and neuromuscular scoliosis. However, there is a paucity of literature investigating surgeon experience and outcomes in EOS. Aims/Objectives: The purpose of this study was to utilize a multicenter, multi-surgeon database to assess the impact of surgeon experience on the outcomes associated with posterior distractionbased growth-friendly instrumentation. We hypothesized that unplanned return to the operating room (UPROR), estimated blood loss (EBL), and surgical time would be greater amongst early career surgeons (ECS) when compared to advanced career surgeons (ACS). Methods: An international pediatric spine database was queried for patients ages $2-10$ years treated by posterior distraction-based GFI with at least of 2-year follow up. Two groups were created for analysis based on surgeon experience: Early Career Surgeons (ECS, with $\leq 10$ years of experience) and Advanced Career Surgeons (ACS, with $>10$ years of experience). The primary outcome was unplanned return to the operating room (UPROR). Additional outcomes included: OR time, estimated blood loss (EBL), neurological deficits, infection rate, hardware failure, and the Early-Onset Scoliosis Questionnaire (EOSQ-24). Subgroup analysis was performed for further assessment based on procedure type, superior anchor type, etiology, and curve severity. Results: A total of 960 patients met inclusion criteria including $243(25.3 \%)$ treated by ECS. Etiology,

\section{\# complications per patient}

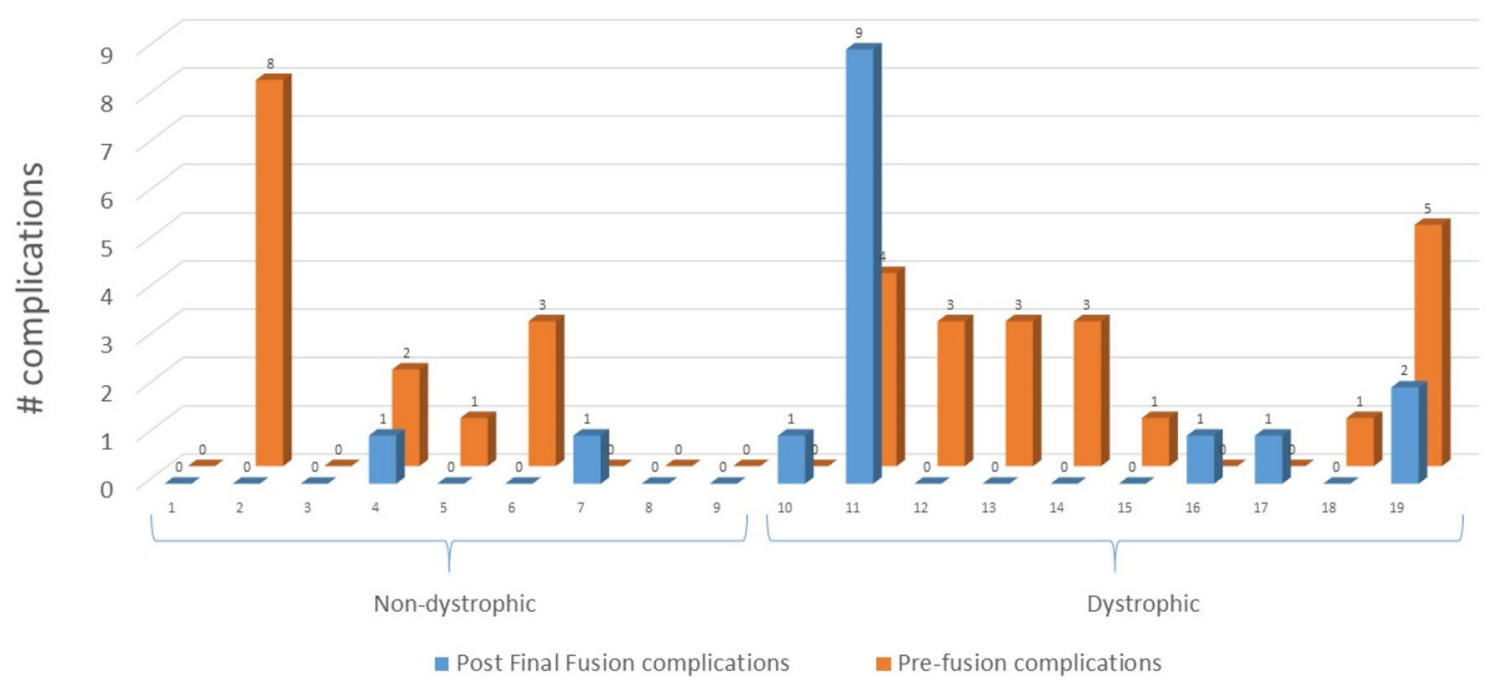

\section{Paper 25}

The effect of surgeon experience on outcomes following growth friendly instrumentation for early onset scoliosis

Michael Heffernan, Manaf Younis, Michael Glotzbecker, Sumeet Garg, Claudia Leonardi, Jaysson T. Brooks, Peter Sturm, Selina C. Poon, Paul Sponseller, Michael Vitale, John Emans, Benjamin Roye, Pediatric Spine Study Group sex, superior anchor, and EOSQ-24 scores were similar between groups $(\mathrm{p}>0.05)$. There were no clinically significant differences in patient age or pre-operative Cobb angle. UPROR (35.8 vs $32.7 \%$, $\mathrm{p}=0.532$ ), infection ( 17.0 vs $15.6 \%, \mathrm{p}=0.698)$, OR time (235 vs. $231 \mathrm{~min}, \mathrm{p}=0.755)$, and EBL ( 151 vs. $155 \mathrm{ml}, \mathrm{p}=0.833)$ were comparable between ECS and ACS groups. The frequency of having at least one complication was relatively high but comparable among groups $(60.7 \%$ vs. $62.6 \%, p=0.709)$. EOSQ-24 subdomain scores were similar between groups at 2-year follow-up ( $p>0.05)$. Subgroup analysis revealed that ECS had increased surgical time 
compared to ACS in severe curves $>90^{\circ}$ (270 vs. 229 min, $\mathrm{p}=0.05$ ). Conclusions: This study represents the first multi-center assessment of surgeon experience on outcomes in EOS. Overall, surgeon experience did not significantly influence UPROR, complication rates, EBL, or surgical time associated with growth friendly instrumentation in this cohort of EOS patients.

Disclosures: J. Brooks, Depuy Synthes (Consulting Fees (e.g., advisory boards)) OrthoPediatrics (Consulting Fees (e.g., advisory boards)); P. Sturm, Depuy Synthes Spine (Consulting Fees (e.g., advisory boards)) Nuvasive (Consulting Fees (e.g., advisory boards)); P. Sponseller, DePuy Synthes Spine (Grant/Research Support,
Consulting Fees (e.g., advisory boards), Royalties) Globus (Royalties) Orthopediatrics (Consulting Fees (e.g., advisory boards)); M. Vitale, Stryker (Consulting Fees (e.g., advisory boards)) Zimmer biomet (Consulting Fees (e.g., advisory boards), Royalties); J. Emans, Synthes/Johnson \& Johnson (Royalties) Zimmer/Biomet (Consulting Fees (e.g., advisory boards)).

The effect of surgeon experience on outcomes following growth friendly instrumentation for early onset scoliosis.

Table 1: Demographics and Clinical Characteristics for Overall GFI Cohort $(\mathrm{N}=960)$

\begin{tabular}{|c|c|c|c|}
\hline Characteristics & $\begin{array}{c}\text { ECS }^{1} \\
(\mathrm{n}=243) \\
\end{array}$ & $\begin{array}{c}\mathrm{ACS}^{1} \\
(\mathrm{n}=717)\end{array}$ & P-Value \\
\hline \multicolumn{4}{|c|}{--------- \% (n) ---------- } \\
\hline Sex & & & 0.060 \\
\hline Female & $60.9(148)$ & $54.0(387)$ & \\
\hline Male & $39.1(95)$ & $46.0(330)$ & \\
\hline Etiology & & & 0.710 \\
\hline Congenital & $24.7(60)$ & $24.0(172)$ & \\
\hline Idiopathic & $16.0(39)$ & $17.9(128)$ & \\
\hline Neuromuscular & $39.1(95)$ & $35.7(256)$ & \\
\hline Syndromic & $20.2(49)$ & $22.4(161)$ & \\
\hline Surgical instrumentation type & & & 0.003 \\
\hline MCGR & $30.5(74)$ & $21.2(152)$ & \\
\hline VEPTR/TGR & $70.5(169)$ & $78.8(565)$ & \\
\hline Superior anchor type & & & 0.062 \\
\hline Rib & $51.9(121)$ & $43.1(297)$ & \\
\hline Spine & $45.9(107)$ & $54.7(377)$ & \\
\hline Mix & $2.2(5)$ & $2.2(15)$ & \\
\hline Surgery timeframe & & & 0.002 \\
\hline $01 / 01 / 1990-12 / 31 / 1999$ & $1.2(3)$ & $3.8(27)$ & \\
\hline $01 / 01 / 2000-12 / 31 / 2004$ & $4.9(12)$ & $12.4(89)$ & \\
\hline $01 / 01 / 2005-12 / 31 / 2009$ & $30.0(73)$ & $28.4(204)$ & \\
\hline $01 / 01 / 2010-12 / 31 / 2014$ & $33.8(82)$ & $32.1(230)$ & \\
\hline \multirow[t]{2}{*}{$01 / 01 / 2015-12 / 31 / 2019$} & $30.1(73)$ & $23.3(167)$ & \\
\hline & \multicolumn{3}{|c|}{------- mean (SD) -------- } \\
\hline Age, years & $5.8(2.3)$ & $6.1(2.4)$ & 0.047 \\
\hline Pre index Major Cobb angle, ${ }^{\circ}$ & $77.1(23.6)$ & $73.4(21.9)$ & 0.043 \\
\hline \multicolumn{4}{|l|}{ EOSQ pre surgery } \\
\hline General health & $69.4(19.5)$ & $70.2(19.2)$ & 0.801 \\
\hline Pain discomfort & $70.6(25.2)$ & $73.5(20.8)$ & 0.401 \\
\hline Pulmonary function & $80.2(25.7)$ & $80.4(24.7)$ & 0.957 \\
\hline Transfer & $68.6(34.1)$ & $66.2(32.4)$ & 0.641 \\
\hline Physical Function & $59.8(36.1)$ & $52.4(36.8)$ & 0.187 \\
\hline Daily living & $45.1(37.8)$ & $41.4(35.4)$ & 0.530 \\
\hline Fatigue energy level & $67.9(27.2)$ & $65.3(28.0)$ & 0.559 \\
\hline Emotion & $68.9(27.7)$ & $71.0(23.6)$ & 0.598 \\
\hline Parental impact & $62.1(25.1)$ & $58.9(23.3)$ & 0.395 \\
\hline Financial impact & $67.0(33.9)$ & $64.3(31.9)$ & 0.603 \\
\hline Child satisfaction & $59.4(29.0)$ & $59.3(26.3)$ & 0.988 \\
\hline Parent satisfaction & $63.9(28.2)$ & $59.1(28.2)$ & 0.292 \\
\hline
\end{tabular}

EOSQ=early-onset scoliosis questionnaire; MCGR=magnetically controlled growing rods; $\mathrm{SD}=$ st. dev; $\mathrm{TGR}=$ traditional growing rods; VEPTR=vertical expandable prosthetic titanium rib.

${ }^{1}$ Patients were classified as having being operated on by either and Early-Career Surgeon (ECS, with $\leq 10$ years of experience) or Advanced-Career Surgeon (ACS, with $>10$ years of experience). 
Table 2: Outcomes for Overall GFI Cohort $(\mathrm{N}=786)$

\begin{tabular}{lccc}
\hline Item & ECS & ACS & P-Value \\
\hline & ------ estimate $(95 \% \text { CI })^{1}--------$ & \\
UPROR & $35.8(27.9-44.6)$ & $32.7(26.9-39.0)$ & 0.532 \\
Any infection, \% & $17.0(11.6-24.3)$ & $15.6(11.8-20.4)$ & 0.698 \\
Deep infection, \% & $9.8(5.9-15.7)$ & $11.7(8.4-16.2)$ & 0.528 \\
Superficial infection, \% & $9.6(6.0-15.1)$ & $6.7(4.7-9.5)$ & 0.224 \\
Implant related, \% & $43.5(34.4-53.1)$ & $46.0(38.7-53.6)$ & 0.661 \\
Neurological deficits, \% & $6.6(3.6-11.5)$ & $4.6(2.9-7.2)$ & 0.348 \\
Any complications, \% & $60.7(52.3-68.6)$ & $62.6(56.4-68.3)$ & 0.709 \\
OR procedure time, min & $235(213-257)$ & $231(212-250)$ & 0.755 \\
Estimated blood loss, ml & $151(120-183)$ & $155(130-181)$ & 0.833 \\
$\Delta$ Major Cobb angle ${ }^{2},{ }^{\circ}$ & $22.7(17.7-27.7)$ & $25.8(21.6-30.1)$ & 0.280 \\
\hline ACS = Advanced-Career Surgeon, with $>10$ years of experience; CI = confidence interval; \\
ECS = Early-Career Surgeon, with $\leq 10$ years of experience,OR = operating room; UPROR \\
$=$ unplanned return to the OR. \\
${ }^{1}$ Model included propensity scores as covariates. & & \\
${ }^{2} \Delta$ Major Cobb angle = preoperative Cobb angle - postoperative Cobb angle. &
\end{tabular}

\section{Paper 26}

Trends in the utilization of implants in index procedures for early onset scoliosis from the Pediatric Spine Study Group

Robert Murphy, Garrett Neel, William Barfield, Jason Anari, Tricia St. Hilaire, Maxwell Marshall, George Thompson, John Emans, Behrooz Akbarnia, John Smith, James Mooney

Abstract: Introduction: Due to the rarity and complexity of Early Onset Scoliosis (EOS) cases, patient registries were developed to combine clinical information from multiple institutions to maximize patient care and outcomes. This study examines the history and trends regarding the use of index growth friendly devices for EOS from the Pediatric Spine Study Group (PSSG). Methods. All index growthfriendly implants were queried from registry inception until October 2020. Scoliosis etiology, device/implant type, and geographic area/ institution at which the procedure took place were recorded. Results: From 1994 to 2020, 2786 patients underwent index growth friendly surgery at a mean age of $6.2 \pm 2.9$ years. EOS etiology was heterogeneous (513 idiopathic, 718 congenital, 621 syndromic, 915 neuromuscular). There were 908 Traditional Growing Rods (TGR) (32.3\%), 922 Vertical Expandable Prosthetic Titanium Rib devices (VEPTR) (33.1\%), 5 hybrid VEPTR/TGR (0.18\%) and 951 Magnetically Controlled Growing Rods (MCGR) (34.2\%) implanted across 56 different institutions during that time period. Comparing 1994 (3 TGR implants) to 2020 (80 total implants, 12 TGR, 6 VEPTR, 66 MCGR), there was a $2566 \%$ increase in index implant insertions annually $(p=0.0001)$. In 2009 the initial MCGR was added to the registry as a growth friendly implant, and implantation has increased $6500 \%$ to the number entered in 2020 ( 1 in 2009, and 66 in 2020, $\mathrm{p}=0.0001)$. MCGR has now surpassed both TGR and VEPTR as the most common growth friendly implant (127 index TGR and VEPTR procedures combined in 2008 compared with a total of 14 TGR and VEPTR combined in 2020 (89\% decrease, $\mathrm{p}=0.0001)$. Discussion: The number of growth friendly implants reported in the registry as part of the initial surgical management of EOS has increased tremendously over the past 20 years. The MCGR is currently the predominant type of device utilized for index surgical procedures by group members, surpassing the use of VEPTR and TGR in 2014. Abstract: 310 words. Level of Evidence: Level IV.

Disclosures: G. Thompson, Orthopediatrics (Consulting Fees (e.g., advisory boards), Ownership Interest, Royalties); J. Emans, Synthes/
Johnson \& Johnson (Royalties) Zimmer/Biomet (Consulting Fees (e.g., advisory boards)); J. Smith, Globus (Royalties) GS Medical (Royalties, Product Development).

\section{Paper 27}

When is pelvic fixation necessary in children with hypotonic neuromuscular scoliosis treated with growing instrumentation?

Arya Ahmady, Bianca Parker, Joel Gagnier, Jaysson Brooks, Patrick Cahill, Ryan Fitzgerald, Jack Flynn, Peter Sturm, Michael Vitale, Ying Li, Pediatric Spine Study Group

Abstract: Introduction: Children with hypotonic neuromuscular disorders often develop significant scoliosis that requires operative intervention. Pelvic fixation may be necessary to address truncal shift and pelvic obliquity (PO) to improve sitting balance. However, pelvic fixation is a risk factor for surgical site infection after posterior spinal fusion for neuromuscular scoliosis. Prior studies have shown that lower preoperative PO and L5 tilt were associated with good radiographic outcomes when the fusion ended short of the pelvis in children with neuromuscular scoliosis. Aims/Objectives: The purpose of this study was to identify indications to exclude the pelvis in children with hypotonic neuromuscular scoliosis treated with growing instrumentation. We hypothesized that the pelvis can be successfully excluded in properly selected children with hypotonic neuromuscular scoliosis treated with growing instrumentation. Methods: This was a multicenter retrospective review. Children with spinal muscular atrophy and muscular dystrophy treated with traditional growing rods, magnetically controlled growing rods, or rib-based growing constructs with minimum 2-year follow-up after the index surgery were identified. Patients with prior surgical treatment for scoliosis were excluded. Demographics, radiographic measurements, surgical data, complications, and unplanned returns to the operating room (UPROR) were collected. Quality of life was measured using the 24-Item Early Onset Scoliosis Questionnaire (EOSQ-24). Results: 141 patients met the inclusion criteria. 45 patients had distal spine anchors (DSA) and 96 patients had distal pelvic anchors (DPA) placed at the index surgery. Demographic data at the time of the index surgery was similar except a greater percentage of the DPA patients was nonambulatory (96 vs $69 \%, \mathrm{p}<0.001$ ). There was no difference in mean pre-index 
curve magnitude between the DSA and DPA patients $\left(71^{\circ}\right.$ vs $72^{\circ}$, $\mathrm{p}=0.856$ ). However, the DSA patients had a lower mean pre-index PO $\left(12^{\circ}\right.$ vs $\left.19^{\circ}, \mathrm{p}=0.003\right)$ and L5 tilt $\left(8^{\circ}\right.$ vs $\left.12^{\circ}, \mathrm{p}=0.011\right)$. Postindex and most recent radiographic data were comparable between the groups (Table). $11(24 \%)$ of the DSA and $32(33 \%)$ of the DPA patients had a $\mathrm{PO} \geq 10^{\circ}$ at most recent follow-up. There was no difference in the complication and UPROR rates. 24 (53\%) DSA patients and $57(59 \%)$ DPA patients experienced a complication ( $\mathrm{p}=0.456) .10(22 \%)$ DSA patients and $24(25 \%)$ DPA patients had an UPROR ( $\mathrm{p}=0.910)$. At most recent follow-up, the DSA group had significantly better EOSQ-24 Physical Function, Daily Living, and Satisfaction scores than the DPA group. Only 2 DSA patients have undergone extension of their instrumentation to the pelvis. Conclusions: Lower PO and L5 tilt may be indications to exclude the pelvis in children with hypotonic neuromuscular scoliosis treated with growing instrumentation. Revision surgery to include the pelvis was rare and PO remained stable at most recent follow-up in the distal spine anchor group. Distal spine anchors and distal pelvic anchors were equally effective at long-term major curve control, and complication and UPROR rates were similar. Some limitations of this study are that not all patients have undergone final fusion and preindex EOSQ-24 scores could not be compared due to incomplete data in the database.

Disclosures: J. Brooks, Depuy-Synthes (Consulting Fees (e.g., advisory boards)) OrthoPediatrics (Consulting Fees (e.g., advisory boards)); R. Fitzgerald, Depuy (Consulting Fees (e.g., advisory boards)) Medtrionic (Consulting Fees (e.g., advisory boards)) Orthopediatrics (Consulting Fees (e.g., advisory boards)); J. Flynn, Biomet (Royalties, IP Royalties) Wolters Kluwer Health-Lippincott Williams \& Wilkins (Royalties, Publishing royalties, financial or material support); P. Sturm, Depuy Synthes Spine (Consulting
Fees (e.g., advisory boards)) Nuvasive (Consulting Fees (e.g., advisory boards)); M. Vitale, Stryker (Consulting Fees (e.g., advisory boards)) Zimmer biomet (Consulting Fees (e.g., advisory boards), Royalties); P. Study Group, DePuy Synthes Spine (Grant/Research Support) Globus Medical, Inc. (Grant/Research Support) Medtronic (Grant/Research Support) NuVasive (Grant/Research Support) OrthoPediatrics (Grant/Research Support) Pediatric Spine Foundation (Grant/Research Support) Stryker (Grant/Research Support) Zimmer Biomet (Grant/Research Support). 
Table 1. Comparison of patients with distal spine anchors vs distal pelvic anchors placed at the index surgery.

\begin{tabular}{|c|c|c|c|}
\hline Demographics & $\begin{array}{l}\text { Distal spine anchors } \\
(\mathrm{N}=45)\end{array}$ & $\begin{array}{c}\text { Distal pelvic anchors } \\
(\mathrm{N}=96)\end{array}$ & p-value \\
\hline Age at index surgery (years; mean $\pm \mathrm{SD}$ ) & $7.3 \pm 2.5$ & $7.7 \pm 2.2$ & 0.415 \\
\hline BMI at index surgery $\left(\mathrm{kg} / \mathrm{m}^{2} ;\right.$ mean $\left.\pm \mathrm{SD}\right)$ & $17.3 \pm 5.4$ & $16.5 \pm 4.6$ & 0.521 \\
\hline Nonambulatory status at index surgery $[\mathrm{n}(\%)]$ & $31(69)$ & $92(96)$ & $<0.001$ \\
\hline Length of follow-up (years; mean \pm SD) & $4.3 \pm 2.7$ & $5.0 \pm 3.0$ & 0.197 \\
\hline \multicolumn{4}{|l|}{ Radiographic data } \\
\hline \multicolumn{4}{|l|}{ Major curve $\left({ }^{\circ} ;\right.$ mean $\left.\pm \mathrm{SD}\right)$} \\
\hline Pre-index & $71 \pm 21$ & $72 \pm 24$ & 0.856 \\
\hline Post-index & $43 \pm 17$ & $43 \pm 18$ & 0.803 \\
\hline Most recent & $44 \pm 18$ & $48 \pm 20$ & 0.240 \\
\hline \multicolumn{4}{|l|}{ Pelvic obliquity $\left({ }^{\circ}\right.$; mean $\left.\pm \mathrm{SD}\right)$} \\
\hline Pre-index & $12 \pm 10$ & $19 \pm 12$ & 0.003 \\
\hline Post-index & $8 \pm 5$ & $8 \pm 6$ & 0.878 \\
\hline Most recent & $9 \pm 10$ & $9 \pm 8$ & 0.879 \\
\hline \multicolumn{4}{|l|}{ L5 tilt $\left({ }^{\circ} ;\right.$ mean \pm SD $)$} \\
\hline Pre-index & $8 \pm 6$ & $12 \pm 9$ & 0.011 \\
\hline Post-index & $5 \pm 4$ & $5 \pm 4$ & 0.831 \\
\hline Most recent & $7 \pm 8$ & $6 \pm 5$ & 0.250 \\
\hline \multicolumn{4}{|l|}{ Outcomes } \\
\hline Total complications (n) & 43 & 148 & 0.005 \\
\hline Number of patients with complications [n (\%)] & $24(53)$ & $57(59)$ & 0.456 \\
\hline Total UPRORs (n) & 19 & 34 & 0.256 \\
\hline Number of patients with UPRORs [n (\%)] & $10(22)$ & $24(25)$ & 0.910 \\
\hline \multicolumn{4}{|l|}{ EOSQ-24 Domains } \\
\hline Pain/Discomfort [mean $(95 \% \mathrm{CI})]$ & $72(64-79)$ & $62(57-68)$ & 0.070 \\
\hline Physical Function [mean $(95 \% \mathrm{CI})]$ & 47 (37-58) & $23(17-29)$ & $<0.001$ \\
\hline Daily Living [mean $(95 \% \mathrm{CI})]$ & $41(31-51)$ & $20(14-26)$ & $<0.001$ \\
\hline Satisfaction [mean $(95 \%$ CI)] & $60(53-68)$ & $49(43-54)$ & 0.026 \\
\hline
\end{tabular}

SD, standard deviation; BMI, body mass index; UPROR, unplanned return to operating room; CI, confidence interval

\section{Paper 28}

Younger age at spinal cord detethering is potentially associated with a reduced risk of curve progression in children with early onset scoliosis

Rajiv Iyer, Adam Fano, Hiroko Matsumoto, Rishi Sinha, Benjamin Roye, Michael Vitale, Richard Anderson

Abstract: Introduction: In children with early onset scoliosis (EOS) who also have tethered spinal cords (TSC), spinal cord detethering procedures are commonly performed prior to spinal deformity surgery. Previous reports have described curve stabilization or improvement in some patients following the detethering procedure alone. However, there is currently very little information regarding whether patient age or the degree of curve magnitude at the time of detethering is associated with subsequent scoliosis progression. Aims/ Objectives: The purpose of this study was to investigate whether EOS patient age or curve magnitude at the time of spinal cord detethering was associated with curve progression at a follow-up of at least 2 years. It was hypothesized that patients who undergo detethering at a younger age, or those with a smaller curve magnitude, would experience a reduced rate of curve progression compared to those who are older or with larger curves. Methods: In this retrospective cohort study, patients with EOS who underwent spinal cord detethering at least 2 years prior to index surgical intervention for their spinal deformity were identified in a multicenter international 
registry. Radiographs were assessed just prior to the detethering procedure (pre-detether) and at the most recent visit prior to any spinal deformity surgery (most recent post-detether). Rates of curve progression $>10^{\circ}$, stabilization within $10^{\circ}$, and improvement $>10^{\circ}$ were examined. Due to unequal follow-up in individual patients, Cox regression was utilized to investigate associations between primary variables (age and magnitude of major coronal curve) and rate of curve progression. Results: 37 patients met inclusion criteria, and 18 (mean age: $3.7 \pm 2.9$ years, $66.7 \%$ female, mean follow-up: $3.4 \pm 1.3$ years) had radiographic data available for analysis. Predetether and most recent post-detether major coronal curves were $44.8^{\circ} \pm 18.5^{\circ}$ and $47.6^{\circ} \pm 23.9^{\circ}$, respectively. Etiologies of scoliosis included $11(61.1 \%)$ congenital, $3(16.7 \%)$ idiopathic, $2(11 \%)$ neuromuscular, $1(5.6 \%)$ syndromic, and $1(5.6 \%)$ unknown. $5(27.8 \%)$ patients had curve progression $>10^{\circ}$ at a follow-up of $3.2 \pm 1.2$ years. $6(33.3 \%)$ patients experienced stabilization within $10^{\circ}$ at a follow-up of $2.9 \pm 0.8$ years. $7(38.9 \%)$ patients experienced improvement $>10^{\circ}$ at a follow-up of $3.9 \pm 1.6$ years. Patients with progression $>10^{\circ}$ were older at the time of detethering when compared to those without $(5.6 \pm 2.8$ vs. $3 \pm 2.7$ years, $p=0.084)$ (Table). Regression analysis demonstrated that as age at detethering increased by 1 year, the rate of curve progression $>10^{\circ}$ increased by $28.6 \%$ [95\% confidence Interval (CI): $0.899 ; 1.839, \mathrm{p}=0.169]$. There was no evidence of an association between pre-detethering curve magnitude and rate of curve progression $>10^{\circ}$ [HR: $1.027,95 \% \mathrm{CI}$ $0.977 ; 1.079, p=0.297]$. Conclusions: In a small multicenter cohort of EOS patients with concomitant TSC, younger age, but not curve size, at the time of detethering was found to be associated with a lower rate of scoliosis progression. Each additional year at the time of detethering was associated with a nearly $30 \%$ increase in the rate of curve progression $>10^{\circ}$. These results indicate a potential role for early spinal cord detethering in the EOS population but require further investigation with a larger number of patients.

Disclosures: H. Matsumoto, Pediatric Spine Study Group (Consulting Fees (e.g., advisory boards)) POSNA (Grant/Research Support) SRS (Grant/Research Support); M. Vitale, Stryker (Consulting Fees (e.g., advisory boards)) Zimmer biomet (Consulting Fees (e.g., advisory boards), Royalties).

Table.

\begin{tabular}{lccc}
\hline & \multicolumn{2}{c}{ Progression $>10^{\circ}$} & \\
\cline { 2 - 3 } & Yes & No & p-value \\
\hline Age at Detethering & $5.6 \pm 2.8$ & $3 \pm 2.7$ & 0.084 \\
Major Coronal Curve at Detethering & $46.6 \pm 15$ & $44.1 \pm 20.2$ & 0.804 \\
Follow-up & $3.2 \pm 1.2$ & $3.4 \pm 1.4$ & 0.749 \\
\hline
\end{tabular}

\section{Paper 29}

Does casting/ bracing prevent curve progression in EOS patients with connective tissue disease?

Smitha Mathew, Majd Marrache, A. Noelle Larson, Paul Sponseller

Abstract: Introduction: Non-operative treatment options of syndromic scoliosis include casting and bracing. If successful, this could help to postpone initial surgical treatment until the patient is older. However, the efficacy and success of these approaches are not known, specifically in patients with connective tissue disease. Aims/Objectives: We sought to determine the results of bracing and casting in children with connective tissue disease, including Ehlers Danlos, Loeys Dietz, and Marfan syndrome, and whether non-operative treatment can serve as an effective delay tactic for children with early onset scoliosis. Methods: A large multicenter registry of prospectively enrolled early onset patients was queried. Inclusion criteria were connective tissue disease and minimum 2-year follow-up. Radiographs and clinical course was evaluated. Successful treatment was defined as curve progression $<6^{\circ}$ per year. Results: 38 patients were identified with a maximum Cobb angle of greater than $10^{\circ}$. Mean age at enrollment was 5.3 years (range $0.3-13.3$ years). Mean Cobb angle at enrollment was $38^{\circ}$. Mean time to follow-up overall was 4.6 years. Seven patients eventually underwent surgical management (3 fusions, 4 growing rods) at a mean of 2.9 years following initiation of bracing/casting, and mean age at surgery was 8.2 years. Radiographic follow-up was available during non-operative treatment for 19 patients for a mean of 3.8 years (Table). Seven patients were treated with bracing alone, and 11 treated with both bracing and casting. During this time point, mean major curve changed from $39^{\circ}$ to $40^{\circ}$ at latest pre surgical follow-up $(\mathrm{p}=1.0)$. Excluding the three patients who went on to surgery, non-operative treatment was successful in 16 patients, with a stable Cobb angle (initial Cobb $36^{\circ}$ and Cobb $24^{\circ}$ at latest follow-up; $\mathrm{p}=0.3$ ). Conclusion: Bracing and casting are effective delay tactics for patients with connective tissue disease. Limited data suggests that casting and bracing may be effective treatment strategies for patients with connective tissue disease with moderate early onset scoliosis. Further prospective studies on these topics are needed.

Disclosures: A. Larson, Globus, Medtronic, Stryker, Depuy, Orthopediatrics (Consulting Fees (e.g., advisory boards), All proceeds to Mayo Clinic research); P. Sponseller, DePuy Synthes Spine (Grant/Research Support, Consulting Fees (e.g., advisory boards), Royalties) Globus (Royalties) Orthopediatrics (Consulting Fees (e.g., advisory boards)). 
Does Casting/ Bracing Prevent Curve Progression in EOS Patients with Connective Tissue Disease?

Table: Casting/ Bracing in EOS Patients with Connective Tissue Disease

\begin{tabular}{|l|c|c|c|c|}
\hline & $\begin{array}{c}\text { Pretreatment } \\
(\mathrm{N}=19)\end{array}$ & $\begin{array}{c}\text { Posttreatment } \\
(\mathrm{N}=19)\end{array}$ & $\begin{array}{c}\text { Pretreatment } \\
\text { Excluding 3 } \\
\text { surgical patients } \\
(\mathrm{N}=16)\end{array}$ & $\begin{array}{c}\text { Posttreatment } \\
\text { Excluding 3 } \\
\text { surgical patients } \\
(\mathrm{N}=16)\end{array}$ \\
\hline Age (years) & 4.6 & 8.4 & 4.9 & 9.3 \\
\hline Height $(\mathrm{cm})$ & 107.0 & 137.0 & 110.2 & 144.0 \\
\hline Weight (kg) & 20.1 & 29.6 & 21.9 & 32.9 \\
\hline Mean Major Cobb $\left(^{\circ}\right)$ & 42.6 & 39.0 & 3.6 .3 & 23.6 \\
\hline T1-51 $(\mathrm{mm})$ & 276.9 & 327.8 & 262.8 & 348.3 \\
\hline T1-T12 $(\mathrm{mm})$ & 176.7 & 206.9 & 171.0 & 22.7
\end{tabular}

Table: Casting/bracing in EOS patients with connective tissue disease

\section{Paper 30}

\section{Wireless in vivo electronic measurement of tether tension}

Benjamin Sinder, Vincent Ruggieri, Adriana Barba, Edward Vresilovic, Jason Anari, Brian Snyder, Thomas Schaer, Patrick Cahill

Abstract: Introduction: Tether tension is a key factor regulating correction of spinal deformity in vertebral body tethering (VBT). While tether tension is set during surgery, the resulting tether tension over time will regulate a patient's adaptive response. There is likely a great variation in tether tension in vivo due to dynamic loading from motion, growth, and viscoelasticity of the spine. Aim/Objective: The purpose of this study was to determine in vivo tether tension in a swine model. Methods: To measure tether tension, a calibrated strain gauge was attached to a custom flexible tether construct in a swine model of axial deformation using a 4-week-old Yorkshire pig. The animal had an uneventful recovery from surgery. Tether tension data was remotely recorded during surgery $(8 \mathrm{~Hz})$, and following recovery from general anesthesia, during rest and ambulation $(32 \mathrm{~Hz}) 3 \times$ per week for two weeks. Synchronized video data aligned animal activity state with recorded tether tension values. Results: Immediately after imparting $\sim 60 \mathrm{~N}$ of tether tension during surgery to induce a mild axial deformity, a rapid $(\sim 1 \mathrm{~h})$ decline in tether tension to $\sim 15 \mathrm{~N}$ was observed-likely related to the viscoelasticity of the spine (Fig.). In vivo data in the following recovery period revealed that ambulation and activity produced tether tensions with a range of $60 \mathrm{~N}$ from peak to trough. Synchronized video and high frequency $(32 \mathrm{~Hz})$ tether tension data show correlation of movement with implant forces. Conclusion: Tether tension declines after it is set during surgery and is highly dynamic with activity and movement. 

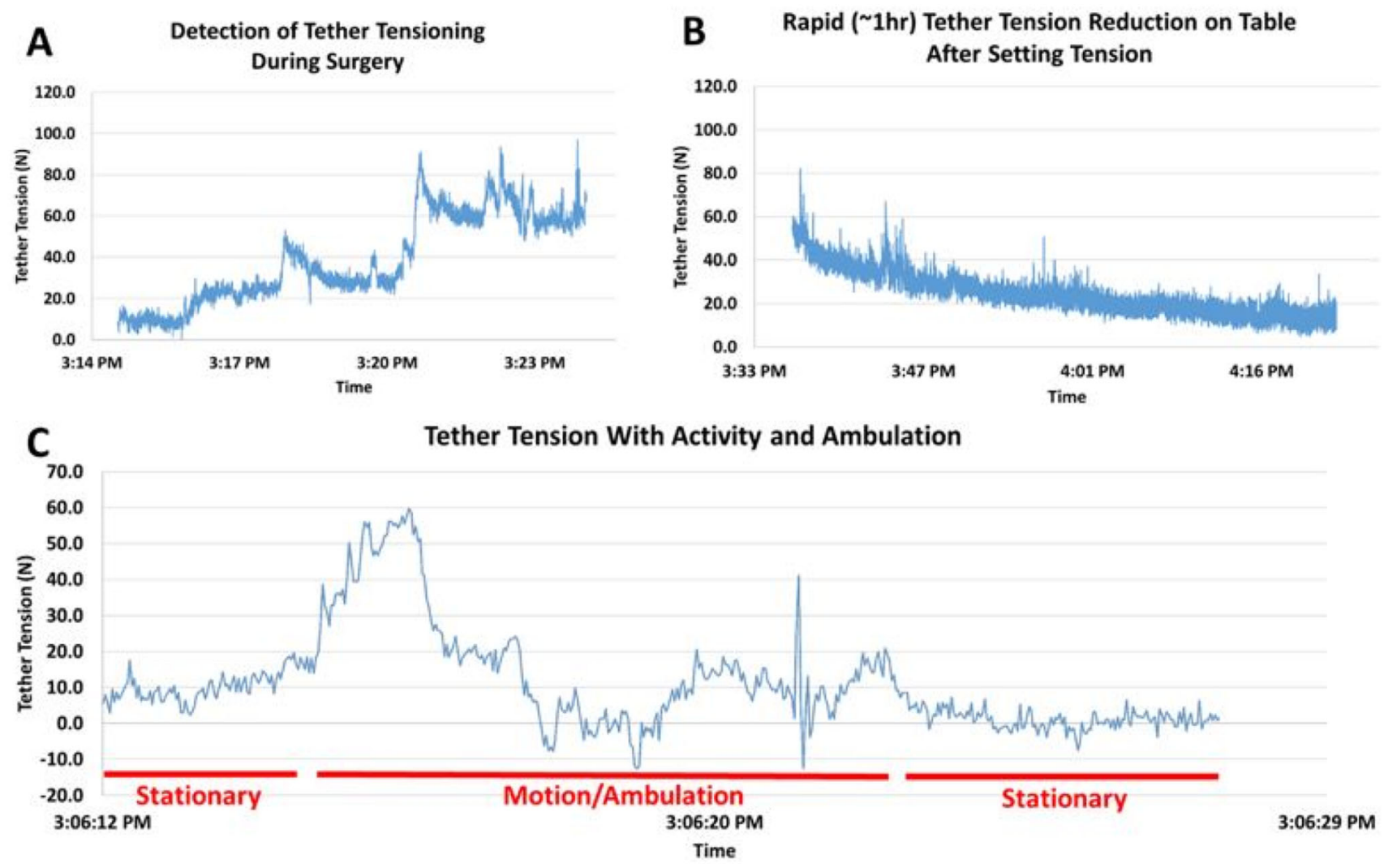

\section{Paper 31}

Retrospective analysis of associated anomalies in 637 congenital scoliosis patients

Nan Wu, Terry Jianguo Zhang, Lian Liu, Shengru Wang, Guixing Qiu

Abstract: Introduction: Congenital scoliosis (CS) is frequently associated with defects in other organ systems. Studies have been mainly focusing on the incidence and distribution of intraspinal and cardiac malformations in the CS population, and the corresponding data varied among different studies. Objective: Our study aims to summarize the landscape characteristics and the incidence of systemic anomalies associated with CS in a large dataset, and to explore the potential correlations among various associated malformations. Methods: A monocentric and retrospective study of a total of 637 Chinese patients who underwent spinal surgery at Peking Union Medical College Hospital from January 2012 to July 2019. Medical materials of each subject were collected. The main outcomes included the incidence of associated anomalies and significant associations among concomitant defects in congenital scoliosis patients. Results: Intraspinal abnormalities were found in $188 / 615$ (30.6\%) patients, in which diastematomyelia $(116 / 188,61.7 \%)$ was the most common defect. The incidence of intraspinal abnormalities in patients with fasilure of segmentation (6.8\%) and mixed deformity (19.7\%) were remarkably higher than in patients with failure of formation $(4.1 \%$, $\left.\mathrm{P}=8.11 \times 10^{-11}\right)$. CS patients with intraspinal anomalies have more severe deformities including larger Cobb angle of the major curve $\left(\mathrm{P}=5.43 \times 10^{-9}\right)$, complex rib anomaly $\left(\mathrm{P}=3.6 \times 10^{-5}\right)$, and worse pulmonary function. Other associated systemic malformations are cardiac $(11.5 \%)$, gastrointestinal $(8.8 \%)$, musculoskeletal $(7.9 \%)$, urogenital $(9.9 \%)$ and maxillofacial anomalies $(3.5 \%)$. Association among different concomitant malformations were also identified. Conclusion: The comorbidities of congenital scoliosis occurred at a rate of $60.8 \%$. Our study firstly proved that CS patients with intraspinal and cardiac anomalies had worse pulmonary functions, which presented with lower FEV1 and FVC. Moreover, the potential significant associations among concomitant defects make magnetic resonance imaging, echocardiography, and abdominal ultrasound indispensable components of preoperative evaluation scheme.

\section{Paper 32}

Mortality in neuromuscular early onset scoliosis following spinal deformity surgery

Hiroko Matsumoto, Adam Fano, Elizabeth Herman, Brian Snyder, Benjamin Roye, Patrick Cahill, Brandon Ramo, Paul Sponseller, Michael Vitale, Pediatric Spine Study Group

Abstract: Introduction: Current treatment paradigms for neuromuscular (NM) early onset scoliosis (EOS) patients are aimed at maximizing function and improving mortality. However, medical comorbidities and functional disabilities often complicate management, and our understanding of mortality following surgical intervention is currently incomplete. This is the first comprehensive analysis of mortality and associated risk factors in patients undergoing surgery for NM EOS using a large international registry with midterm follow-up. Aims/Objectives: The purpose of this study was to 
report mortality risk and investigate the demographic, clinical, and radiographic factors associated with mortality rate in patients with NM EOS following spinal surgery. It was hypothesized that mortality is high in NM EOS patients undergoing spinal surgery and that markers of disease severity are associated with an increased mortality rate. Methods: In this retrospective cohort study, patients with NM EOS who underwent index surgery from 1994 to 2020 were identified in a multicenter international registry. NM diagnoses included cerebral palsy (CP), spinal muscular atrophy (SMA), myelodysplasia, muscular dystrophy (MD), and myopathy. Analyzed risk factors included various demographics, clinical characteristics, and radiographic characteristics. Mortality risk was calculated at 1, 2, 5 and 10 years following surgery. To account for unequal follow-up, proportional hazard modeling was utilized to investigate associations between risk factors and mortality rate. Results: 808 patients with a mean age of $7.7 \pm 2.8$ years, major coronal curve of $69.9^{\circ} \pm 28.6^{\circ}$, and mean follow-up of $6 \pm 3.9$ years were identified. Diagnoses included $296(36.6 \%)$ CP, 182 (22.5\%) SMA, 174 (21.5\%) myelodysplasia, $109(13.5 \%) \mathrm{MD}$, and 47 (5.8\%) myopathy. $73 \%$ were non-ambulatory and $36.1 \%$ required respiratory assistance. Postoperative 30-, 90-, and 120-day mortality was $0,0.001$, and $0.01 \%$, respectively. $1-, 2-, 5-$, and 10 -year mortality was $0.5,1.1,5.4$, and $17.4 \%$, respectively. Multiple proportional hazard models demonstrated that patients with CP [hazard ratio (HR): $3.14,95 \%$ confidence interval (CI): $1.71 ; 5.79, \mathrm{p}<0.01)$, non-ambulatory status [HR: $3.01,95 \%$ CI $1.06 ; 8.5, p=0.04]$, or need for respiratory assistance [HR: $2.17,95 \%$ CI 1.00; 4.69, $\mathrm{p}=0.05$ ] had an increased rate of mortality. Age, gender, race, body mass index (BMI), magnitude of major coronal or sagittal curve, thoracic height, and pelvic obliquity demonstrated no evidence of association with mortality rate. Conclusions: Mortality is high in surgically treated NM EOS patients at 10-year follow-up, although it is likely not a direct result of spine surgery as mortality is low within 2 years. Diagnosis (CP) and markers of disease severity (non-ambulatory status, respiratory assistance) were hazards associated with an increased rate of mortality.

Disclosures: H. Matsumoto, Pediatric Spine Study Group (Consulting Fees (e.g., advisory boards)) POSNA (Grant/Research Support) SRS (Grant/Research Support); P. Sponseller, DePuy Synthes Spine (Grant/Research Support, Consulting Fees (e.g., advisory boards), Royalties) Globus (Royalties) Orthopediatrics (Consulting Fees (e.g., advisory boards)); M. Vitale, Stryker (Consulting Fees (e.g., advisory boards)) Zimmer biomet (Consulting Fees (e.g., advisory boards), Royalties); P. Study Group, DePuy Synthes Spine (Grant/Research Support) Globus Medical, Inc. (Grant/Research Support) Medtronic (Grant/Research Support) NuVasive (Grant/ Research Support) OrthoPediatrics (Grant/Research Support) Pediatric Spine Foundation (Grant/Research Support) Stryker (Grant/ Research Support) Zimmer Biomet (Grant/Research Support).

Table. Mortality risk at 1-, 2-, 5-, and 10-year follow-up stratified by diagnosis

\begin{tabular}{lcccc}
\hline & \multicolumn{4}{c}{ Mortality } \\
\cline { 2 - 5 } & 1-Year Postop & 2-Year Postop & 5-Year Postop & 10-Year Postop \\
\hline (Censored) & $(N=10,1.3 \%)$ & $(N=25,3.5 \%)$ & $(N=42,8 \%)$ & $(N=58,22.4 \%)$ \\
All NM & $4 / 786(0.5 \%)$ & $8 / 698(1.1 \%)$ & $26 / 481(5.4 \%)$ & $35 / 201(17.4 \%)$ \\
CP & $1 / 287(0.3 \%)$ & $4 / 251(1.6 \%)$ & $15 / 149(10.1 \%)$ & $22 / 65(33.8 \%)$ \\
SMA & $1 / 178(1 \%)$ & $2 / 155(1 \%)$ & $5 / 111(5 \%)$ & $7 / 42(17 \%)$ \\
Myelodysplasia & $1 / 169(1 \%)$ & $1 / 156(1 \%)$ & $2 / 118(2 \%)$ & $2 / 51(4 \%)$ \\
MD & $1 / 107(1 \%)$ & $1 / 97(1 \%)$ & $2 / 77(3 \%)$ & $2 / 32(6 \%)$ \\
Myopathy & $0 / 45(0 \%)$ & $0 / 39(0 \%)$ & $2 / 26(8 \%)$ & $2 / 11(18 \%)$ \\
\hline NM = neuromuscular; $\mathrm{CP}=$ cerebral palsy; SMA = spinal muscular atrophy; MD = muscular dystrophy
\end{tabular}

Figure 1. Mortality risk by diagnosis

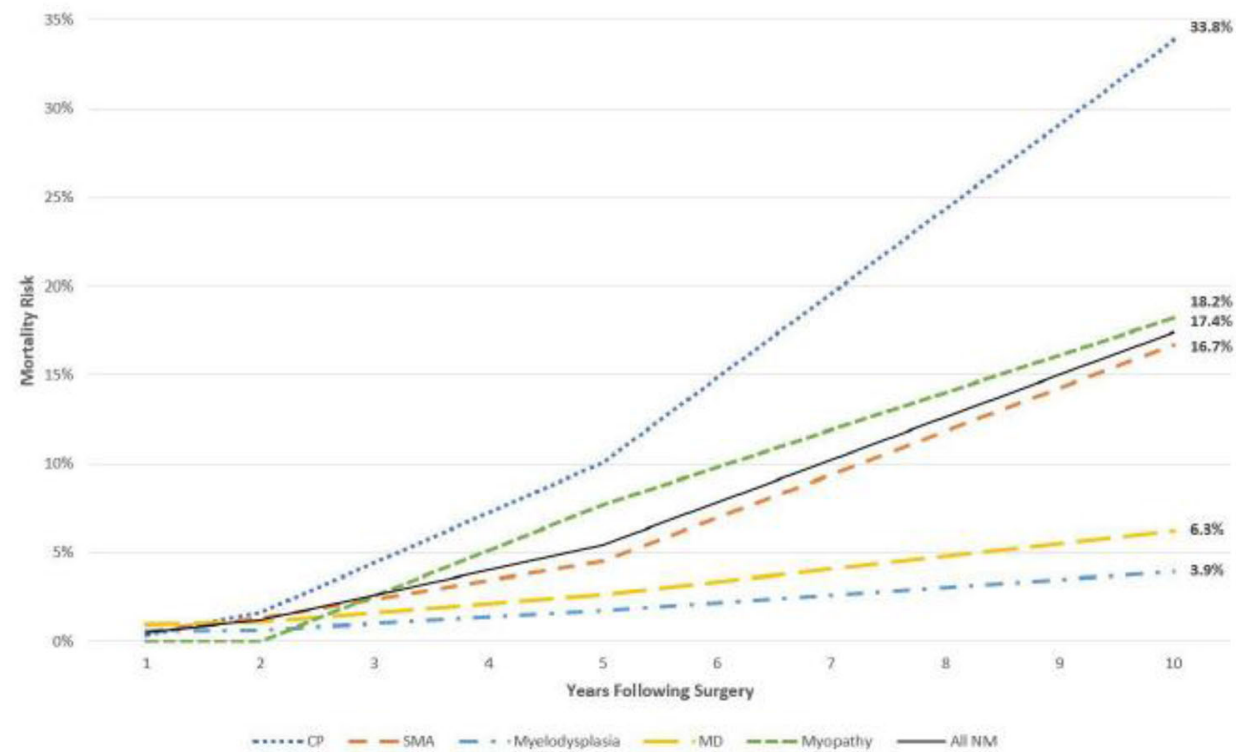


Figure 2. Risk factors associated with an increased mortality rate: cerebral palsy (A), non-ambulatory status (B), and dependence on respiratory assistance (C)

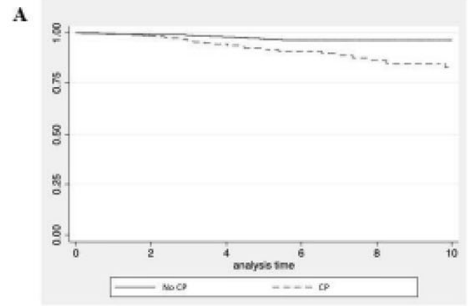

B

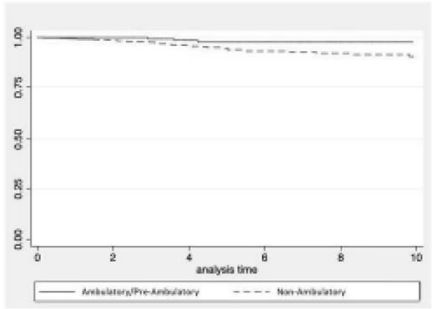

C

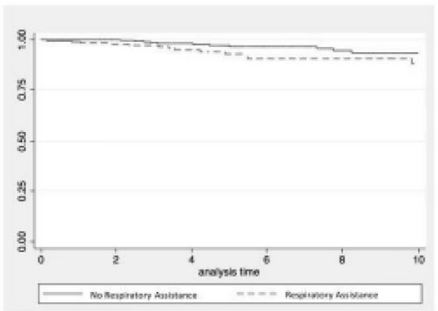

\section{Paper 33}

\section{Salvage treatment of failed growth-friendly surgery for early onset spinal deformity}

Rajiv Iyer, Venkat Boddapati, Meghan Cerpa, Adam Fano, Richard Anderson, Benjamin Roye, Michael Vitale, Lawrence Lenke

Abstract: Introduction: Growth-friendly surgery (GFS) for early onset spinal deformity (EOSD) can control curve progression through distraction-based, compression-based, and growth-guidance techniques, until adequate chest wall development and skeletal maturity is neared, at which point a definitive segmental fusion is performed. While many patients with EOSD pass through such GFS treatment programs successfully, in some instances, deformity progression occurs despite, and possibly as a result of the use of GFS. This may include those with apical crankshaft, those with progressive kyphosis due to sequential distraction procedures, or those in whom the implants themselves act as a spinal tether. In these scenarios, uncontrolled multiplanar curve progression sometimes occurs, leading to failed growth friendly surgery (f-GFS) and significant morbidity requiring challenging surgical solutions. In children with $\mathrm{f}$ GFS, consideration of more substantial "salvage" therapy may be appropriate, involving the use of prolonged halo-gravity traction (HGT), three-column osteotomies (3COs) such as vertebral column resection (VCR), or significant correction of the deformity and replacement with another growing system in those with substantial remaining growth. Here, we describe our institutional experience as a tertiary referral practice with salvage therapy for f-GFS in EOSD patients, seeking to increase the awareness of this patient population by describing the clinical management and treatment outcomes. Objectives: We sought to describe the clinical and radiographic features of a population of EOS patients with f-GFS, their surgical solutions, and outcomes following these interventions. Methods: This was a retrospective case series of consecutive surgical patients referred to a tertiary children's hospital from 2015 to 2020. In most cases, index surgeries were performed at outside institutions $(n=27$, $93 \%$ ), while the most recent surgical treatment was performed by three spinal surgeons with practices exclusive to the treatment of spinal deformity. The majority of cases were referred to the senior author from treating surgeons around the country, and sometimes from international centers. Original imaging was unavailable in several cases for which the index surgery as well as other GFS was performed at outside institutions. The study was conducted under the approval of the institutional review board. EOSD patients with f-GFS and subsequent salvage treatment were identified. Indications for intervention included curve progression and one or more of the following findings: (1) trunk imbalance, (2) neurological compromise, (3) respiratory insufficiency, and 4. wound issues and/or implant prominence. Results: 29 patients with f-GFS were identified. Mean age at first surgery was $5.3 \pm 2.6$ years. Mean age at most recent salvage intervention was $14.6 \pm 5.6$ years. Mean follow up from index procedures to latest evaluation was $10.9 \pm 6.6$ years. Mean follow up duration after salvage intervention was $1.1 \pm 1.1$ years. Patients were previously instrumented with VEPTR (7), TGRs (10), MCGRs (4), Shilla (3), or none/In-situ fusions (6). 16 patients $(55.2 \%)$ presented with scoliosis $>90^{\circ}$, and $19(65.5 \%)$ presented with kyphosis $>90^{\circ}$. 14 patients $(48.2 \%)$ had both kyphosis and scoliosis $>90^{\circ}$. All patients undergoing intervention had evidence of coronal and/or sagittal curve progression. Mean preoperative coronal malalignment was $4.3 \mathrm{~cm} \pm 3.5 .19$ patients $(65.5 \%)$ presented with evidence of trunk imbalance in the coronal and/or sagittal planes. Mean preoperative sagittal malalignment was $3.7 \mathrm{~cm} \pm 4.5$. Nine patients $(31 \%)$ presented with evidence of a neurological deficit, including weakness and/or myelopathy. For salvage of these 29 patients, $16(55 \%)$ underwent preoperative HGT for an average of $4.9 \pm 2.5$ weeks. $21(72 \%)$ underwent staged procedures and 21 (72\%) underwent VCR. 6 (21\%) had placement of a new growing system, while $23(79 \%)$ underwent definitive fusion. Mean preoperative and postoperative Cobb angle was $87.4 \pm 49.8$ and $24.0^{\circ} \pm 18.2^{\circ}$, respectively $(72.5 \%$ correction). Mean preoperative and postoperative kyphosis was $102.7 \pm 36.3$ and $45.2^{\circ} \pm 26.2^{\circ}$, respectively (56\% correction). Mean postoperative coronal alignment was $2.0 \mathrm{~cm} \pm 1.6$ (46.5\% correction) and mean postoperative sagittal alignment was $2.6 \pm 1.4$ (68.5\% correction). Intraoperative spinal cord monitoring changes occurred in 8 cases (28\%). In each of these 8 cases, preoperative kyphosis was at least $100^{\circ}$, and VCR was performed. There were 10 total unplanned return to the operating room (UPROR) events in 7 patients (24\%), including 4 for neurological compromise requiring decompression/spinal shortening. 2 patients (7\%) had persistent neurologic deficits following salvage treatment. Conclusion: Salvage treatment of f-GFS for EOSD is complex and challenging, often requiring a period of HGT and/or subsequent 3COs. Early recognition of curve progression despite GFS in the EOSD population may help avoid this type of high-risk salvage intervention. When required, these challenging surgical solutions can result in successful treatment with markedly improved radiographic, clinical and overall outcomes in the majority of patients despite the risks and complications.

Disclosures: M. Vitale, Stryker (Consulting Fees (e.g., advisory boards)) Zimmer biomet (Consulting Fees (e.g., advisory boards), Royalties); L. Lenke, Abryx (Consulting Fees (e.g., advisory boards), 1) Paid Consultant) Acuity Surgical (Consulting Fees (e.g., advisory boards), 1) Paid Consultant) AOSpine (Grant/Research Support, 1) reimbursement for airfare/hotel; 2) grant support-monies to institution; 3) fellowship support to institution) Broadwater (Grant/ Research Support, 1) reimbursement for airfare/hotel) EOS (Grant/ Research Support, 1) Grant support-monies to institution) EOS 
Technologies (Consulting Fees (e.g., advisory boards), 1) Paid Consultant) Evans Family Donation (Grant/Research Support, 1) philanthropic research funding from grateful patient/family) Fox Family Foundation (Grant/Research Support, 1) philanthropic research funding from grateful patient) Medtronic (Consulting Fees (e.g., advisory boards), Royalties, 1) paid consultant-monies donated to a charitable foundation; 2) Royalties) Scoliosis Research Society (Grant/Research Support, 1) reimbursement for airfare/hotel; 2) grant support-monies to institution) Setting Scoliosis Straight Foundation (Grant/Research Support, 1) Grant support-monies to institution).

Case example progressed with over $100^{\circ}$ of residual kyphosis and scoliosis, consistent with f-GFS. The patient complained of significant back pain and leg pain. Scoliometer measurement was $30^{\circ}$ and she stood with a significant trunk imbalance. Her rigid deformity was treated with a two-stage multilevel VCR and T2 to sacrum fusion using a multi-rod construct including a kickstand rod for supplemental iliac fixation and to improve her coronal malalignment. She recovered well and demonstrated a well-maintained correction with good alignment at two years postoperatively. Her preoperative and postoperative SRS domain scores were: Pain: 2.6 and 4.2; Self image: 2.2 and 3.2; Function: 3.4 and 4.2; Mental Health: 4.8 and 4.2; Satisfaction: 3.5 and 4.

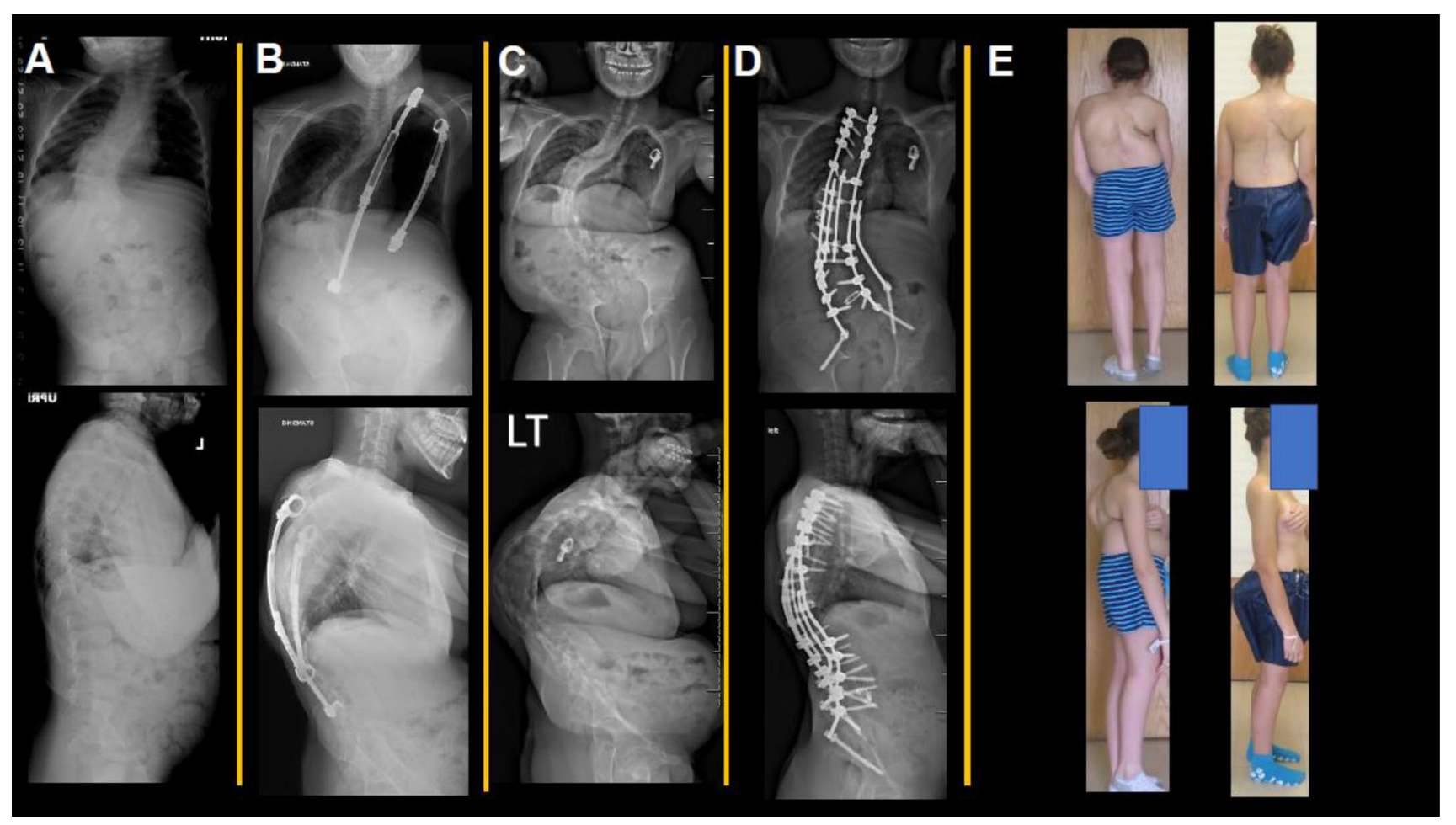

3-year-old girl with VATER syndrome who underwent placement of bilateral VEPTR devices for EOS. She had approximately 20 previous surgeries including multiple expansions, infection control surgeries, and eventual VEPTR removal. Over time, her deformity
Publisher's Note Springer Nature remains neutral with regard to jurisdictional claims in published maps and institutional affiliations. 